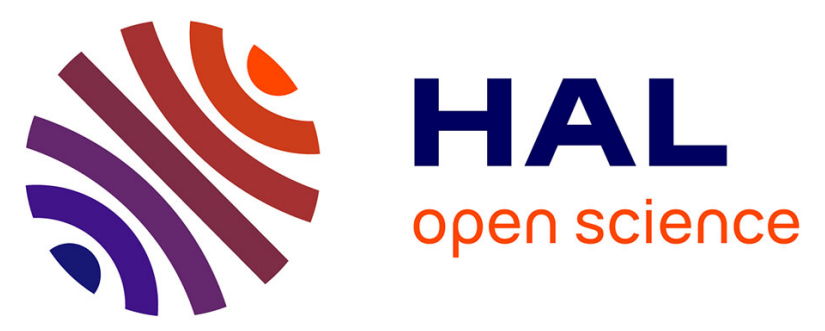

\title{
Directed evolution of artificial repeat proteins as habit modifiers for the morphosynthesis of (111)-terminated gold nanocrystals
}

\author{
Janak Prasad, Sébastien Viollet, Kargal L. Gurunatha, Agathe Urvoas,
} Agathe C. Fournier, Marie Valerio-Lepiniec, Cécile Marcelot, Bulent Baris, Philippe Minard, Erik Dujardin

\section{To cite this version:}

Janak Prasad, Sébastien Viollet, Kargal L. Gurunatha, Agathe Urvoas, Agathe C. Fournier, et al.. Directed evolution of artificial repeat proteins as habit modifiers for the morphosynthesis of (111)terminated gold nanocrystals. Nanoscale, 2019, 11 (37), pp.17485-17497. 10.1039/c9nr04497c . hal02294239

\section{HAL Id: hal-02294239 \\ https://hal.science/hal-02294239}

Submitted on 1 Dec 2020

HAL is a multi-disciplinary open access archive for the deposit and dissemination of scientific research documents, whether they are published or not. The documents may come from teaching and research institutions in France or abroad, or from public or private research centers.
L'archive ouverte pluridisciplinaire HAL, est destinée au dépôt et à la diffusion de documents scientifiques de niveau recherche, publiés ou non, émanant des établissements d'enseignement et de recherche français ou étrangers, des laboratoires publics ou privés. 


\title{
Directed evolution of artificial repeat proteins as habit modifiers for the morphosynthesis of (111)-terminated gold nanocrystals $†$
}

\author{
Janak Prasad, (D) $\ddagger^{\mathrm{a}}$ Sébastien Viollet, $\ddagger^{\mathrm{b}}$ Kargal L. Gurunatha, (D) ${ }^{\mathrm{a}}$ Agathe Urvoas, (D) ${ }^{\mathrm{b}}$ \\ Agathe C. Fournier, ${ }^{a}$ Marie Valerio-Lepiniec, (ID ${ }^{\mathrm{b}}$ Cécile Marcelot, (iD ${ }^{\mathrm{a}}$ Bulent Baris, ${ }^{\mathrm{a}}$ \\ Philippe Minard*b and Erik Dujardin (iD *a
}

Natural biocomposites are shaped by proteins that have evolved to interact with inorganic materials. Protein directed evolution methods which mimic Darwinian evolution have proven highly successful to generate improved enzymes or therapeutic antibodies but have rarely been used to evolve proteinmaterial interactions. Indeed, most reported studies have focused on short peptides and a wide range of oligopeptides with chemical binding affinity for inorganic materials have been uncovered by phage display methods. However, their small size and flexible unfolded structure prevent them from dictating the shape and crystallinity of the growing material. In the present work, a specific set of artificial repeat proteins (aRep), which exhibit highly stable 3D folding with a well-defined hypervariable interacting surface, is selected by directed evolution of a very efficient home-built protein library for their high and selective affinity for the $\mathrm{Au}(111)$ surface. The proteins are built from the extendable concatenation of selfcompatible repeated motifs idealized from natural HEAT proteins. The high-yield synthesis of $\mathrm{Au}(111)$ faceted nanostructures mediated by these aRep proteins demonstrates their chemical affinity and structural selectivity that endow them with high crystal habit modification performances. Importantly, we further exploit the protein shell spontaneously assembled on the nanocrystal facets to drive proteinmediated colloidal self-assembly and on-surface enzymatic catalysis. Our method constitutes a generic tool for producing nanocrystals with determined faceting, superior biocompatibility and versatile biofunctionalization towards plasmon-based devices and (bio)molecular sensors.

\section{Introduction}

Natural protein evolution is remarkably efficient to foster the emergence of specific interactions between proteins and targeted molecules ${ }^{1}$ or biomineral surfaces., ${ }^{2,3}$ Most inorganic structures found in living organisms such as diatom cell wall,

${ }^{a}$ CEMES, CNRS UPR 8011, 29 rue J. Marvig, B.P. 94347, F-31055 Toulouse, France. E-mail:dujardin@cemes.fr

${ }^{b}$ Institute for Integrative Biology of the Cell (I2BC), CEA, CNRS, Univ. Paris-Sud, Université Paris-Saclay, 91198 Gif-sur-Yvette Cedex, France.

E-mail:Philippe.Minard@i2bc.paris-saclay.fr

† Electronic supplementary information (ESI) available: Materials and methods. Screening and biochemical characterization of aRep. Determination of $\mathrm{Au}(111)$ binding affinities. TEM and gel electrophoresis on Au seeds. Two-stage seeded growth details. SEM characterization of aRep coated Au nanocrystals. UV-visible spectral characterization. Control experiments with non-selected aRep. Au nanocrystal size tenability. Effect of $\mathrm{pH}$ and temperature. Chemical analysis of G8capped nanocrystals. SEM images of core-satellite self-assembled nanostructures. SEM images of in situ DAB encapsulated Au nanocrystals. See DOI: $10.1039 / \mathrm{c} 9 \mathrm{nr} 04497 \mathrm{c}$

‡ These authors contributed equally. magnetosome, sea urchin spicule, and nacre, to cite a few, are shaped and organized at the molecular level through the intimate interactions with proteins. The efficiency of such molecular interactions in natural systems does not rely on prior knowledge of rules governing interactions between poly-peptides and material surfaces but rather on combinatorial selection and optimization. Mimicking the evolutionary exploration of the protein sequence space is therefore a promising strategy to create new proteins endowed with tailored interaction properties. Directed evolution approaches, which have originally been developed and broadly used to address biological questions, ${ }^{4,5}$ are a powerful tool to create artificial proteins with specific chemical affinity and structural selectivity for crystalline material surfaces. Surprisingly, these methods have not yet attracted general attention in nanomaterial sciences with the remarkable exception of short peptides. ${ }^{6-10}$ Oligopeptides with chemical affinity for a chosen inorganic surface (for example, $\mathrm{Au},{ }^{6} \mathrm{ZnS},{ }^{8}$ and $\mathrm{Co}_{3} \mathrm{O}_{4}{ }^{11}$ ) or, even, facetspecific adsorption $\left(\operatorname{Pt}(100) v s . \operatorname{Pt}(111),{ }^{12} \mathrm{GaAs}(100) v s\right.$. GaAs $\left.(111 \mathrm{~A}){ }^{7} \mathrm{Au}(111)^{13}\right)$ have been discovered by genetic sorting methods such as phage display or cellular display. 
However, in nature, the overwhelming majority of materialspecific biomolecules are proteins, not peptides, owing to the very distinct molecular recognition potential of these two classes of molecules. Peptides are too short to have a stable hydrophobic core and hence are usually not able to achieve a stable folded tertiary structure. The molecular recognition capacities of peptides are therefore inherently limited which translates, for peptides selected for a high chemical affinity towards inorganic materials, into a lack of structural selectivity. Single crystals grown in the presence of such peptides do not exceed a few nanometers in size, involving a few tens of peptides per crystalline facet, ${ }^{12}$ beyond which their small size and lack of stable folding cannot prevent serendipitous polycrystalline growth.

This intrinsic shortcoming of peptides is well established in biology and has motivated the development of combinatorial libraries of folded proteins rather than peptides which has had a major impact on biological applications. Antibodies possess a protein architecture known for its versatile binding capabilities and in vitro evolved antibodies have revolutionized the field of targeted therapeutics. ${ }^{14,15}$ Yet, the non-biological applications of antibodies are severely hampered by their strong propensity to aggregate and the low efficiency of their production in bacterial expression systems. Phage display libraries of antibody fragments have nevertheless been successfully used to identify proteins with binding properties for polymeric ${ }^{16}$ or inorganic surfaces ${ }^{17-19}$ but with the binding site being a flexible amino-acid loop, their interaction is also essentially driven by chemical affinity and lacks structural selectivity. ${ }^{19}$

No effective alternative approach is available to design material-binding proteins. The trial-and-error identification of surface-binding molecules remains essentially serendipitous ${ }^{20-23}$ leading to some successful systems exploiting natural globular $^{20,24}$ and fibrillary ${ }^{25,26}$ proteins or complex plant and microbial extracts. ${ }^{27,28}$

However, efficiently produced and highly evolvable artificial proteins have recently been constructed from naturally stable protein scaffolds. ${ }^{29}$ Extremely efficient protein libraries have been designed by the concatenation of self-compatible repeated motifs idealized from natural protein families such as ankyrin, HEAT or leucine-rich repeats. ${ }^{30-32}$ Such artificial repeat proteins are particularly promising since their interaction surface can be extended by additional motifs without compromising the stability of the folded protein scaffold. Our goal is to extend, at the interface with inorganic nanomaterials, the directed evolution strategy so far limited to short and unstructured peptides to the growing field of artificial protein libraries.

Here, we demonstrate a new scalable strategy whereby a library of fully folded and designable proteins is exposed to crystalline $\mathrm{Au}(111)$ prior to the identification of the selected proteins and their use as habit modifiers in a seed-mediated nanocrystal growth approach. Robustness, to favor epitaxial facet binding, and chemical diversity, to optimize the affinity towards the chosen material, are successfully combined by exploiting the stable and rigid artificial $\alpha$-helical repeat proteins $(\alpha \operatorname{Rep})^{33}$ that comprise a fixed rigid multi- $\alpha$-helical scaffold and a binding surface with random sequence changes in designed positions. ${ }^{33-35}$ This variable surface is optimized, without altering the global protein structure, for the specific binding of the non-biological Au(111) target by evolutionary selection and therefore offers a unique possibility for an optimal design of gold nanocrystal habit modifiers. ${ }^{31}$ Importantly, the selection is performed against an atomically smooth, (111)-oriented gold surface, unlike peptide and antibody selections which are usually performed against polycrystalline $^{9,19}$ or amorphous ${ }^{6,21}$ inorganic targets leading to material- but not facet-specific biomolecules. The selected aRep proteins govern efficiently the synthesis of purely (111)faceted crystals. Additionally, the presence of the capping proteins enables the directed self-assembly of stacked ensembles and satellite superstructures, or the surface confinement of enzymatic production of electroactive species. ${ }^{36}$

\section{Results and discussion}

2.1. Selection of anti-Au(111) aRep by aRep protein phage display

The native structure of aRep proteins is illustrated in Fig. 1a and consists of the concatenation of internal repeats composed of two antiparallel $\alpha$-helices. The first (N-cap) and last (C-cap) motifs have a similar topology but their sequence is adapted to shield the hydrophobic core. The internal repeats comprise 31 amino acids (AA) and have been defined by sequence analysis of a group of homologous HEAT-like repeat proteins found in thermophilic organisms. ${ }^{33}$ The resulting consensus sequence combines twenty-five highly conserved positions (green region in Fig. 1a) that ensure the robust structure of the folded $\alpha$ Rep proteins with six specific hypervariable positions that can accommodate a wide range of amino acid substitutions. Interestingly, all the hypervariable positions are gathered in the same concave surface of the proteins (brown region in Fig. 1a) allowing to choose them in order to confer the proteins specific interaction properties. ${ }^{34}$ To exploit the combined assets of structural robustness and functional interaction specificity of these proteins, we have built a large combinatorial phage library of aRep proteins distinct from each other by (i) the number of internal repeats and (ii) the random nature of the AA in the hypervariable positions. ${ }^{34}$ Such a library of $1.7 \times 10^{9}$ unique clones is sufficiently diverse to allow the selection of new $\alpha$ Rep proteins binding tightly and specifically to almost any other protein defined a priori. The $\alpha$ Rep library was initially developed for biological applications such as the generation of crystallization chaperones, ${ }^{37}$ cell tracking $^{38}$ or in protein interference experiments. ${ }^{39}$ In this work, we apply it, for the first time, to optimize the protein-metal surface affinity and to identify aRep proteins that can act as habit modifiers for the growth of crystalline gold nanoparticles by strong and specific adsorption to pre-determined $\mathrm{Au}(111)$ crystal facets. 

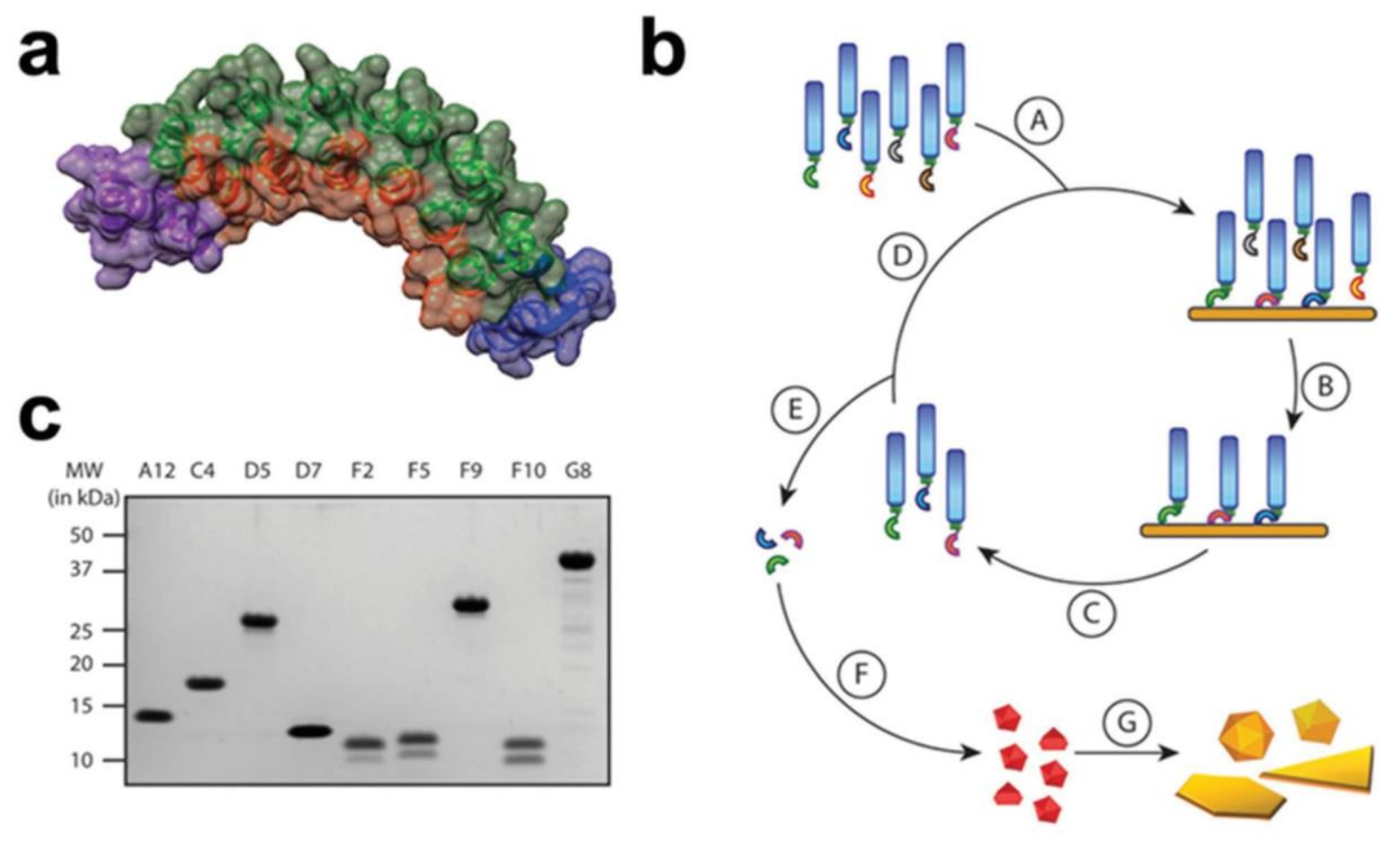

d

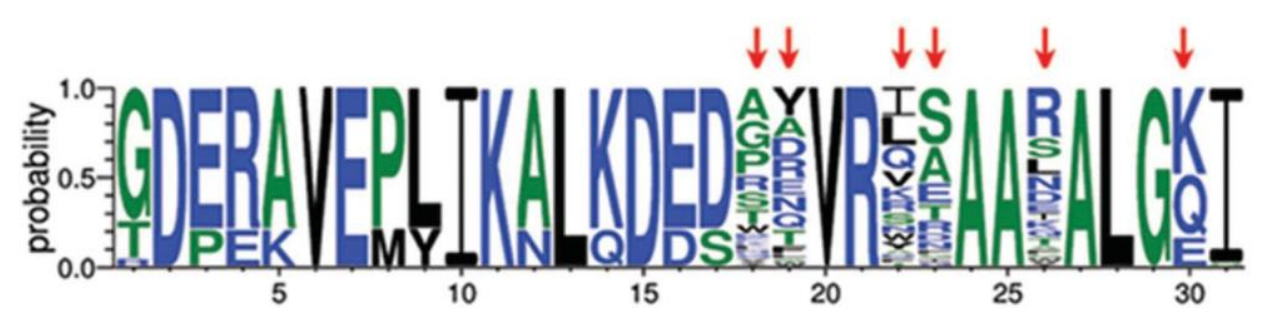

Fig. 1 Construction and directed evolution of Au(111)-binding artificial repeat proteins. (a) 3D representation of the crystallographic structure of a 4repeat aRep protein depicting the internal repeats comprising the hypervariable positions (brown) with their conserved scaffold regions (green), $\mathrm{N}$ (purple) and C-cap (blue). (b) Schematic flowchart showing the phage display design and selection of aRep proteins (A-D) and the aRep directed Au nanocrystal morphosynthesis (F-G) process. These steps involve: (A) construction of the phage display library; (B) aRep selection on a planar $\mathrm{Au}(111)$ substrate on mica and washing steps of unbound phage; (C-D) acid elution of Au-bound phages and bacterial amplification of selected phages; and (E) large scale production and purification of aRep. The morphosynthesis of Au nanocrystals by the seeded growth process comprises: (F) aRep directed Au seed synthesis and (G) nanocrystal growth in the presence of excess aRep through a hydroxylamine-mediated disproportionation mechanism. (c) Coomassie blue stained SDS-PAGE profiles of 9 different Au(111)-selected aRep proteins. The position of the major bands represents the molecular weight of the respective aRep. (d) Sequence logo obtained by multi-alignment of the sequences of all the repeats from the selected aRep, including those of the $\mathrm{N}$-cap that have the same second helix as the internal repeats, hence the apparent variability observed in positions $(1,3,4,5,8,9,12,14,16$, and 17). The binding hypervariable surface is generated by the position indicated by red arrows.

First, $\alpha$ Rep proteins are selected by exposing the combinatorial phage library to a planar $\mathrm{Au}(111)$ film and following the steps depicted in Fig. 1b (see the Experimental section and ESI Section A†). The phage population bearing aRep proteins is incubated at $\mathrm{pH} 7.5$ with freshly prepared $\mathrm{Au}(111)$ surfaces (Step A). Weakly bound phages are eluted (Step B) while the $\mathrm{Au}(111)$-bound clones are collected by acidic elution (Step C) and amplified in bacteria (step D). This iterative biopanning procedure is repeated three times before $96 \mathrm{Au}(111)$-interacting clones are randomly picked from the emerging sub-population, expressed, isolated and tested by standardized ELISA assays against similar freshly prepared $\mathrm{Au}(111)$ substrates (see ESI Fig. S1a†). 18 clones showed a positive ELISA response.
After sequencing, a total of 9 different Au(111)-binders with an internal repeat number $(n)$ comprised between 1 and 10 and pI ranging from 5.3 to 9.05 are identified and are labeled A12, C4, D5, D7, F2, F5, F9, F10, and G8 hereafter (Fig. S1†). The chemical diversity of the hypervariable positions of the 43 selected repeats (Fig. 1d) indicates that the interaction between the protein and the $\mathrm{Au}(111)$ surface is complex. Recent modeling of the peptide-Au interface has indeed shown that optimal adsorption could be attained with $\mathrm{sp}^{2}$ conjugated (Trp, Tyr, Arg), polar (Gln, Asn, Ser), and positively (Arg, Lys) and negatively (Glu, Asp) charged amino acids, thus suggesting a large variety of possible adsorption scenarios for gold-binding proteins. ${ }^{40-43}$ The global AA occurrence in the 
hypervariable positions of the 9 selected $\alpha$ Rep proteins is dominated by glutamine (Gln), arginine (Arg), lysine (Lys) and serine (Ser), which, together, represent $43 \%$ of the hypervariable positions. This suggests that the selected proteins interact with the $\mathrm{Au}(111)$ surface primarily through the binding of amines and hydroxyl groups. Gln, Arg, Lys and Ser are the most frequent for A12, F5, F9 and F10, three of them (Gln-ArgLys or Lys-Gln-Ser) and glutamic acid (Glu) dominate (>54\%) the hypervariable sequence of $\mathrm{G} 8$ and $\mathrm{C} 4$, while two of them (Lys-Arg or Ser-Lys) and threonine (Thr) dominate (>59\%) the hypervariable sequence of D7 and F2. The prevalence of Gln-LysArg-Ser is observed evenly on all repeats. These most frequent AA selected in hypervariable positions are also the ones found in non-thiolated gold-binding polypeptides. ${ }^{6,13}$ The molecular weight of the proteins ranges between 12 and $42 \mathrm{kDa}$ as shown in the SDS-PAGE profile in Fig. 1c. The large size variation of the selected aRep proteins is also consistent with the concomitance of several different gold-binding mechanisms.

\subsection{SPR characterization of the gold affinity of the selected proteins}

To further assess the gold-binding specificity and estimate the affinity constants, each of the nine binders has been immobilized on Surface Plasmon Resonance (SPR) sensor chips and subjected, first, to a high influx of citrate-stabilized, decahedral gold nanoparticles exposing primarily (111) facets ${ }^{44}$ and, second, to an influx of a pure buffer, as described in the Experimental section. This inverted SPR protocol is particularly suited here as gold SPR sensor chips with controlled (111)-terminated surfaces are not available for standard SPR protocols. This approach was already successfully applied to aRep binders selected against other protein targets. ${ }^{45}$ In particular, the selected proteins are uniformly bound on a trisnitrilotriacetic acid/Ni binding sensor chip through a terminal flexible His-tag obviating protein damage upon immobilization. The sensograms for A12, D5, D7, F5 and G8 and buffer are shown in Fig. 2a (see also ESI Fig. S2a† for C4, F9, F10, F2 and extra controls). A significant positive association phase is observed, which shows a maximal response for G8 followed by F5, D5, and D7 and, at a lower level, by A12. When the nanoparticles bound to the protein-coated substrates are washed with a pure buffer a small reduction of the SPR response is observed indicating that some dissociation occurs leading, in the first approximation, to a new equilibrium state. No association is observed during control experiments performed either by replacing the Au nanoparticles with buffer during the initial influx or by immobilizing an aRep protein of identical structure but with no specific affinity for gold such as a GFP-binder a

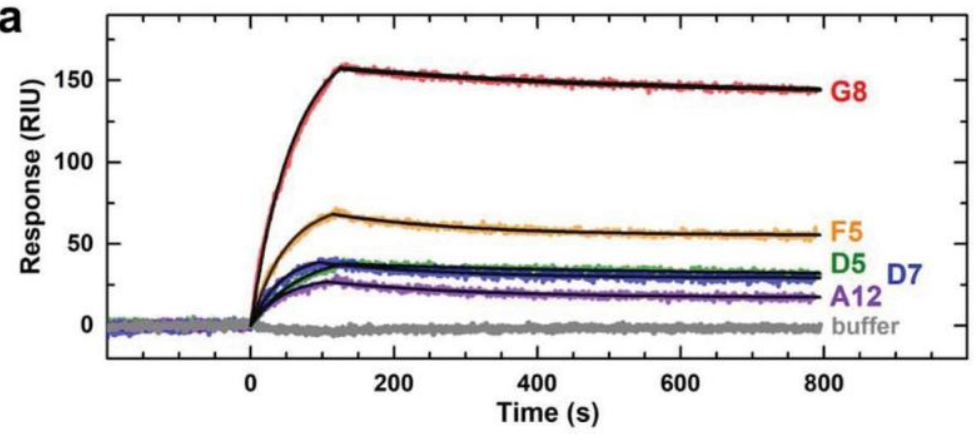

d

\begin{tabular}{|c|c|c|c|c|c|c|}
\hline $\begin{array}{c}\text { Immobilised } \\
\text { a-Rep }\end{array}$ & $\begin{array}{c}k_{\text {on }}\left(10^{6} \mathrm{M}^{-1} \mathrm{~s}^{-1}\right) \\
(\# 1)\end{array}$ & $\begin{array}{c}k_{\text {off }}\left(10^{-3} s^{-1}\right) \\
(\# 1)\end{array}$ & $\begin{array}{c}k_{\text {off }}\left(10^{-3} s^{-1}\right) \\
(\# 2)\end{array}$ & $\begin{array}{c}\mathrm{K}_{\mathrm{D}}(\mathrm{nM}) \\
(\# 1)\end{array}$ & $\begin{array}{c}\mathrm{K}_{\mathrm{o}}(\mathrm{nM}) \\
(\# 2)\end{array}$ & $\begin{array}{c}\mathrm{K}_{\mathrm{D}}(\mathrm{nM}) \\
(\# 3)\end{array}$ \\
\hline G8 & $1.6 \pm 0.4$ & $2.7 \pm 1.8$ & $2.9 \pm 0.02$ & $1.7 \pm 1.55$ & $1.8 \pm 0.47$ & $0.71 \pm 0.06$ \\
\hline F5 & $1.5 \pm 0.3$ & $6.4 \pm 1.5$ & $5.7 \pm 0.07$ & $4.3 \pm 1.85$ & $3.8 \pm 0.81$ & $1.61 \pm 0.09$ \\
\hline A12 & $1.6 \pm 0.5$ & $8.2 \pm 2.8$ & $5.1 \pm 0.08$ & $5.1 \pm 3.35$ & $3.2 \pm 1.05$ & $3.36 \pm 0.75$ \\
\hline D7 & $2.1 \pm 0.3$ & $3.7 \pm 1.8$ & $5.0 \pm 0.11$ & $1.8 \pm 1.11$ & $2.4 \pm 0.39$ & $4.56 \pm 1.01$ \\
\hline D5 & $0.9 \pm 0.2$ & $6.3 \pm 1.3$ & $3.3 \pm 0.05$ & $7.3 \pm 3.00$ & $3.7 \pm 0.57$ & $5.10 \pm 0.80$ \\
\hline
\end{tabular}

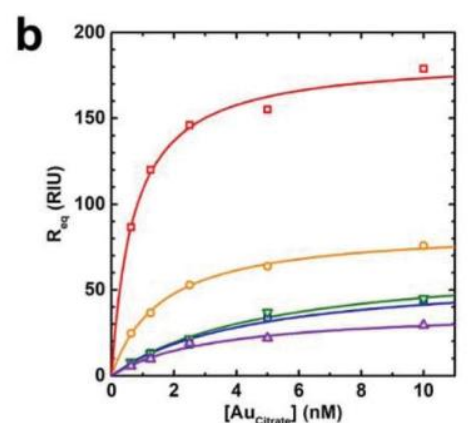

C

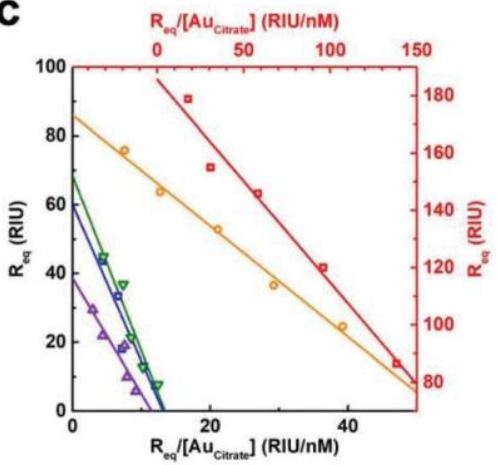

Fig. 2 Gold affinity of the selected anti-Au(111) repeat proteins. (a) SPR sensograms during adsorption and desorption phases monitoring the interactions between immobilized aRep proteins (see labels) and citrate-stabilized Au nanoparticles $\left(\left[\mathrm{Au}_{\mathrm{cit}}\right]=10 \mathrm{nM}\right)$. Solid black lines are exponential fits to the association and dissociation phases. The exponent of the association fits provides the association (kon) and dissociation (koff \#1) kinetic constants tabulated in (d). The dissociation phase fits provide the $k_{\text {OFF }} \# 2$ kinetic constant in table (d). Each set of protein data is associated with the same color throughout the figure. (b) SPR equilibrium analysis along with Langmuir fits (continuous lines). (c) Scatchard plot for the empirical estimation of the dissociation constants labelled $K_{\mathrm{D}} \# 3$ which is obtained from the slopes of the linear fits. G8 data (red) are plotted on the red $x-y$ axis while all other data share the black $x-y$ axis. (d) Summary table of all association ( $\left.k_{\mathrm{ON}}\right)$ and dissociation ( $k_{\mathrm{OFF}} \# 1$ and $k_{\mathrm{OFF}} \# 2$ ) kinetic constants alongside the dissociation constant $\left(K_{\mathrm{D}}\right)$ values obtained from the ratio of kinetic constants $\left(K_{\mathrm{D}} \# 1=k_{\mathrm{OFF}} \# 1 / k_{\mathrm{ON}}, K_{\mathrm{D}} \# 2=k_{\mathrm{OFF}} \# 2 / k_{\mathrm{ONN}}\right)$ and from the

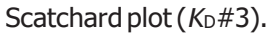


with 4 internal repeats (bGFPa). ${ }^{34}$ The maximal SPR response is observed with the largest protein containing 10 internal repeats (G8). A control sensogram performed with a nonselected $\alpha$ Rep with 10 internal repeats (N10) is shown in Fig. S2a. $†$ The low binding signal observed for N10 is clearly marginal compared to the one of G8, which precludes the control of the protein-gold surface simply by the protein size and confirms the role of the AA selection in the variable positions. The general behavior indicates that G8, F5, D5, D7 and A12 gold-binding proteins have the ability to capture citratestabilized gold nanoparticles, while the other proteins show no significant detectable affinity during SPR tests. More quantitative insight can be gained by extracting dissociation constants from the sensograms using the three approaches detailed in ESI Section S2. $†$ The first dataset $\left(K_{\mathrm{D}} \# 1\right)$ is derived from the kinetic constants of the association phase, $k_{\text {on }}$ and $k_{\text {off\#1 }}$ (Fig. 2d). The second dataset (KD\#2) takes into account the corrected $k_{\text {off } \# 2}$ values from the dissociation phase. The third dataset (KD\#3) is obtained by fitting the data with the Langmuir isotherm model (Fig. 2b) followed by a Scatchard linearization (Fig. 2c). All three quantitative analyses consistently yield sub-10 $\mathrm{nM}$ dissociation constants similar to the ones routinely measured in protein pairs involving at least one aRep binder. ${ }^{34}$ This SPR study demonstrates that the selected aRep proteins readily associate with the solid gold surface and quantifies the $\mathrm{Au}(111)$-binding strength, which is maximal for G8. Furthermore, taking into consideration their intrinsic rigid tridimensional folded shape, their high $\mathrm{pH}$ and thermal stability and their high expression potential that allows the production of $\mathrm{mM}$ solutions, these proteins possess strong potential as selective $\mathrm{Au}(111)$ capping agents and even as crystal habit modifiers in the synthesis of Au nanoparticles.

\subsection{Protein-controlled nanocrystal morphosynthesis}

This unique feature is revealed by the reduction of a gold precursor in the presence of aRep-capped seeds and free aRep, which results in the morphosynthesis of protein-capped gold nanocrystals exclusively terminated with (111) facets (Fig. 1b, steps $F$ and $G)$. First, gold seeds $(7 \pm 1 \mathrm{~nm})$ are produced by the reduction of $\mathrm{Au}^{3+}$ to $\mathrm{Au}^{0}$ with an extrinsic mild reducing agent, sodium formaldehyde sulfoxylate (SFS), ${ }^{46}$ in a buffered

( $\mathrm{pH}$ 7.5) solution of aRep protein acting as capping agents (Fig. 3a and Fig. S3at). The bright red seed solution is produced within two hours after SFS addition, ten times faster than known protein-free methods, ${ }^{20,21,24}$ probably due to the stabilization by the protein capping. The seeds are crystalline with frequent single or penta twin boundaries and occasionally polycrystalline (Fig. $3 \mathrm{~b}$ and Fig. S3d-h $\dagger$ ). The presence of a protein shell is confirmed by a $7 \mathrm{~nm}$ red shift of the plasmon resonance peak of the aRep-capped seeds compared to protein-free seeds (Fig. S4b†), by the light organic halo surrounding the Au seeds in TEM micrographs (Fig. S3a†) and by the prolonged colloidal stability with no sign of aggregation after several months at $4{ }^{\circ} \mathrm{C}$. Furthermore, the electrophoretic mobility of seeds synthesized with any selected aRep protein having different numbers of internal repeats $(n)$ varies consist-
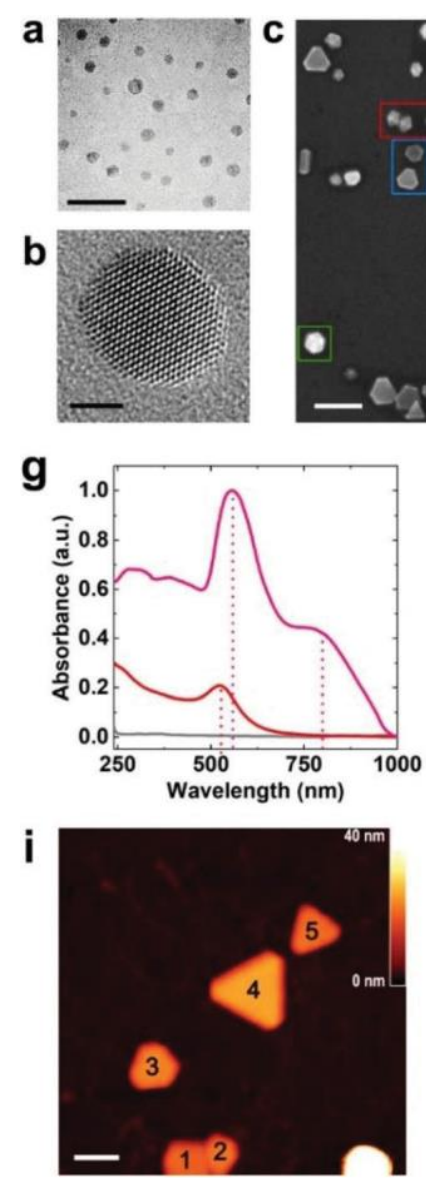
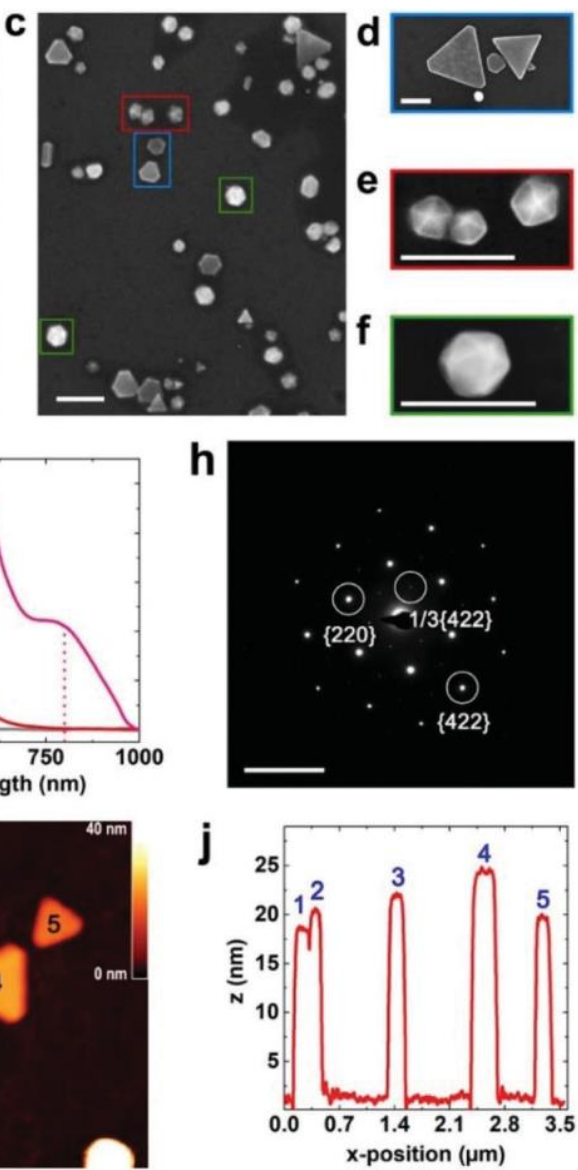

Fig. 3 Morphological and structural characterization of aRep-coated, (111)-terminated Au nanocrystals. (a, b) High resolution TEM images of spherical G8-stabilized seeds showing a high degree of crystallinity. The seed in (b) is single crystalline and oriented along the [011] zone axis. (c) Representative SEM micrograph of G8-capped, (111)-facet terminated Au nanostructures showing nanoplate (blue box), decahedral (red box) and icosahedral (green box) morphologies. (g) UV-visible spectra of G8 templated Au seeds (red, $\lambda_{\max }=524 \mathrm{~nm}$ ), seedless growth solution (grey) and $\mathrm{Au}$ nanostructures synthesized by the G8-templated, seeded growth approach (pink), which exhibit two peaks at $\lambda_{\max }=556 \mathrm{~nm}$ and $\lambda_{\max }=804 \mathrm{~nm}$. (h) Selected area electron diffraction of a Au nanoplate showing diffraction spots along the [111] zone axis. (i) AFM image of five Au nanoplates. ( $\mathrm{j}$ ) Height profile of the five nanoplates shown in (i), which all have a thickness of $21 \pm 3 \mathrm{~nm}$. Scale bars are (a) $20 \mathrm{~nm}$, (b) $2 \mathrm{~nm}$, (c-f, i) $200 \mathrm{~nm}$, and (h) $10 \mathrm{~nm}^{-1}$.

ently with the net surface charge of the corresponding protein in $\mathrm{pH} 8.5$ tris-borate buffer (Fig. S3c†). In spite of the presence of the proteins, the seeds are systematically spherical, which suggests that the proteins, at this stage, merely act as surface stabilizers when the direct reduction is performed with SFS. The seeds are then injected in a fresh solution set at $\mathrm{pH} 5$ and containing $\mathrm{Au}^{3+}$, one of the selected $\alpha$ Rep proteins and hydroxylamine, which is not able to fully reduce gold at this $\mathrm{pH}$ and in the absence of seeds (see ESI Section S4†). ${ }^{47}$ The appearance of a pink-to-purple color in the different solutions confirms the surface-mediated growth through the disproportionation reaction ${ }^{48}$ onto the metallic $\mathrm{Au}$ seeds, as demonstrated for G8 in Fig. 3 and generalized to all selected $\alpha$ Rep 
proteins in Fig. 5i-1 and in ESI Sections S5 and S6. $†$ Detailed electron microscopic examination reveals that the resulting colloid is composed of three (111)-terminated subpopulations of 2D nanoplates $(38.2 \%)$, decahedra (30.4\%) and icosahedra $(16.2 \%)$ with only $15.2 \%$ of other random structures (Fig. 3a and $4 a)$. The ensemble absorption spectrum of as-synthesized nanostructures displays two peaks centered at $556 \mathrm{~nm}$ and $804 \mathrm{~nm}$ (Fig. 3b), suggesting a composite nanocrystal population. The former one dominates and is associated with a plasmon resonance in quasi-isotropic nanoparticles (decahedra and icosahedra). The latter peak shouldering at $780 \mathrm{~nm}$ arises from the in-plane higher order plasmon modes of prismatic nanoplates. ${ }^{49}$ Selected area electron diffraction (SAED) patterns recorded on the nanoplates exhibit three sets of spots of decreasing intensity that are indexed to the (220), (422) and 1/3(422) planes of fcc gold (Fig. 3h). ${ }^{50}$ The 2D prisms are single twinned crystals sharing the same [111] zone axis
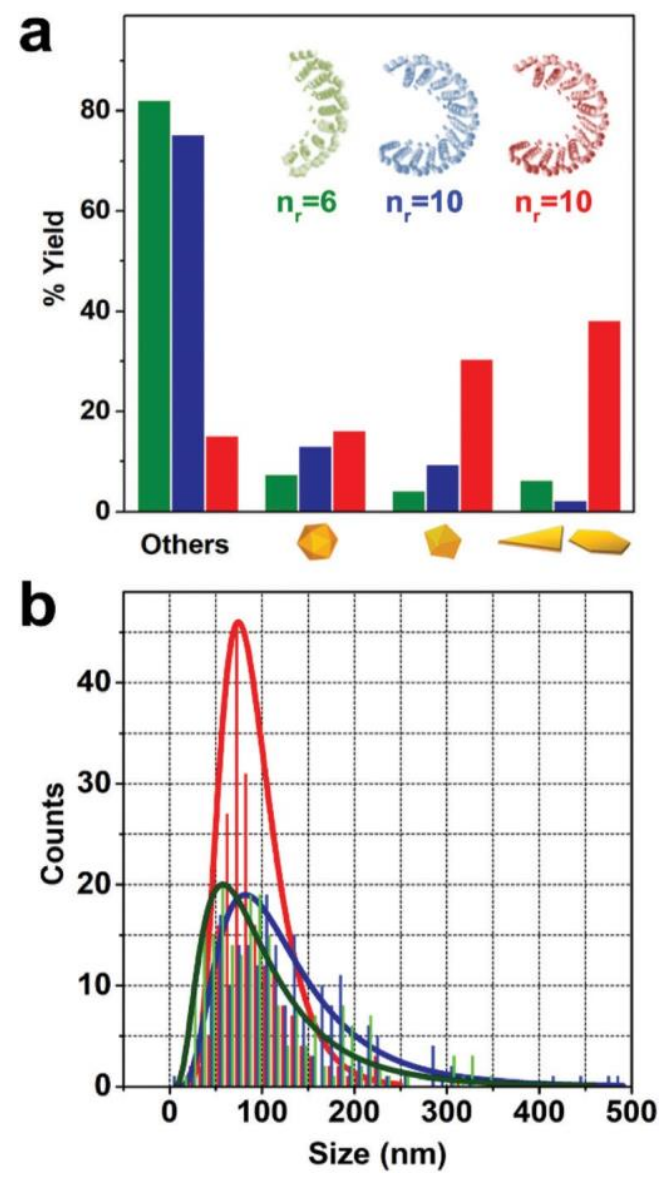

Fig. 4 Comparative analysis of nanocrystal shapes and sizes obtained in the presence of control proteins, anti-GFP and N10, or anti-Au(111) G8. (a) Histogram showing the relative occurrence of nanoprisms, decahedra, icosahedra and other shapes (spheroidal and irregular shapes) obtained by morphosynthesis with anti-GFP aRep (green) or the consensus sequence N10 aRep (blue) and the isomorphic anti-Au(111) G8 aRep (red). (b) Size distribution histograms and log-normal fits of as-synthesized nanocrystals with anti-GFP (green), N10 (blue) and G8 (red) aRep proteins (200 measurements for each set). aligned with the electron beam and thus exposing two extended (111) basal facets. While the lateral dimensions of the nanoplates vary between $c a$. 50 and $500 \mathrm{~nm}$, they show a fairly uniform thickness of $22 \mathrm{~nm}$ as evidenced by atomic force microscopy (AFM) measurements displayed in Fig. 3d and $\mathrm{e}$, in good agreement with twinned nanoprisms of similar morphology produced by other methods. ${ }^{51-53}$

Fig. 4 demonstrates that the direct effect of the facetspecific gold affinity of $\mathrm{Au}(111)$-selected G8 proteins on the morphology and structure of the gold nanocrystals is absent for analogous proteins that have not been selected against $\mathrm{Au}(111)$. The exact same synthesis conditions used with G8 in Fig. 3 are performed with the two control aRep proteins, N10 and bGFPa, that have no specific affinity for $\mathrm{Au}(111)$ surfaces (Fig. S7†). ${ }^{34}$ Fig. 4a clearly illustrates that the (111)-faceted nanoplates, icosahedrons and decahedrons represent only $25 \%$ and $18 \%$ of the particles produced in the presence of bGFP and N10 respectively while they amount to $85 \%$ when the morphosynthesis is performed with G8. The vast prevalence of (111)-terminated nanoparticles in the latter case results from the specific and strong binding of the designed proteins to emerging (111) facets as the metal growth proceeds under $\mathrm{pH}$ conditions similar to the ones corresponding to the binding step during the protein selection (Fig. 1, step B). The strong protein-surface affinity hinders the build-up on (111) facets, which are thus stabilized, and results in enhanced growth rates in other available crystallographic directions. Decahedra and icosahedra only expose (111) facets and thus are fully coated with $\alpha$ Rep proteins leading to a rapid inhibition of their growth. As a consequence of the seed-mediated protocol and of the effective growth inhibition of the (111) facets, the size distribution of the G8-driven synthesis is twice narrower $(92 \mathrm{~nm} \pm 35 \mathrm{~nm})$ than the two control experiments $(130 \mathrm{~nm} \pm 77 \mathrm{~nm}$ for $\mathrm{N} 10$ and $106 \mathrm{~nm} \pm 75 \mathrm{~nm}$ for bGFP) as seen in Fig. 4b.

Interestingly, nanoplates are formed by inhibiting the two basal (111) facets of single twinned seeds but their edges expose the (100) and (110) facets that keep growing even in the presence of the selected proteins as witnessed by the larger edge length distribution (Fig. 3 and 4b), which further confirms the (111) binding specificity of the selected aRep proteins. The kinetic control obtained by performing the hydroxylamine reduction at $\mathrm{pH} 5$ allows the tuning of the nanocrystal size distribution by adjusting the $\mathrm{Au}^{3+}$ ion flux in the growth solution. In Fig. 5a-h, the G8-mediated nanocrystal synthesis is performed with increasing $\mathrm{Au}^{3+}$ concentrations and shows the same types of structures with a marked increase of the nanoplate edge length. The overall size distributions shift from $48 \pm 14 \mathrm{~nm}$ for $\left[\mathrm{Au}^{3+}\right]=0.5 \mathrm{mM}$ to $105 \pm 72 \mathrm{~nm}$ for $\left[\mathrm{Au}^{3+}\right]=3.5 \mathrm{mM}$ and is accompanied by a red-shift of both plasmon resonances (Fig. S8a and b†).

This shift is more pronounced for the higher order plasmon mode peak in agreement with the significant increase of the nanoplate edge length (from $54 \pm 4 \mathrm{~nm}$ for $\left[\mathrm{Au}^{3+}\right]=0.5 \mathrm{mM}$ to $180 \pm 7 \mathrm{~nm}$ for $\left[\mathrm{Au}^{3+}\right]=2.5 \mathrm{mM}$ ) compared to the moderate growth of the spheroidal nanocrystals (from 

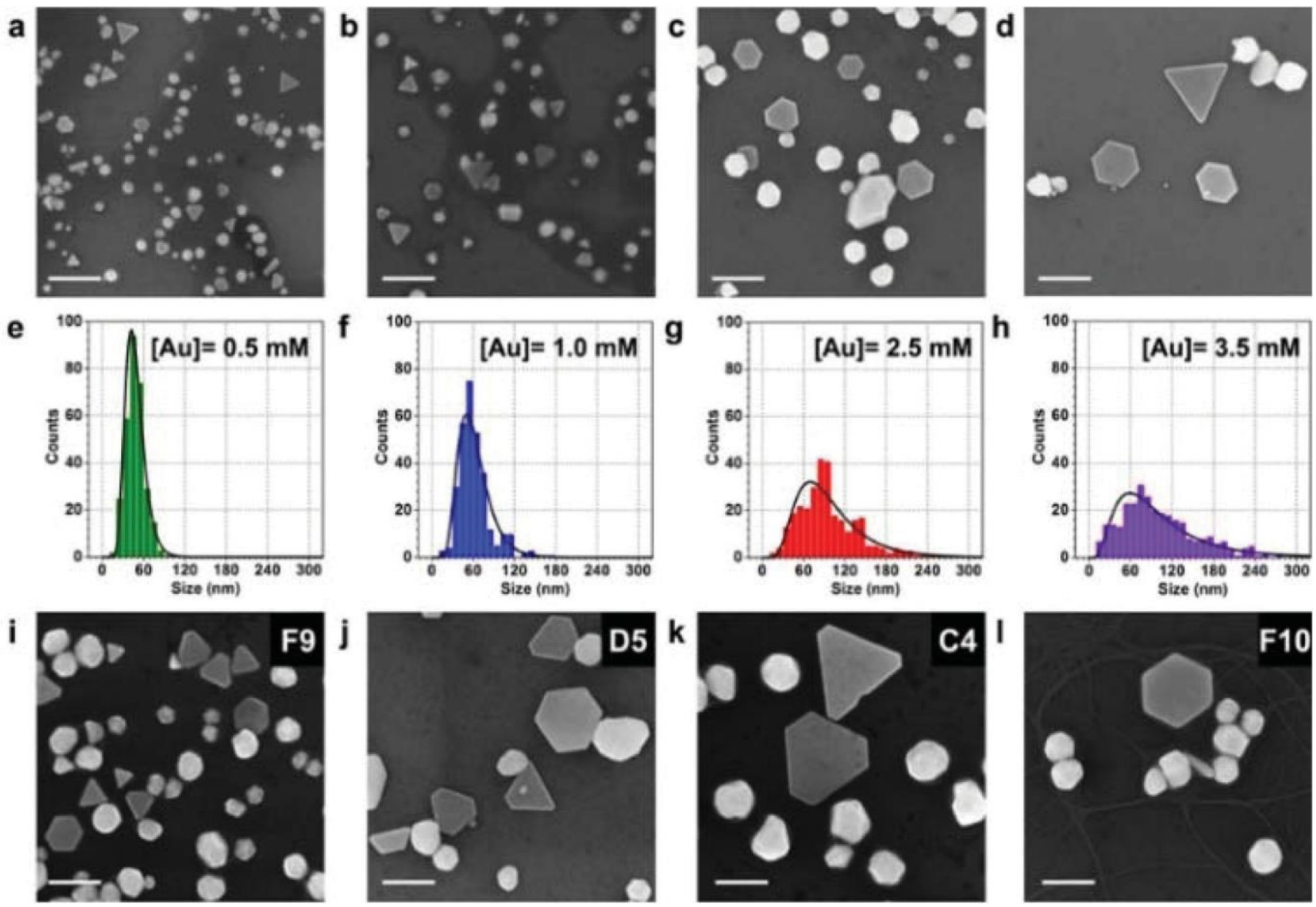

Fig. 5 Nanocrystal size adjustment by varying the initial $\mathrm{Au}^{3+}$ concentration and generalized synthesis with other selected proteins. (a-h) SEM micrographs and nanocrystal size distribution of kinetically controlled G8-capped $\mathrm{Au}$ nanostructures for four different $\mathrm{Au}^{3+}$ concentrations: $(\mathrm{a}, \mathrm{e}) 0.5 \mathrm{mM}$; (b, f) $1.0 \mathrm{mM}$; (c, g) $2.5 \mathrm{mM}$; and (d, h) $3.5 \mathrm{mM}$. The histograms follow lognormal distributions (black lines) with sizes of (e) $48 \pm 14 \mathrm{~nm}$, (f) $62 \pm 24 \mathrm{~nm},(\mathrm{~g}) 99 \pm 50 \mathrm{~nm}$ and (h) $105 \pm 72 \mathrm{~nm}$. (i-I) SEM micrographs of nanostructures synthesized in the presence of different aRep proteins at the same $\mathrm{Au}^{3+}$ concentration of $2.5 \mathrm{mM}$ : (i) F9; (j) D5; (k) C4; and (I) F10. Scale bars: $200 \mathrm{~nm}$.

$46 \pm 2 \mathrm{~nm}$ to $78 \pm 3 \mathrm{~nm}$ ) and the quasi-negligible thickening of the nanoplates (Fig. S8c and d†). Indeed, at the lowest concentrations, the in-plane size of the nanoplates is similar to the diameter of the decahedra and icosahedra (Fig. 5a). However, as $\left[\mathrm{Au}^{3+}\right]$ increases, the overall increase of mean size and size spread is predominantly ascribed to the lateral growth of the nanoplate subpopulation, with the in-plane size reaching $c a$. 3-4 times the spheroidal diameter at $\left[\mathrm{Au}^{3+}\right]$ $=3.5 \mathrm{mM}$ (Fig. 5d). This further illustrates that the (111) growth inhibition by the proteins does not apply to other crystallographic directions, like (100) and (110). Very similar results, albeit with specific nanocrystal size distributions, were obtained for several of the selected proteins, F9, D5, C4 and $\mathrm{F} 10$ as shown, for $\left[\mathrm{Au}^{3+}\right]=2.5 \mathrm{mM}$, in Fig. 5i-1 respectively. Contrary to previous studies ${ }^{20,21,54}$ where $\mathrm{pH}$ and temperature are commonly used to control the shape and yield of nanocrystal morphosynthesis, these parameters have no marked influence on the growth process (see ESI Sections S9 and $\mathrm{S} 10 \dagger$ ), which indicates that our approach is predominantly determined by the effective design of the protein-gold interactions.
2.4. Structural and interfacial characterization of the proteincoated (111)-faceted nanocrystals

Remarkably, at elevated temperatures $\left(T>37^{\circ} \mathrm{C}\right)$, basal stacking of nanoplates is observed suggesting an inter-particle assembly process mediated by interactions between proteins strongly tethered to the basal surfaces. ${ }^{55}$ Since the direct evidence of robust protein attachment to the nanocrystal surface is challenging for low molecular weight proteins like aRep ( $\sim 12-42 \mathrm{kDa})$, we have performed a series of analyses of the $\alpha$ Rep-gold interface, which are presented in Fig. 6. Proteolytic trypsinization of G8-coated gold nanocrystals was conducted by addition of $20 \mu \mathrm{M}$ trypsin in $0.01 \mathrm{M}$ phosphate buffer at pH 8 (Fig. 6a). The originally clear red solution (tube 1) rapidly turns grey with the appearance of a small black precipitate (tube 2) as the proteins are degraded. This correlates to the complete disappearance of the $530 \mathrm{~nm}$ plasmon peak in the absorbance spectrum. Non-contact AFM (nc-AFM) was performed under ultrahigh vacuum (UHV) on individual nanoplates deposited onto a smooth silica substrate (Fig. 6b-d). This AFM mode is used for atomic resolution imaging and it 

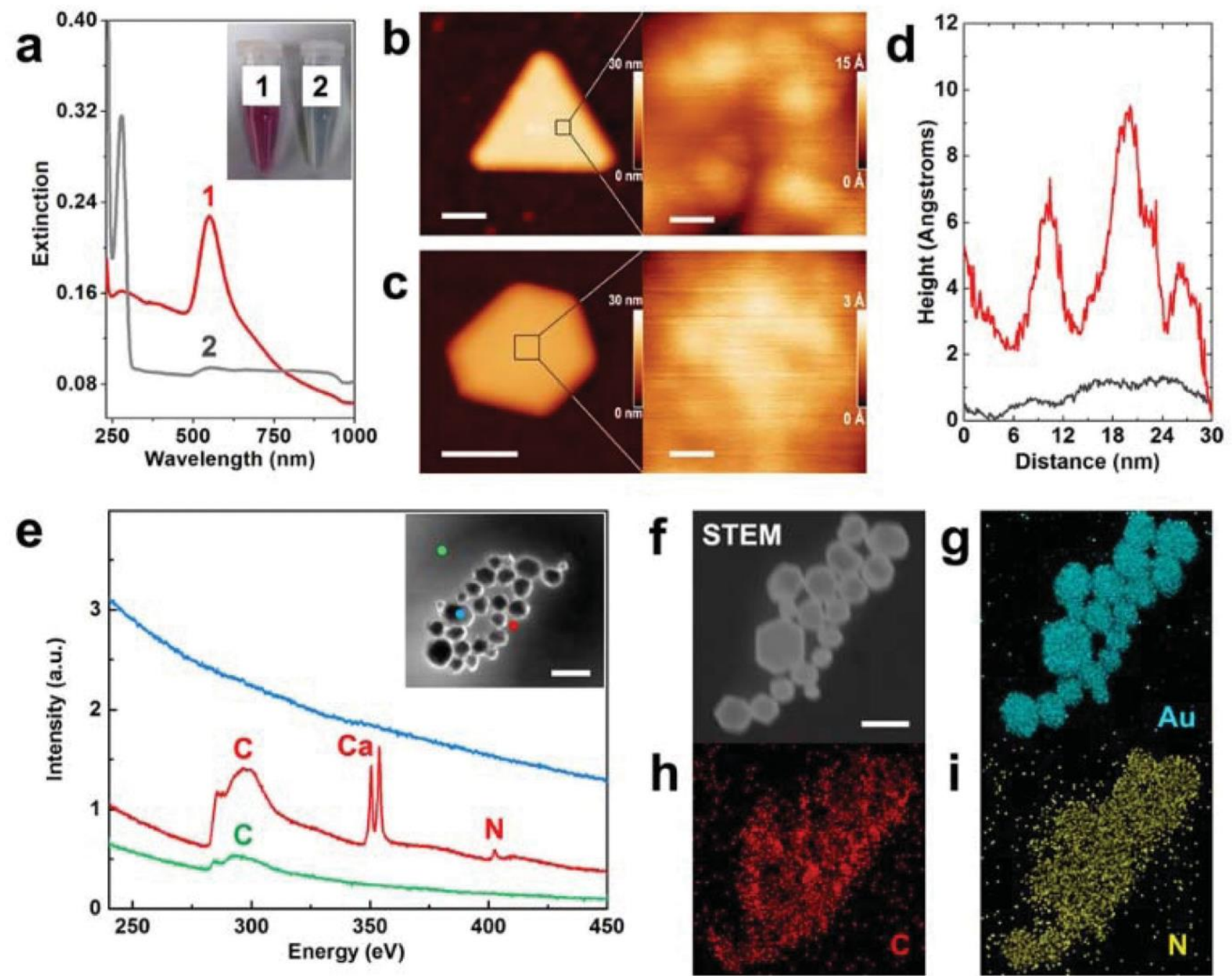

Fig. 6 Chemical analysis of the aRep-Au interface on the surface of the G8-coated nanocrystals. (a) Trypsinization test on G8-capped nanocrystals monitored by UV-visible spectrometry. The sample in tube 1 consists of stable nanocrystals produced with G8 that show a clear plasmon resonance at $520 \mathrm{~nm}$ (spectrum 1). In tube 2, trypsin is used to degrade the protein shell resulting in nanocrystal aggregation and the disappearance of the resonance peak (spectrum 2). (b, c) nc-AFM images of (b) G8-capped and (c) $\mathrm{O}_{2}$ plasma cleaned nanoplates. The black squares indicate the areas zoomed in the right panels. Scale bars are $100 \mathrm{~nm}$ and $6 \mathrm{~nm}$ for the left and right panels respectively. (d) nc-AFM height profiles of the G8-coated triangular nanoprism (red) and of the plasma-cleaned hexagonal nanoprisms (black) shown in (b) and (c) respectively. (e) EELS spectra obtained from three locations in the TEM image of streptavidinylated G8-capped nanocrystals shown in the inset. The background spectrum (green) shows only the carbon peak. The blue spectrum obtained from the center of a Au nanocrystal shows a large uniform background due to a strong interaction of the e-beam with gold atoms. The red spectrum recorded tangentially to the nanocrystal reveals the presence of nitrogen, carbon, and calcium. Note that the Ca signal is obtained from the calcium-based purification method of commercial streptavidin. Scale bar in the inset is $200 \mathrm{~nm}$. ( $\mathrm{f}$ ) STEM image and ( $\mathrm{g}-\mathrm{i})$ corresponding EDS maps showing elemental distribution of $(\mathrm{g})$ gold, (h) carbon and (i) nitrogen. Scale bar in ( $\mathrm{f}$ ) is $400 \mathrm{~nm}$.

ensures that the proteins are not distorted during the raster scanning of the tip. When performed on the as-synthesized nanoplates, a uniform surface is observed which is constellated with globular objects of typical lateral sizes of $5-15 \mathrm{~nm}$ (Fig. 6b) and a height corrugation of about 5-7 $\AA$ (Fig. 6d, red line). This is consistent with an irregular protein coating surface. The sample was then treated with a r.t. $\mathrm{O}_{2}$ plasma to remove all organic adsorbates and re-introduced to UHV, outgassed for $24 \mathrm{~h}$ before resuming nc-AFM imaging (Fig. 6c). The apparent total height of the nanoplates is about $5 \mathrm{~nm}$ smaller after plasma cleaning, which is consistent with the removal of the protein capping layer. Moreover, the upper surface is extremely smooth (Fig. 6c) with the corrugation reduced down to $1-1.5 \AA$, which corresponds to atomically flat Au terraces (Fig. 6d, black line). Similar samples dropcasted onto electron microscopy grids were analyzed by electron energy loss spectroscopy (EELS) in the 250-450 eV energy loss window as shown in Fig. 6e. The EELS signal from the core of the nanocrystals (cyan spot and line) is dominated by the continuous background due to the strong electron-gold interactions. However, spectra recorded just on the edge of the nanocrystal (red spot and line) reveal the 
peaks associated with carbon and nitrogen loss energies, as expected from a thin protein coating. The supporting carbon film (green spot and line) only accounts for a small fraction of the carbon signal, which can be predominantly ascribed to the proteins. Finally, STEM/EDS elemental analysis performed on nanocrystals drop-casted onto ultrathin $\mathrm{SiO}_{2}$ membranes is shown in Fig. 6f-i and S11.† The gold (Fig. 6g), carbon (Fig. 6h) and nitrogen (Fig. 6i) EDS maps perfectly match the STEM image with very little background signal. Taken together, these analyses clearly demonstrate that the nanocrystals are coated by proteins which remain on the surface after the morphosynthesis and purification steps. We expect the hyper-variable side, which is the only one able to discriminate the $\mathrm{Au}(111)$ surface during the selection process, to be strongly interacting with the nanocrystal surface and thus probably exposing the non-variable backside of the proteins to the surrounding medium.

\subsection{Versatile functionalization of the aRep-coated} nanocrystals

To fully exploit the potential of these protein-coated nanoparticles, we use the displayed aRep proteins as modules to directly integrate functional bioactive elements onto the anisotropic nanocrystals without resorting to tedious ligand exchange procedures. ${ }^{35}$ One first option is to incorporate a secondary streptavidin (STV) layer through biotinylation of the Lys residues present in the exposed $\alpha$ Rep backside via the standard NHS- $\mathrm{NH}_{2}$ coupling method. This streptavidinylation of $\alpha$ Rep offers a versatile platform to confer the gold nanocrystals targeted self-assembly and catalysis functionalities. The feasibility of this approach is demonstrated in Fig. 7a-c where streptavidinylated $\alpha$ Rep gold nanocrystals are coupled to NHSbiotin modified aRep gold nanocrystals resulting in large 3D self-assemblies mostly driven by the face-to-face stacking of a

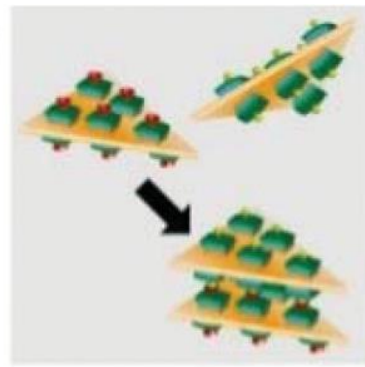

e

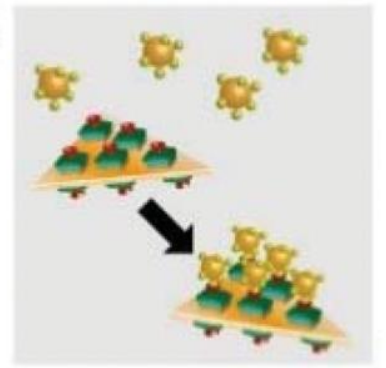

i

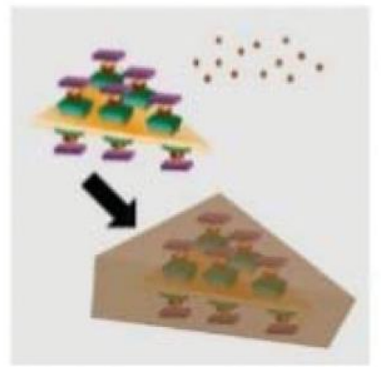

b

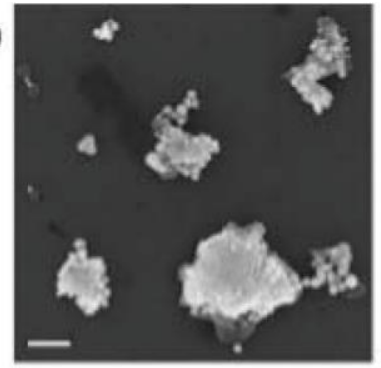

f

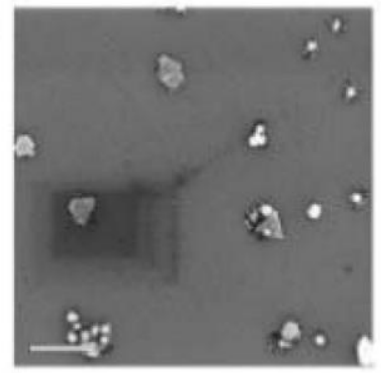

j

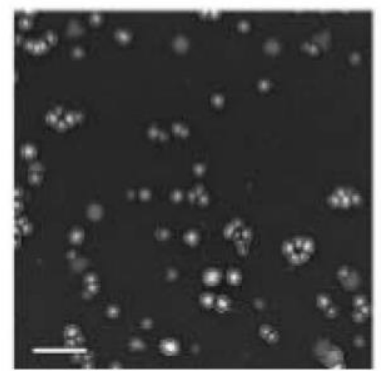

C

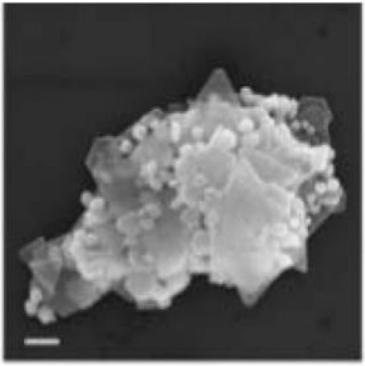

g
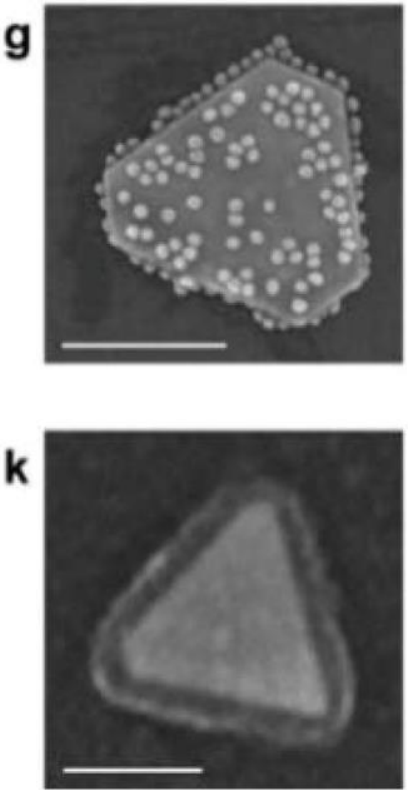

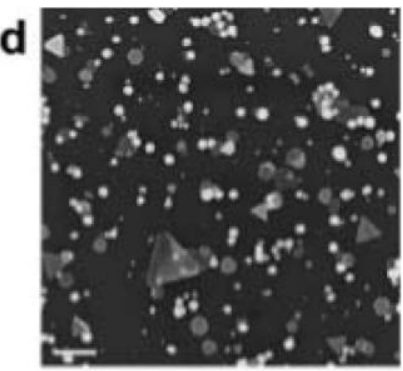

h

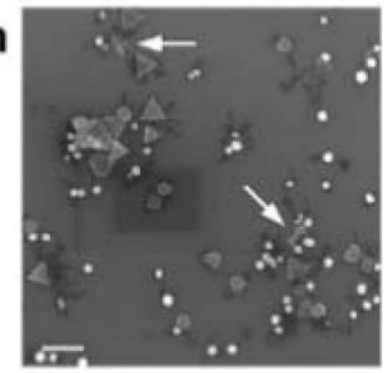

I

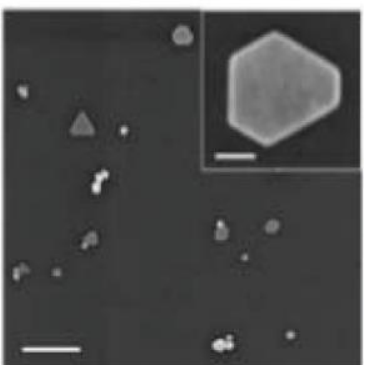

Fig. 7 Functional surface derivatization of aRep protein coated nanocrystals. (a) Scheme and (b, c) SEM images of basal stacking of G8-capped Au nanocrystals obtained by self-assembly between streptavidinylated and biotinylated nanocrystals. (d) Control experiment in the absence of biotin shows no stacking. (e) Scheme and ( $f, g)$ SEM images of core-satellite hybrid assemblies obtained by combining streptavidinylated G8 nanocrystals and biotin-PEG Au nanospheres which results in the decoration of the top and bottom prism facets by the nanospheres. (h) Control experiment with non-streptavidinylated G8-capped Au nanocrystals. No satellite is observed even though segregated nanosphere clumps can be found (white arrows). (i) Scheme and ( $j, k$ ) SEM images of on-surface DAB catalysis by HRP-biotin tagged streptavidinylated G8 nanocrystals which results in a uniform wrapping polymer corona. (I) Control experiment run with simply streptavidinylated nanocrystals in the absence of HRP. No polymer capping layer as shown also in the inset. Scale bars are (b, d, f, h, j, l) $500 \mathrm{~nm},(\mathrm{c}, \mathrm{g}) 200 \mathrm{~nm},(\mathrm{k}) 100 \mathrm{~nm}$ and inset of (I) $50 \mathrm{~nm}$. 
the nanoplates by streptavidin-biotin recognition. Beyond this direct basal stacking, a detailed examination of micrographs suggests that the platonic nanostructures, which probably exhibit accessible biotin and streptavidin molecules on all facets, also contribute to the crosslinking of the large assemblies $^{56}$ and are often found inserted between nanoplates. UVvisible spectroscopy monitoring of equimolar mixtures of streptavidinylated and biotinylated gold nanocrystals shows a marked decrease of the plasmon resonance peak and suggests that self-assembly occurs in solution. In the absence of biotin (bn) on the second partner, the nanocrystals remain isolated from each other and no aggregation is observed (Fig. 7d). This first scheme demonstrates that fully functional aRep proteins are present on the (111) facets of nanocrystals where they can be freely coupled to other biomolecules to create patch antenna-like stacks. ${ }^{57}$

Replacing the biotinylated nanoplates with PEG-biotin functionalized $30 \mathrm{~nm}$ gold nanospheres leads to core-satellite assemblies $^{58}$ as shown in Fig. 7e-g and Fig. S12. † Such structures have been predicted to modulate the native spatial and spectral plasmonic properties of the core nanoplates. ${ }^{19,59}$ The decoration of the nanoplates by the nanospheres occurs preferentially on both basal (111) facets but structures with a core decahedron or icosahedron are also easily identified. No coresatellite structure is formed upon incubation of streptavidinylated aRep gold nanocrystals with non-biotinylated nanospheres, which remain randomly segregated (Fig. 7h, white arrows).

Finally, we have converted the streptavidinylated $\alpha$ Rep gold nanocrystals into catalytic nano-platforms by adding a tertiary layer of biotin-HRP enzyme (Fig. 7i-k). HRP catalyzes the oxidation of benzidines to form water insoluble polymer aggregates. Here, we show that the HRP-tagged gold nanocrystals trigger the polymerization of $1 \mathrm{mM} 3,3^{\prime}$-diaminobenzidine (DAB), in the presence of $\mathrm{H}_{2} \mathrm{O}_{2} \cdot{ }^{60}$ Since the catalytic reaction occurs locally at the nanocrystal surface, a uniform layer of polymerized DAB is grown around the nanocrystals as seen in Fig. 7j, k and Fig. S13a, b. $†$ The thickness can be adjusted by the amount of DAB or the reaction time and is about $25 \mathrm{~nm}$ in the displayed sample. When simply streptavidinylated aRep gold nanocrystals are used, no polymerization reaction takes place and the surface of the nanostructures remains free of polymer over-coating (Fig. 71). This form of catalysis reflects the stability of the Au/aRep/enzyme construction as no side polymer particles were found in the sample, away from the nanocrystals as it should have been expected if HRP had been grafted to aRep loosely bound to the Au surface. The in situ production of the polymer near plasmonic structures to tune the local dielectric constant could be extended to embed complex optically active moieties ${ }^{61}$ for sensing applications. ${ }^{62}$

\section{Conclusions}

The design and combinatorial selection of fully folded artificial proteins are applied here for the first time in the construc- tion of crystal habit modifiers able to shape noble metals such as gold at the nanoscale. Nine new Au(111) binding proteins have been isolated, sequenced, mass produced and used as habit modifiers in a gold nanocrystal seeded growth synthesis. All proteins demonstrated a high chemical affinity for gold and structural selectivity for (111) facets, which results in an effective morphosynthetic action yielding $>85 \%$ of (111)-terminated $\mathrm{Au}$ nanoplates, icosahedra and decahedra. The thin nanoplate size could be tuned up to $500 \mathrm{~nm}$ that requires the recruitment of thousands of proteins per crystalline facet. The detailed structural characterization of the nanocrystals has established the crystalline structure of the gold nanoparticles and the functional activity of the capping protein layer. We further demonstrated the benefit of the artificial protein coating by derivatizing them with streptavidin, biotin and HRP enzyme, therefore incorporating extra surface functionalities such as self-assembling or on-surface catalytic capabilities. Our approach presents several assets compared to the design of goldbinding peptides or antibody fragments and hence offers a promising generic tool for the morphosynthesis of high-index facet nanocrystals with superior biocompatibility and versatile in situ construction of (bio)molecular platforms at the solid interface, which could be capitalized towards plasmon-based optical devices ${ }^{52,57}$ and (bio-) molecular sensing applications ${ }^{63-65}$ on individual or 2D/3D arrayed nanoparticles. ${ }^{35,56}$

\section{Experimental}

\subsection{Selection of $\mathrm{Au}(111)$-binding aRep proteins}

aRep proteins exhibiting binding affinity to a $\mathrm{Au}(111)$ coated mica substrate are selected by phage display. Typically, (111)oriented $\mathrm{Au}$ films are produced by thermal evaporation on freshly cleaved mica slides according to a well-established procedure. The protein library 2.1 comprising $1.7 \times 10^{9}$ variants of aRep proteins fused with the phage coat protein pIII is exposed to the $\mathrm{Au}(111)$ film at $\mathrm{pH} 7.5$ and room temperature (r.t.). ${ }^{34}$ Phages from the library are loaded on a 96-well ELISA plate exposing the $\mathrm{Au}(111)$ surface using a MicroArrayIt system (http://www.arrayit.com) and incubated for $2 \mathrm{~h}$ at $20{ }^{\circ} \mathrm{C}$ and $300 \mathrm{rpm}$. Non-specific phages are removed by ten TBS $0.05 \%$ Tween 20 and ten TBS washing steps. Bound phages are eluted in a glycine solution $(0.1 \mathrm{M}, \mathrm{pH} 2.5)$ for $10 \mathrm{~min}$ at $20^{\circ} \mathrm{C}$ and recovered by infecting a suspension of growing XL1blue MRF' bacteria. This selection round is performed 3 times. 96 clones are analyzed by ELISA. Soluble bacterial extracts are incubated on the $\mathrm{Au}(111)$ film and specific binding is revealed by an antiflag-tag HRP-antibody. 18 positive hits from the ELISA test were sequenced and 9 different $\alpha$ Rep proteins were identified and labelled A12, C4, D5, D7, F2, F5, F9, F10, and G8. The expression and purification of these proteins are performed according to a standard procedure detailed in the ESI. $\dagger$

\subsection{Surface plasmon resonance (SPR) analysis}

SPR data are recorded using the ProteOn XPR36 (Bio-Rad). aRep proteins are immobilized on HTG ProteOn sensor chips 
until reaching a response signal around $200 \mathrm{RU}$ in $10 \mathrm{mM}$ phosphate buffer, $\mathrm{pH} 7.5,137 \mathrm{mM} \mathrm{NaCl}, 2.7 \mathrm{mM} \mathrm{KCl}$ and $0.005 \%$ Tween 20 . Interactions are recorded at a $100 \mu \mathrm{L} \mathrm{min}^{-1}$ flow rate and a $120 \mathrm{~s}$ contact time followed by a dissociation of $600 \mathrm{~s}$ with citrate stabilized $5 \mathrm{~nm}$ diameter gold nanoparticles at different concentrations $(10,5,2.5,1.25$ and $0.625 \mathrm{nM})$. The interspot signal is removed from the sensograms.

\section{3. $\quad$ aRep stabilized Au seed synthesis}

$50 \mu \mathrm{l}$ of $20 \mu \mathrm{M}$ aRep protein solution in $0.1 \mathrm{M}$ phosphate buffer ( $\mathrm{pH}$ 7.5) are mixed with $10 \mu \mathrm{l}$ aqueous solution of $20 \mathrm{mM}$ sodium formaldehyde sulfoxylate at r.t. This solution is immediately injected into $100 \mu \mathrm{l}$ of $2 \mathrm{mM} \mathrm{HAuCl}_{4}$ solution under vigorous stirring at $900 \mathrm{rpm}$ at r.t. After stirring for $2 \mathrm{~min}$, the resulting red solution is left to grow for 2 hours until full completion of the reduction process. The seed solution is stored at $4{ }^{\circ} \mathrm{C}$.

\section{4. aRep mediated seeded growth of nanocrystals}

The growth of aRep capped Au nanocrystals is performed by adapting the hydroxylamine reduction method. ${ }^{47}$ Briefly, $2.5 \mu \mathrm{l}$ Au seeds are mixed with $20 \mu 1$ of $100 \mu \mathrm{M}$ aRep protein solution (0.1 M phosphate buffer, $\mathrm{pH}$ 7.5) and diluted to a final volume of $245 \mu \mathrm{l}$ with MilliQ water. Concomitantly, $5 \mu \mathrm{l}$ of freshly prepared $200 \mathrm{mM}$ hydroxylamine hydrochloride is injected to the seed and $\alpha$ Rep solution. The resulting solution is promptly injected to a series of $250 \mu 1 \mathrm{HAuCl}_{4}$ solutions with final [ $\mathrm{Au}^{3+}$ ] concentrations of $1 \mathrm{mM}, 2 \mathrm{mM}$ and $5 \mathrm{mM}$. The $\mathrm{pH}$ value of the reaction mixture is adjusted to the desired values by adding aliquots of $0.1 \mathrm{M} \mathrm{HCl}$ or $\mathrm{NaOH}$ solutions. The final reaction volume is homogenized by stirring at $900 \mathrm{rpm}$ for $2 \mathrm{~min}$, followed by incubation at r.t. for $2 \mathrm{~h}$. After synthesis, the final products are washed 4 times by centrifugation at $8000 \mathrm{rpm}$ for $5 \mathrm{~min}$ and re-suspended in $1 \mathrm{~mL}$ MilliQ water in order to remove the uncoordinated $\alpha$ Rep proteins.

4.5. Structural characterization of as-synthesized gold nanocrystals

Absorbance of as-synthesized gold nanocrystals is recorded on a Cary-5000 UV-vis NIR spectrophotometer in the range of 200-1200 nm and at a $600 \mathrm{~nm} \mathrm{~min}^{-1}$ scan rate. Structural analyses of the nanocrystals are carried out by scanning electron microscopy (SEM), transmission electron microscopy (TEM), selected area electron diffraction (SAED) and atomic force microscopy (AFM). Samples for SEM and AFM analyses are prepared by drop casting $20 \mu \mathrm{L}$ of the nanocrystal suspension in MilliQ water on an oxide-coated silicon wafer followed by overnight drying in air. FEG-SEM images are recorded on a Zeiss $1540 \mathrm{XB}$ system operated at $20 \mathrm{kV}$. Tapping mode AFM is conducted using a Bruker Dimension 3000 microscope. Extra topological information of the corrugation of the flat prismatic nanocrystals is obtained from non-contact AFM (nc-AFM) imaging under ultrahigh vacuum (UHV). ${ }^{66}$ The samples are introduced in a Scienta Omicron Nanotechnology UHV-STM/ nc-AFM microscope and probed with Pt-Ir coated silicon cantilevers (Nanosensors PPP-QNCHR) at 280-300 kHz resonance frequency and quality factors of 32 000-40 000. With an overall oscillation amplitude fixed at $5 \mathrm{~nm}$, this attractive mode obviates protein distortion under the AFM tip and so provides accurate height measurements and sub-molecular resolution on organic molecules. ${ }^{67}$ Bright field TEM and SAED analyses are conducted on a Philips CM20FEG TEM operated at $200 \mathrm{kV}$ accelerating voltage and equipped with a Gatan CCD camera and Digital Micrograph acquisition software. Size and shape distribution analyses of the electron micrographs are performed using ImageJ software. Electron energy loss spectroscopy (EELS) is carried out in a Hitachi HF3300 microscope equipped with a GIF (Gatan Imaging Filter) Quantum. STEM-EDS was performed on a Phillips CM20FEG equipped with a Brücker SDD detector. TEM samples are prepared by drop-casting and air-drying a $10 \mu \mathrm{L}$ droplet onto 300 mesh carbon film copper grids, for TEM, SAED and EELS, or $10 \mathrm{~nm}$ thick $\mathrm{SiO}_{2}$ membranes for STEM-EDX.

\subsection{Streptavidinylation of aRep capped nanocrystals}

To integrate streptavidin to aRep-capped gold nanocrystals, the lysine residues present in the $\alpha$ Rep backbone are biotinylated. $500 \mu \mathrm{l}$ of as-synthesized and washed gold nanocrystals are mixed with $20 \mu \mathrm{l}$ of $2 \mathrm{mg} \mathrm{ml}^{-1}$ NHS-biotin dissolved in DMF and incubated at r.t. for 2 hours. Following incubation, the biotinylated gold nanocrystals are washed four times with a $0.01 \%$ Tween 20 solution adjusted at $\mathrm{pH} 7$ to remove free NHS-biotin molecules and re-suspended in PBST solution. $50 \mu 1$ of $1 \mathrm{mg} \mathrm{ml}^{-1}$ streptavidin solution is added to the biotinylated, aRep-capped gold nanocrystals. The suspension is incubated at r.t. for 3 hours and subsequently washed 4 times with a $0.01 \%$ Tween 20 solution adjusted at $\mathrm{pH} 7$. The streptavidin-coupled gold nanocrystal assemblies are stored at $4{ }^{\circ} \mathrm{C}$.

4.7. Synthesis and PEGylation of $15 \mathrm{~nm}$ citrate stabilized Au nanospheres

Citrate stabilised gold nanospheres (AuNPs) are synthesised using Turkevich's method. ${ }^{68}$ Briefly, $20 \mathrm{ml}$ of $0.25 \mathrm{mM} \mathrm{HAuCl}_{4}$ solution is heated to the boiling point prior to the rapid addition of $120 \mu \mathrm{l}$ of a $50 \mathrm{mg} \mathrm{ml}^{-1}$ sodium citrate solution under vigorous stirring. The solution is continuously stirred for $30 \mathrm{~min}$, until it turns ruby red. The AuNP suspension is allowed to cool down to r.t. over 4 hours. $2 \mathrm{ml}$ of AuNP suspension are centrifuged at $14500 \mathrm{rpm}$ for $15 \mathrm{~min}$. The supernatant is discarded and the pellet is re-suspended in $500 \mu \mathrm{l}$ of a $2 \mathrm{mg} \mathrm{ml} \mathrm{m}^{-1}$ biotin-PEG-SH solution and incubated for $6 \mathrm{~h}$. PEGylated AuNPs are washed eight times with MilliQ water at $14500 \mathrm{rpm}$ for $15 \mathrm{~min}$ and, finally, re-suspended in $100 \mu \mathrm{l}$ MilliQ water before storage at $4{ }^{\circ} \mathrm{C}$.

\subsection{Peroxidase-catalyzed 3,3' diaminobenzidine polymerization}

A $2 \mathrm{mg} \mathrm{ml}^{-1}$ solution of horseradish peroxidase (HRP) in PBS buffer is mixed with $20 \mu \mathrm{l}$ of $2 \mathrm{mg} \mathrm{ml}^{-1}$ NHS-biotin dissolved in DMF. Biotinylation of HRP is allowed to proceed for $2 \mathrm{~h}$. Excess NHS-biotin is removed by passing the solution through a Zeba spin desalting column (Thermo Fisher Scientific). Next, $500 \mu 1$ of streptavidinylated, $\alpha$ Rep-capped gold nanocrystals are 
reacted with the biotinylated HRP enzyme at r.t. for 2 h. The HRP-coupled gold nanocrystals are washed four times at 8000 rpm for 5 min with a $0.01 \%$ Tween 20 solution adjusted at $\mathrm{pH}$ 7 to eliminate unconjugated biotin-HRP. $5 \mu \mathrm{l}$ of HRP-gold nanocrystals are drop-casted on silicon substrates and allowed to dry for $3 \mathrm{~h}$. Enzyme-catalyzed polymerisation and precipitation (ECPP) ${ }^{69}$ of 3,3'-diaminobenzidine (DAB) is triggered locally by drop-casting $30 \mu \mathrm{l}$ of a freshly prepared $1 \mathrm{mM}$ aqueous solution of $\mathrm{DAB}$ on top of the silicon-immobilized $\mathrm{HRP}-$ gold nanocrystals, in the presence of $5 \mu \mathrm{l} 30 \%$ w/w $\mathrm{H}_{2} \mathrm{O}_{2}$ solution. The DAB polymerization reaction by HRP is allowed to proceed for $3 \mathrm{~h}$. Finally, the silicon substrate is washed 6 times with $100 \mu$ l of MilliQ water and air dried.

\section{Conflicts of interest}

There are no conflicts to declare.

\section{Acknowledgements}

This work was funded by the European Research Council (ERC, Grant No. FP7-ERC-2007-StG-203872 COMOSYEL to E.D.), the CNRS High Risk Program "NanoBriques" and the Agence Nationale de la Recherche (ANR, Contract No. ANR-14CE08-0004-ARTEMIS). The authors thank O. Guillermet for preparing the $\mathrm{Au}(111)$ films on mica and M. Alchaar for technical assistance in nc-AFM.

\section{References}

1 Protein-Ligand Interactions. Methods and Applications, ed. M. Williams and T. Daviter, Humana Press, New York, 2013.

2 S. Mann, Biomineralization. Principles and Concepts in Bioinorganic Materials Chemistry, Oxford University Press, Oford, 2001.

3 F. H. Wilt, Dev. Biol., 2005, 280, 15-25.

4 S. G. Peisajovich and D. S. Tawfik, Nat. Methods, 2007, 4, 991-994.

5 M. S. Packer and D. R. Liu, Nat. Rev. Genet., 2015, 16, 379394.

6 S. Brown, Nat. Biotechnol., 1997, 15, 269-272.

7 S. R. Whaley, D. S. English, E. L. Hu, P. F. Barbara and A. M. Belcher, Nature, 2000, 405, 665-668.

8 S. W. Lee, C. B. Mao, C. E. Flynn and A. M. Belcher, Science, 2002, 296, 892-895.

9 M. Sarikaya, C. Tamerler, A. K. Y. Jen, K. Schulten and F. Baneyx, Nat. Mater., 2003, 2, 577-585.

10 A. Vallee, V. Humblot and C. M. Pradier, Acc. Chem. Res., 2010, 43, 1297-1306.

11 K. T. Nam, D. W. Kim, P. J. Yoo, C. Y. Chiang, N. Meethong, P. T. Hammond, Y. M. Chiang and A. M. Belcher, Science, 2006, 312, 885-888.

12 C.-Y. Chiu, Y. Li, L. Ruan, X. Ye, C. B. Murray and Y. Huang, Nat. Chem., 2011, 3, 393-399.
13 C. R. So, J. L. Kulp, E. E. Oren, H. Zareie, C. Tamerler, J. S. Evans and M. Sarikaya, ACS Nano, 2009, 3, 1525-1531.

14 G. Winter, A. D. Griffiths, R. E. Hawkins and H. R. Hoogenboom, Annu. Rev. Immunol., 1994, 12, 433455.

15 N. Buss, S. J. Henderson, M. McFarlane, J. M. Shenton and L. de Haan, Curr. Opin. Pharmacol., 2012, 12, 615-622.

16 A. Soshee, S. Zurcher, N. D. Spencer, A. Halperin and C. Nizak, Biomacromolecules, 2014, 15, 113-121.

17 A. Artzy Schnirman, E. Zahavi, H. Yeger, R. Rosenfeld, I. Benhar, Y. Reiter and U. Sivan, Nano Lett., 2006, 6, 18701874.

18 T. Hattori, M. Umetsu, T. Nakanishi, S. Sawai, S. Kikuchi, R. Asano and I. Kumagai, Bioconjugate Chem., 2012, 23, 1934-1944.

19 P. Jain, A. Soshee, S. S. Narayanan, J. Sharma, C. Girard, E. Dujardin and C. Nizak, J. Phys. Chem. C, 2014, 118, 14502-14510.

20 J. Xie, J. Y. Lee and D. I. C. Wang, J. Phys. Chem. C, 2007, 111, 10226-10232.

21 J. Kim, Y. Rheem, B. Yoo, Y. Chong, K. N. Bozhilov, D. Kim, M. J. Sadowsky, H.-G. Hur and N. V. Myung, Acta Biomater., 2010, 6, 2681-2689.

'22 M. Darnell and D. J. Mooney, Nat. Mater., 2017, 16, 11781185.

23 A. R. D. Voet and J. R. H. Tame, Curr. Opin. Biotechnol., 2017, 46, 14-19.

24 Y. Liu and R. Guo, Mater. Chem. Phys., 2011, 126, 619627.

25 C. Li, S. Bolisetty and R. Mezzenga, Adv. Mater., 2013, 25, 3694-3700.

26 B. Cantaert, D. Ding, C. M. Rieu, L. Petrone, S. Hoon, K. H. Kock and A. Miserez, Macromol. Rapid Commun., 2015, 36, 1877-1883.

27 B. Liu, J. Xie, J. Y. Lee, Y. P. Ting and J. P. Chen, J. Phys. Chem. B, 2005, 109, 15256-15263.

28 S. S. Shankar, A. Rai, B. Ankamwar, A. Singh, A. Ahmad and M. Sastry, Nat. Mater., 2004, 3, 482-488.

29 H. K. Binz, P. Amstutz and A. Pluckthun, Nat. Biotechnol., 2005, 23, 1257-1268.

30 Y. L. Boersma and A. Pluckthun, Curr. Opin. Biotechnol., 2011, 22, 849-857.

31 A. Urvoas, M. Valerio-Lepiniec and P. Minard, Trends Biotechnol., 2012, 30, 512-520.

32 F. Parmeggiani and P. S. Huang, Curr. Opin. Struct. Biol., 2017, 45, 116-123.

33 A. Urvoas, A. Guellouz, M. Valerio-Lepiniec, M. Graille, D. Durand, D. C. Desravines, H. van Tilbeurgh, M. Desmadril and P. Minard, J. Mol. Biol., 2010, 404, 307327.

34 A. Guellouz, M. Valerio-Lepiniec, A. Urvoas, A. Chevrel, M. Graille, Z. Fourati-Kammoun, M. Desmadril, H. van Tilbeurgh and P. Minard, PLoS One, 2013, 8, e71512.

35 K. L. Gurunatha, A. C. Fournier, A. Urvoas, M. ValerioLepiniec, V. Marchi, P. Minard and E. Dujardin, ACS Nano, 2016, 10, 3176-3185. 
36 S. H. Mejias, J. Lopez-Andarias, T. Sakurai, S. Yoneda, K. P. Erazo, S. Seki, C. Atienza, N. Martin and A. L. Cortajarena, Chem. Sci., 2016, 7, 4842-4847.

37 A. Chevrel, A. Mesneau, D. Sanchez, L. Celma, S. QuevillonCheruel, A. Cavagnino, S. Nessler, I. L. de la Sierra-Gallay, H. van Tilbeurgh, P. Minard, M. Valerio-Lepiniec and A. Urvoas, J. Struct. Biol., 2018, 201, 88-99.

38 A. Chevrel, A. Urvoas, I. L. de la Sierra-Gallay, M. AumontNicaise, S. Moutel, M. Desmadril, F. Perez, A. Gautreau, H. van Tilbeurgh, P. Minard and M. Valerio-Lepiniec, Biosci. Rep., 2015, 35, e00223.

39 S. Hadpech, S. Nangola, K. Chupradit, K. Fanhchaksai, W. Furnon, A. Urvoas, M. Valerio-Lepiniec, P. Minard, P. Boulanger, S. S. Hong and C. Tayapiwatana, Sci. Rep., 2017, 7, 16335.

40 R. L. Willett, K. W. Baldwin, K. W. West and L. N. Pfeiffer, Proc. Natl. Acad. Sci. U. S. A., 2005, 102, 7817-7822.

41 A. Calzolari, G. Cicero, C. Cavazzoni, R. Di Felice, A. Catellani and S. Corni, J. Am. Chem. Soc., 2010, 132, 4790-4795.

42 M. Hoefling, F. Iori, S. Corni and K. E. Gottschalk, Langmuir, 2010, 26, 8347-8351.

43 J. Feng, R. B. Pandey, R. J. Berry, B. L. Farmer, R. R. Naik and H. Heinz, Soft Matter, 2011, 7, 2113-2120.

44 C. L. Johnson, E. Snoeck, M. Ezcurdia, B. RodriguezGonzalez, I. Pastoriza-Santos, L. M. Liz-Marzan and M. J. Hytch, Nat. Mater., 2008, 7, 120-124.

45 C. Leger, T. Di Meo, M. Aumont-Nicaise, C. Velours, D. Durand, I. Li de la Sierra-Gallay, H. van Tilbeurgh, N. Hildebrandt, M. Desmadril, A. Urvoas, M. ValerioLepiniec and P. Minard, Sci. Rep., 2019, 9, 1178.

46 P. K. Khanna, R. Gokhale, V. V. V. S. Subbarao, A. K. Vishwanath, B. K. Das and C. V. V. Satyanarayana, Mater. Chem. Phys., 2005, 92, 229-233.

47 K. R. Brown and M. J. Natan, Langmuir, 1998, 14, 726-728.

48 L. Scarabelli, A. Sánchez-Iglesias, J. Pérez-Juste and L. M. Liz-Marzán, J. Phys. Chem. Lett., 2015, 6, 4270-4279.

49 S. Viarbitskaya, A. Teulle, A. Cuche, J. Sharma, C. Girard, E. Dujardin and A. Arbouet, Appl. Phys. Lett., 2013, 103, 131112.

50 R. Jin, Y. Cao, C. A. Mirkin, K. L. Kelly, G. C. Schatz and J. G. Zheng, Science, 2001, 294, 1901.

51 L. Chen, F. Ji, Y. Xu, L. He, Y. Mi, F. Bao, B. Sun, X. Zhang and Q. Zhang, Nano Lett., 2014, 14, 7201-7206.
52 S. Viarbitskaya, A. Teulle, R. Marty, J. Sharma, C. Girard, A. Arbouet and E. Dujardin, Nat. Mater., 2013, 12, 426432.

53 J. E. Millstone, G. S. Metraux and C. A. Mirkin, Adv. Funct. Mater., 2006, 16, 1209-1214.

54 S. Brown, M. Sarikaya and E. Johnson, J. Mol. Biol., 2000, 299, 725-735.

55 S. Bolisetty, J. J. Vallooran, J. Adamcik, S. Handschin, F. Gramm and R. Mezzenga, J. Colloid Interface Sci., 2011, 361, 90-96.

56 J. X. Gong, R. S. Newman, M. Engel, M. Zhao, F. G. Bian, S. C. Glotzer and Z. Y. Tang, Nat. Commun., 2017, 8, 14038.

57 G. Haberfehlner, F. P. Schmidt, G. Schaffernak, A. Horl, A. Trugler, A. Hohenau, F. Hofer, J. R. Krenn, U. Hohenester and G. Kothleitner, Nano Lett., 2017, 17, 6773-6777.

58 Y. S. Xia, T. D. Nguyen, M. Yang, B. Lee, A. Santos, P. Podsiadlo, Z. Y. Tang, S. C. Glotzer and N. A. Kotov, Nat. Nanotechnol., 2011, 6, 580-587.

59 A. Cuche, S. Viarbitskaya, J. Sharma, A. Arbouet, C. Girard and E. Dujardin, Sci. Rep., 2015, 5, 16635.

60 S. Chen, M. Svedendahl, R. P. Van Duyne and M. Käll, Nano Lett., 2011, 11, 1826-1830.

61 M. C. Gather, K. Meerholz, N. Danz and K. Leosson, Nat. Photonics, 2010, 4, 457-461.

62 L. Rodriguez-Lorenzo, R. de la Rica, R. A. Alvarez-Puebla, L. M. Liz-Marzan and M. M. Stevens, Nat. Mater., 2012, 11, 604-607.

63 S. R. Beeram and F. P. Zamborini, J. Am. Chem. Soc., 2009, 131, 11689-11691.

64 N. Nuraje, S. Mohammed, L. Yang and H. Matsui, Angew. Chem., Int. Ed., 2009, 48, 2546-2548.

65 F. Qin, T. Zhao, R. Jiang, N. Jiang, Q. Ruan, J. Wang, L.-D. Sun, C.-H. Yan and H.-Q. Lin, Adv. Opt. Mater., 2016, 4, 76-85.

66 B. Baris, M. Alchaar, J. Prasad, S. Gauthier, E. Dujardin and D. Martrou, Appl. Phys. Lett., 2018, 112, 113101.

67 A. Cerreta, D. Vobornik and G. Dietler, Eur. Polym. J., 2013, 49, 1916-1922.

68 J. Turkevich, P. C. Stevenson and J. Hillier, J. Phys. Chem., 1953, 57, 670-673.

69 A. M. Klibanov, T.-M. Tu and K. P. Scott, Science, 1983, $221,259$. 


\section{Directed evolution of artificial repeat proteins designed as habit modifiers for the morphosynthesis of (111)-terminated gold nanocrystals}

Janak Prasad, ${ }^{\text {\# }}$ Sébastien Viollet, ${ }^{2 \#}$ Kargal L. Gurunatha, ${ }^{1}$ Agathe Urvoas, ${ }^{2}$ Agathe C. Fournier, ${ }^{1}$ Marie Valerio-Lepiniec, ${ }^{2}$ Cécile Marcelot, ${ }^{1}$ Bulent Baris, ${ }^{1}$ Philippe Minard ${ }^{2}$ and Erik Dujardin ${ }^{1}$ *

${ }^{1}$ CEMES, CNRS UPR 8011, 29 rue J. Marvig, B.P. 94347, F-31055 Toulouse, France

${ }^{2}$ I2BC, CEA, CNRS, Univ. Paris-Sud, Université Paris-Saclay, 91198, Gif-sur-Yvette cedex, France

\#: both authors contributed equally to this work

* Corresponding authors: Erik.Dujardin@cemes.fr, Philippe.Minard@i2bc.paris-saclay.fr

\section{Electronic Supplementary Information (ESI)}

\section{Table of Contents}

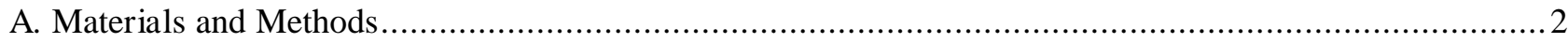

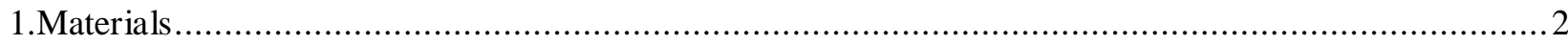

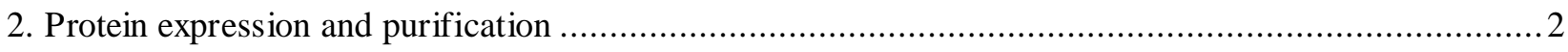

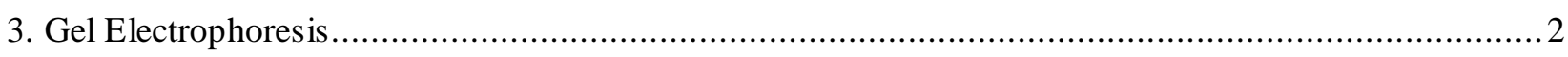

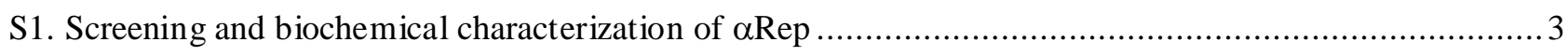

S2. Determination of Au(111)-binding affinity of selected $\alpha$ Rep by SPR............................................... 5

S3. TEM and agarose Gel Electrophoresis on $\alpha$ Rep-capped Au seeds..................................................... 10

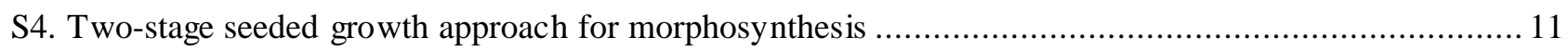

S5. SEM characterization of Au nanocrystals synthesized in the presence of Au(111)-selected $\alpha$ Rep. ........ 13

S6. Spectral characterization of Au nanocrystals synthesized in the presence of $\mathrm{Au}(111)$-selected $\alpha \mathrm{Rep} . . . .15$

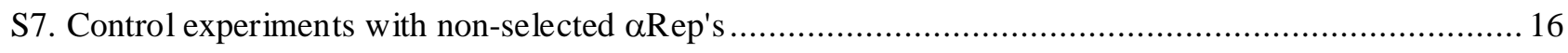

S8. Au nanocrystal size tunability during $\alpha$ Rep-controlled morphosynthesis. ....................................... 17

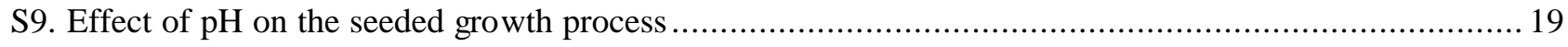

S10. Effect of reaction temperature on morphosynthesis .................................................................. 20

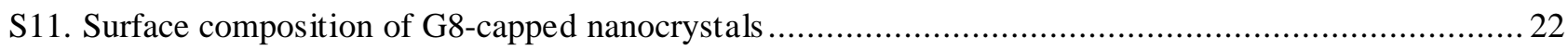

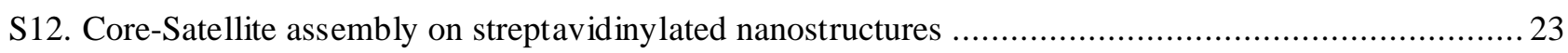

S13. On-surface DAB encapsulation on HRP-functionalized streptavidinylated nanostructures ................. 24

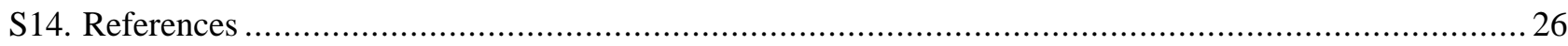




\section{A. Materials and Methods}

1.Materials. Hydrogen tetrachloroauratetrihydrate $\left(\mathrm{HAuCl}_{4}\right)$, sodium formaldehyde sulfoxylate $\left(\mathrm{CH}_{3} \mathrm{NaO}_{3} \mathrm{~S}\right)$, hydroxylamine hydrochloride $\left(\mathrm{NH}_{2} \mathrm{OH} . \mathrm{HCl}\right)$, monobasic dihydrogen phosphate $\left(\mathrm{KH}_{2} \mathrm{PO}_{4}\right)$, dibasic monohydrogen phosphate $\left(\mathrm{K}_{2} \mathrm{HPO}_{4}\right)$, calcium chloride dihydrate $\left(\mathrm{CaCl}_{2} \times 2 \mathrm{H}_{2} \mathrm{O}\right)$, phosphate buffer saline (PBS), tris buffered saline (TBS), sodium citrate, hydrochloric acid ( $\mathrm{HCl}$ ), sodium hydroxide $(\mathrm{NaOH})$, dimethylformamide $(\mathrm{DMF})$ and $30 \%(\mathrm{w} / \mathrm{w})$ hydrogen peroxide were purchased from sigma. Biotin N-hydroxysuccinimide ester (NHS-Biotin), polyethylene glycol sorbitanmonolaurate (Tween 20), Streptavidin, Horseradish Peroxidase, Trypsin (Porcine), 3,3'Diaminobenzidine (DAB) and 5-nm diameter citrate stabilized Au nanoparticles were purchased from Sigma. Protein LoBind tubes were purchased from Eppendorf. Biotin-PEG-SH (MW: 3000 $\mathrm{g} / \mathrm{mol}$ ) was purchased from Interchim. All reagents were used as received without further purification. Deionized water from a Purelab system $(>18 \mathrm{M} \Omega . \mathrm{cm})$ was used in all experiments. $\mathrm{pH}$ 7 adjusted $0.01 \%$ Tween 20 solution (solution A), PBS solution supplemented with $0.01 \%$ Tween 20 (PBST) and TBS solution supplemented with 0.01\% Tween 20 (TBST) were preparedin situ.

2. Protein expression and purification. $\alpha$ Rep proteins were cloned into the plasmid pQE-81 (Qiagen) in order to fuse a His-tag at the N-terminal and were expressed in M15 bacteria strain. Protein productions were performed into $1 \mathrm{~L}$ of $2 \mathrm{YT}$ medium supplemented with kanamycin $(50 \mu \mathrm{g} / \mathrm{mL})$ and ampicillin $(100 \mu \mathrm{g} / \mathrm{mL})$ from an inoculation of an overnight preculture and grown at $37^{\circ} \mathrm{C}$. When an OD600 of 0.6 was reached, bacteria were induced by an addition of IPTG for a final concentration of $0.5 \mathrm{mM}$ and were incubated for an additional of 16 hours at $30^{\circ} \mathrm{C}$. Cells were harvested by centrifugation, resuspended into 1X TBS supplemented by protease inhibitor (Roche) and frozen until the beginning of the purification procedure. The $\alpha$ Rep purification process was carried out by a nickel affinity chromatography (Protino NI-NTA Agarose, Macherey Nagel) followed by a size exclusion chromatography SEC (HiLoad 16/600 superdex 75 pReparation grade column, GE Healthcare) in a phosphate buffer $(50 \mathrm{mM}$ phosphate buffer $\mathrm{pH} 7.0,150 \mathrm{mM} \mathrm{NaCl})$. Fractions containing samples of interest were visualized on SDS-PAGE, concentrated and stored at $-80^{\circ} \mathrm{C}$ for further analysis.

A TEV cleavage site was inserted by site directed mutagenesis between the His-tag and the Nterminal extremity of the protein. Purification procedure of modified proteins was performed as previously described and followed by an additional step consisting in the TEV protease cleavage after the SEC: the SEC fractions were collected, mixed with TEV protease (with an OD ratio of 1 TEV protein for 50 proteins of interest) and incubated for 16 hours at $4{ }^{\circ} \mathrm{C}$ in $50 \mathrm{mM}$ phosphate buffer $\mathrm{pH} 7.0,150 \mathrm{mM} \mathrm{NaCl}, 1 \mathrm{mM}$ DTT and $0.5 \mathrm{mM}$ EDTA. A counter purification was made with a nickel affinity chromatography to remove TEV protease from cleaved proteins. Cleavage digestion was checked by SDS-PAGE and fractions containing the $\alpha$ Rep were desalted in a phosphate buffer, concentrated and stored.

3. Gel Electrophoresis. To conduct electrophoretic mobility of $\alpha$ Rep capped Au seeds, Enduro Gel XL with standard casting set, gel tank with safety lid and power supply, 120 V (E0160) w/FREE UPS was purchased from Labnet International, Inc. A 0.3\% agarose gel was prepared by dissolving $300 \mathrm{mg}$ of agarose in $100 \mathrm{~mL}$ of $0.5 \mathrm{X}$ Tris borate EDTA (TBE) buffer at $90{ }^{\circ} \mathrm{C}$ under vigorous stirring. $10 \mu \mathrm{L}$ of Au seeds were premixed with $2.5 \mu \mathrm{L}$ of $30 \%$ sucrose solution and loaded into sample wells. Electrophoresis was performed at $150 \mathrm{~V}$ in $0.5 \mathrm{X}$ TBE buffer for $30 \mathrm{~min}$. 


\section{S1. Screening and biochemical characterization of $\alpha \operatorname{Rep}$}

The details of $\alpha$ Rep phage display libraries construction and screening has been described in reference ${ }^{1}$. Here, we provided a brief overview of the diversity and screening completeness of this method. Each $\alpha$ Rep contains 6 hypervariable positions which implies about $10^{5}$ different repeat units and so $10^{5 n}$ different proteins with $n$ repeat. With an average 3 repeats per protein in our library, this corresponds to a potential of ca. $10^{14}$ different proteins whereas the library comprises ca. $10^{9}$ clones. A similar ratio is true for the peptides and antibody libraries, which are used in therapeutics.

In practice, in spite of severely limited $\left(10^{-5}\right)$ exploration of the entire parameter space, the $\alpha$ Rep library, as well as other recent protein libraries such as Darpins, ${ }^{2,3}$ have successfully identified binders among the $10^{9}$ clones when selected against numerous biological targets. This implies that there is much more than one effective binder solution for a given interaction scheme. The optimal selection performed in phage display is not the exhaustive exploration of a given parameter space but rather the identification of best suited (within our library) yet probably sub-optimal binders to a given target.

The diversity of our library is indeed practically sufficient to identify a reasonable number of binders for a chosen biomolecular targetand has so far let to the identification of more than 30 biomolecular $\alpha$ Rep binders.

Here, we test for the first time the $\alpha$ Rep library against an atomically smooth metallic surface. After three runs of phage display selection, about 100 clones where checked for gold affinity by ELISA screening (Fig. S1a). Nine different $\mathrm{Au}(111)$ binders are identified, sequenced and characterized (Figs. S1b, c) and their performances as morphosynthetic agents demonstrated in the main text.

The library is thus sufficiently diverse to provide multiple proteins with specific and strong affinity for inorganic surfaces.

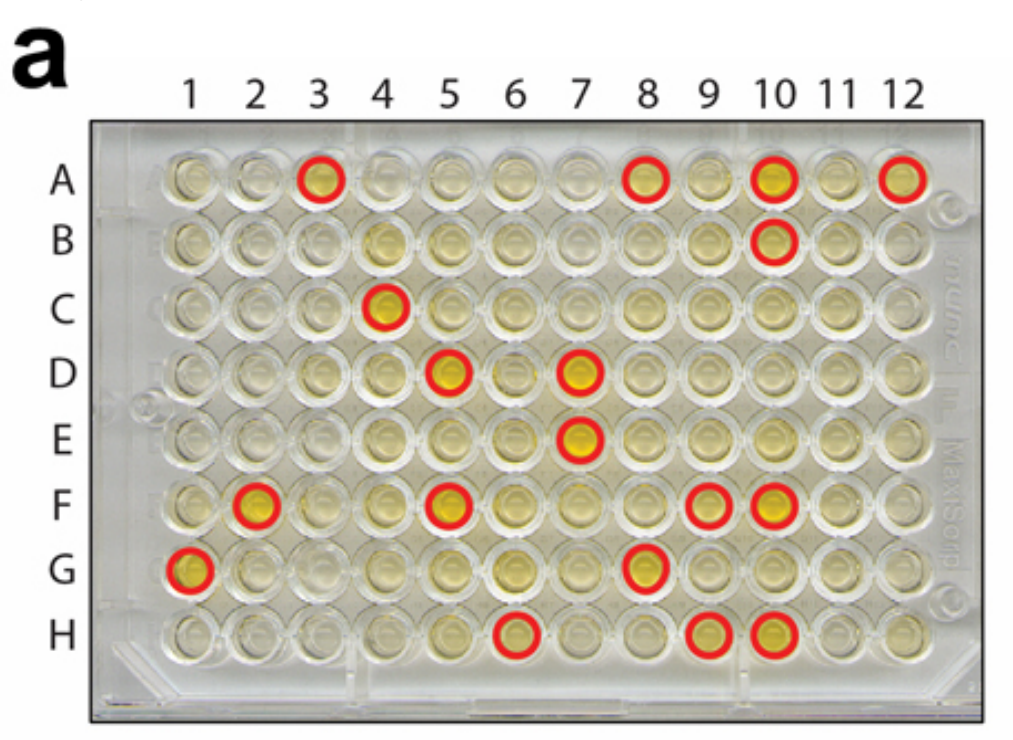

\begin{tabular}{|c|c|c|}
\hline$\alpha-\operatorname{Rep}$ & $\mathbf{N}$ & pl \\
\hline F2 & 1 & 9.00 \\
\hline F5 & 1 & 9.05 \\
\hline F10 & 1 & 6.05 \\
\hline D7 & 2 & 8.89 \\
\hline A12 & 3 & 7.97 \\
\hline $\mathrm{C} 4$ & 3 & 5.67 \\
\hline D5 & 6 & 5.42 \\
\hline bGFPa* & 6 & 5.52 \\
\hline F9 & 7 & 5.30 \\
\hline G8 & 10 & 5.19 \\
\hline$N 10^{*}$ & 10 & 5.11 \\
\hline
\end{tabular}

Figure S1. (a) ELISA screening for high affinity Au(111) binding $\alpha$ Rep's. Each well corresponds to one isolated clone obtained after 3 rounds of phage display panning. Bacterial soluble fractions are incubated on the Au(111) film and positive clones (red circles) are revealed using an anti-flagTag HRP antibody (b) Biochemical characterization of $\mathrm{Au}(111)$-selected $\alpha$ Rep indicating the number of internal repeats (n) and the estimated isoelectric point (pI).

(*) Proteins marked by an asterisk are used as controls and were not selected against Au(111) but obtained from the consensus sequence (N10) or selected against a Green Fluorescent Protein (bGFPa). ${ }^{1}$ 


\begin{tabular}{|c|c|c|}
\hline aRep & Repeats & Sequence \\
\hline $\mathrm{A} 12$ & $\begin{array}{c}\text { N-Cap } \\
1 \\
2 \\
3\end{array}$ & $\begin{array}{l}\text { TDPEKVEMYIKNL_QDDSQRVRNSAANALGGKT } \\
\text { GDERAVEPLIKALKRDEDQVRYSAADALGKI } \\
\text { RDERAVEPLIKALKDEDPWVRQSAARALGKT } \\
\text { GDERAVEPLIKALKDEDARVRQAAAYALGKSETNVRLNR }\end{array}$ \\
\hline C4 & $\begin{array}{l}\text { N-Cap } \\
1 \\
2 \\
3 \\
\text { C-cap }\end{array}$ & $\begin{array}{l}\text { TDPEKVEMYTKNLQDDSTDVRVSAAFALGKI } \\
\text { GDERAVEPLIKALKDEDGYVRI.EAALALGKI } \\
\text { GDERAVEPLTKALKDEDDEVRFSAAKALGQI } \\
\text { GDERAVEPLIKALKKDEDPFVRTEAARALGQI } \\
\text { GGERVRAAMEKLAETGTGFARKVAVNYLETH }\end{array}$ \\
\hline D5 & $\begin{array}{l}\text { N-Cap } \\
1 \\
2 \\
3 \\
4 \\
5 \\
6 \\
\text { C-Cap }\end{array}$ & $\begin{array}{l}\text { TDPEKVEMYIKNLQDDSRNVRNNAANALGKI } \\
\text { GDERAVEPLIKALKDEDEAVRLISAASALGQI } \\
\text { GDERAVEPLIKALKDEDAYVRLSAAWALGKI } \\
\text { RDERAVEPLIKALKDEDERVRLSAASALGQI } \\
\text { GDERAVEPLIKALKDEDTDVRVAAAEALGEI } \\
\text { GDERAVEPLIKALKDEDGYVRYAAALALGKI } \\
\text { GDERAVEPLIKALKDEDYSVRWAAAAALGQI } \\
\text { GGERVRAAMEKLAETGTGEARKVAVNYLETH }\end{array}$ \\
\hline D7 & $\begin{array}{l}\text { N-Cap } \\
1 \\
2 \\
\text { C-Cap }\end{array}$ & $\begin{array}{l}\text { TDPEKVEMYIKNLODDSLAVRTFAAIALGKI } \\
\text { GDERAVEPLIKALKDEDKNVRLTAARALGEI } \\
\text { GDERAVEPLIKALKDEDAAVRRTAARALGKI } \\
\text { GGERVRAAMEKLAETGTGEARKVAVNYLETH }\end{array}$ \\
\hline $\mathrm{F} 2$ & $\begin{array}{l}\text { N-Cap } \\
\stackrel{1}{\text { C-Cap }}\end{array}$ & $\begin{array}{l}\text { TDPEKVEMYTKNL,QDDSTTVRSNAANALGGKT } \\
\text { GDERAVEPLIKAIIKDEDSAVRQSAARALGKT } \\
\text { GGERVRAAMEKLAETGTGFARKVAVNYLETH }\end{array}$ \\
\hline F5 & $\begin{array}{l}\text { N-Cap } \\
\stackrel{1}{\text { C-Cap }}\end{array}$ & $\begin{array}{l}\text { TDPEKVEMYIKNLQDDSNRVRVDAASALGKI } \\
\text { GDERAVEPLIKALKDEDREVRARAATALGQI } \\
\text { GGERVRAAMEKLAETGTGFARKVAVNYLETH }\end{array}$ \\
\hline F9 & $\begin{array}{l}\text { N-Cap } \\
1 \\
2 \\
3 \\
4 \\
5 \\
6 \\
7 \\
\text { C-Cap }\end{array}$ & $\begin{array}{l}\text { TDPEKVEMYIKNLQDDSGEVRVDAASALGKI } \\
\text { GDERAVEPLIKALKDEDAIVRQTAASALGKI } \\
\text { GDERAVEPLIKALKDEDSDVRRAAAQALGQI } \\
\text { GDERAVEPLIKALKDEDPTVRLSAARALGOI } \\
\text { GDERAVEPLIKALKDEDSNVRRGAARALGQI } \\
\text { GDERAVEPLIKALKDEDSDVRKTAAOALGEI } \\
\text { GDERAVEPLIKALKDEDGYVRSFAAGALGEI } \\
\text { GDERAVEPLIKALKDEDALVRWAAAEALGKI } \\
\text { GGERVRAAMEKLAETGTGFARKVAVNYLETH }\end{array}$ \\
\hline $\mathrm{F} 10$ & $\begin{array}{l}\text { N-Cap } \\
1 \\
\text { C-Cap }\end{array}$ & $\begin{array}{l}\text { TDPEKVEMYIKNLQDDSGAVRISAADALGKI } \\
\text { GDERAVEPLIKALKDEDPEVROAAARALGQI } \\
\text { GGERVRAAMEKLAETGTGFARKVAVNYLETH }\end{array}$ \\
\hline G8 & $\begin{array}{c}\text { N-Cap } \\
1 \\
2 \\
3 \\
4 \\
5 \\
6 \\
7 \\
8 \\
9 \\
10 \\
\text { C-Cap }\end{array}$ & $\begin{array}{l}\text { TDPEKVEMYIKNLODDSGEVRDIAATALGKI } \\
\text { GDERAVEPLIKALKDEDROVRLAAARALGQI } \\
\text { GDERAVEPLIKALKDEDATVRIAAAKALGEI } \\
\text { GDERAVEPLIKALKDEDRYVRISAALALGKI } \\
\text { GDERAVEPLIKALKDEDVNVRSOAAIALGGI } \\
\text { GDERAVEPLIKALKDEDAYVRKEAARALGOI } \\
\text { GDERAVEPLIKAL.KDEDARVRQSAARALGQI } \\
\text { GDERAVEPLIKALKDEDPDVRIEAADALGEI } \\
\text { GDERAVEPLIKALKDEDTOVRISAAIALGOI } \\
\text { GNERA KALKDEDWQVRKEAARALGQI } \\
\text { GDERAVEPLIKALKDEDGYVRIRAANALGKI } \\
\text { GGERVRAAMEKLAETGTGFARKVAVNYLETH }\end{array}$ \\
\hline bGFPa & $\begin{array}{c}\text { N-Cap } \\
1 \\
2 \\
3 \\
4 \\
5 \\
6 \\
\text { C-Cap }\end{array}$ & $\begin{array}{l}\text { TDPEKVEMYIKNLQDDSPPVRVYAAFALGKI } \\
\text { GDERAVEPLIKALKDEDASVRYAAATALGQI } \\
\text { GDERAVEPLIKALKDEDGYVRTAAAEALGQI } \\
\text { GDERAVEPLIKALKDEDPWVRLTAARALGEI } \\
\text { GDERAVEPLIKALKDEDPWVRLTAARALGQI } \\
\text { GDERAVEPLIKALKDEDASVRKAAAVALGQI } \\
\text { GDERAVEPLIKALKDEDEYVRQRAASALGKI } \\
\text { GGERVRAAMEKLAEPAPGFARKVAVNYLETH }\end{array}$ \\
\hline N10 & $\begin{array}{c}\text { N-Cap } \\
1 \\
2 \\
3 \\
4 \\
5 \\
6 \\
7 \\
8 \\
9 \\
10 \\
\text { C-Cap }\end{array}$ & 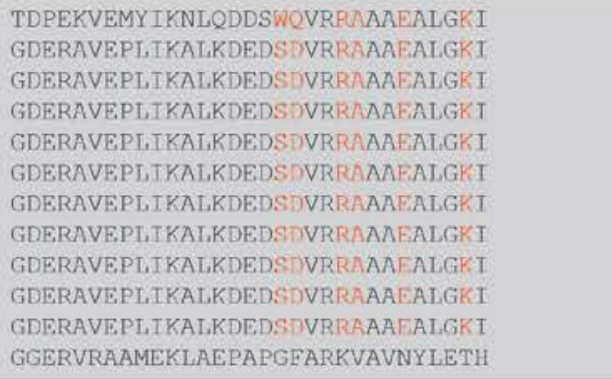 \\
\hline
\end{tabular}

Figure S1c. Sequences of the selected and nonselected $\alpha$ Reps. For each protein, each line represent one repeated motif, the first line is the nCap, the last line is the C-cap. Variable residues are highlighted in red. 


\section{S2. Determination of Au(111)-binding affinity of selected $\alpha$ Rep by SPR}
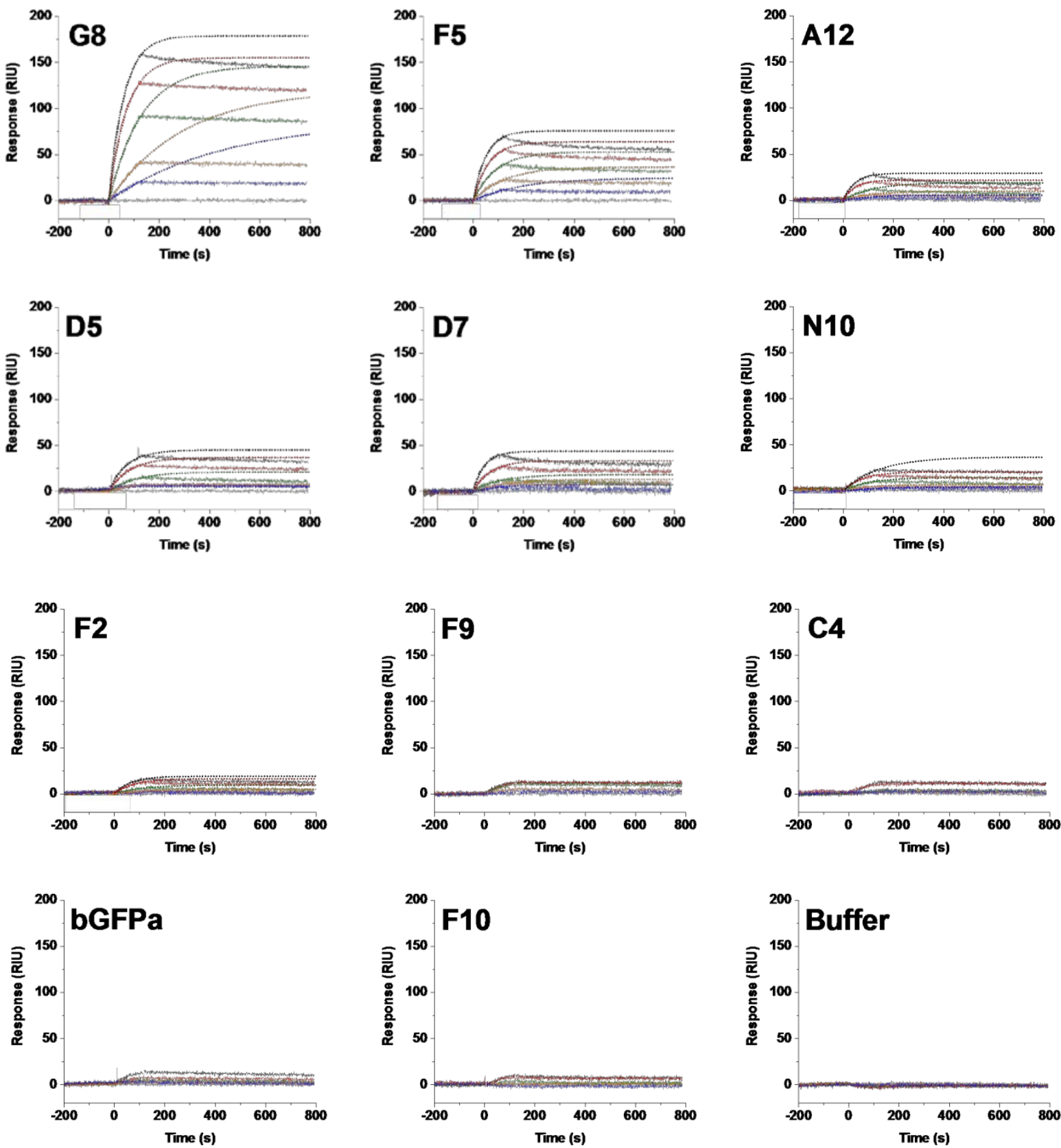

Figure S2a. SPR sensogram overlays showing interaction of immobilised $\alpha$ Rep proteins with citrate-stabilised 5-nm $\mathrm{Au}$ nanospheres at concentrations of $10 \mathrm{nM}$ (black), $5 \mathrm{nM}$ (red), $2.5 \mathrm{nM}$ (green), $1.25 \mathrm{nM}$ (orange), $0.625 \mathrm{nM}$ (navy blue) and $0 \mathrm{nM}$ (grey). The dotted line shows the fit of the data to a 1:1 Langmuir binding model (for the association phase only). A flow rate of $100 \mu \mathrm{l} / \mathrm{min}$ was used.

The SPR based optical biosensor, ProteOn XPR36 (Bio-rad), was used to determine the affinity and binding kinetics of $\alpha$ Rep's interaction to gold nanoparticle surface. In a typical experiment, $200 \mathrm{RU}$ of histidine-tagged $\alpha$ Rep protein are immobilized onto tris-NTA sensor chip in $10 \mathrm{mM}$ phosphate buffer to obtain a homogeneous ligand surface. Nonspecific adsorption during immobilization process is blocked by adding $0.005 \%$ Tween 20 to the phosphate buffer. Next, interaction with gold nanoparticles $\left(\mathrm{Au}_{\mathrm{cit}}\right)$ is measured at $100 \mu \mathrm{l} / \mathrm{min}$ to avoid mass transport effects. At this flow, the initial on-rate is maximum. Flow is allowed to occur for several seconds to establish a baseline, and 
then various concentrations of gold nanospheres (10, 5, 2.5, 1.25 and $0.625 \mathrm{nM})$ are injected. The association is followed for 120 seconds, after which the gold nanoparticle sample is replaced with $10 \mathrm{mM}$ phosphate buffer, and the dissociation of the $\alpha \mathrm{Rep} / \mathrm{Au}_{\mathrm{cit}}$ complex is monitored for 600 seconds.

\section{Detailed SPR data analysis}

Figure S2a demonstrates the steady-state response at different concentrations of injected gold nanoparticles $\left(\mathrm{Au}_{\mathrm{cit}}\right)$ over the surface-immobilized $\alpha$ Rep. The association (resp. dissociation) phases are clearly visible on all the sensograms, $\mathrm{R}(\mathrm{t})$, and more quantitative insight can be gained by analysing them with the model described by Equation (1) (resp. Equation (2)):

$$
\begin{gathered}
R(t)=R_{e q}\left(1-e^{-\left(k_{o n}\left[A u_{c i t}\right]+k_{o f f}\right) \cdot t}\right), \text { for } 0 \leq \mathrm{t} \leq \mathrm{t} 1 \\
R(t)=R_{\infty}+\left(R_{1}-R_{\infty}\right) e^{-k_{o f f} \cdot\left(t-t_{1}\right)}, \text { for } \mathrm{t} \geq \mathrm{t} 1 \\
K_{D}=\frac{k_{o f f}}{k_{o n}}
\end{gathered}
$$

where $R_{e q}$ and $R_{\infty}$ are the asymptotic equilibrium values of the association and dissociation phases respectively. $t_{1}$ and $R_{1}$ are the time and SPR signal at the onset of the dissociation phase. $k_{\text {on }}$ and $k_{\text {off }}$ are the kinetic constants associated with the nanoparticle-protein binding equilibrium.

The fits to the association phase of the experimental data using equation (1) are displayed as continuous black lines in Figure 2a and were repeated for concentrations of gold nanoparticles, [ $\mathrm{Au}_{\mathrm{cit}}$ ], ranging from 1 to $10 \mathrm{nM}$ (Fig. S2a). This kinetic analysis of the association phase shows the linear variation of the exponential factor with $\left[\mathrm{Au}_{\mathrm{cit}}\right], \mathrm{k}=\mathrm{k}_{\mathrm{on}}$. $\left[\mathrm{Au}_{\mathrm{cit}}\right]+\mathrm{k}_{\text {off, }}$, from which $\mathrm{k}_{\text {on }}$ and $\mathrm{k}_{\text {off }}$ are extracted (Fig. S2b). These kinetic constants are given in Figure 2d along with a first estimate of the affinity constants $\mathrm{K}_{\mathrm{D}} \# 1$ calculated from equation (3).
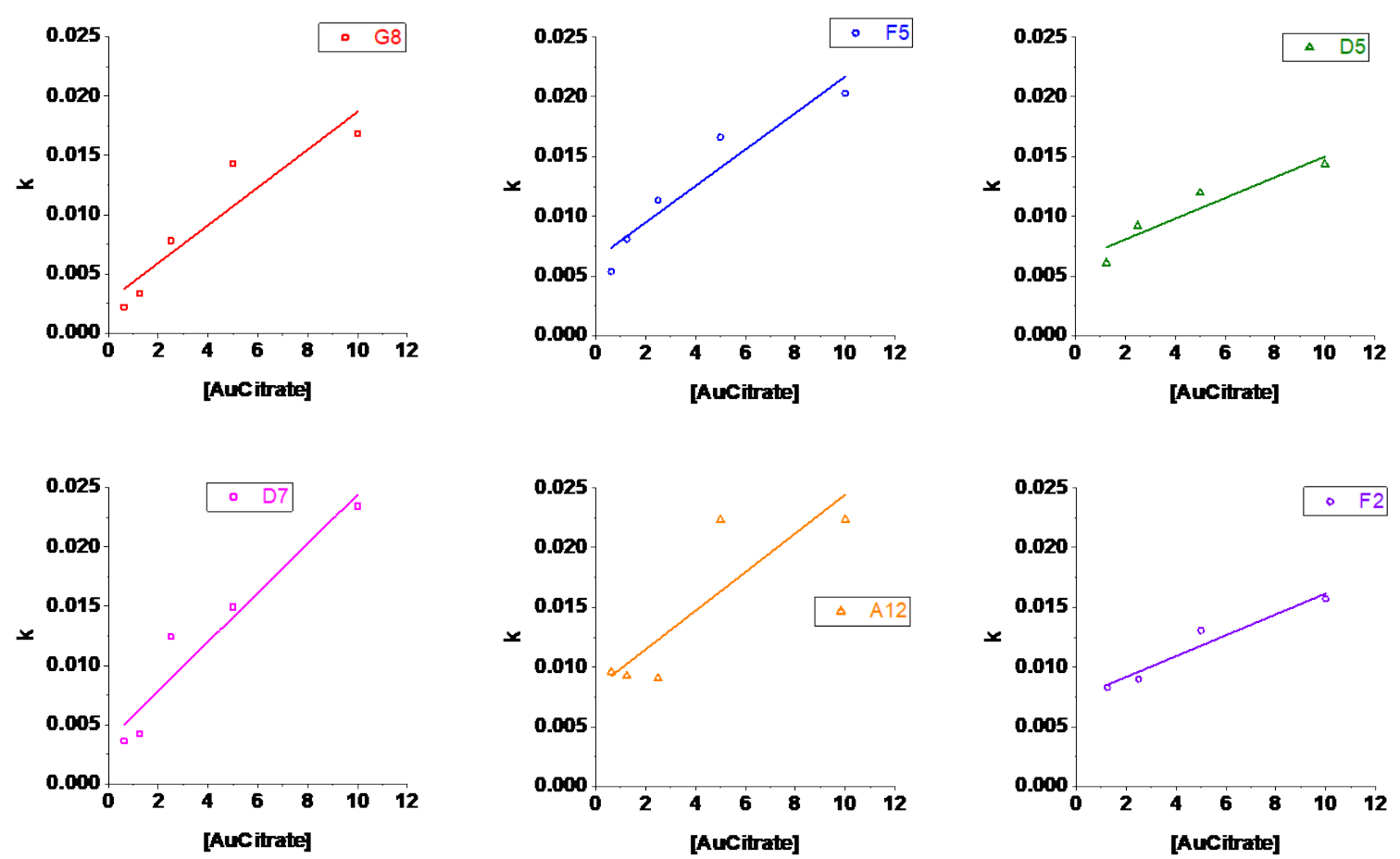

Figure S2b. Linear analysis of k Vs [Au cit $\left._{1}\right]$ plots obtained for 6 different $\alpha$ Rep’s. 
However, several reasons such as mass transport limitation, steric hindrance or negative cooperativity between binding sites or analyte multivalence have been invoked for the plateauing, in the $\mathrm{k}$ vs [ $\left.\mathrm{Au}_{\mathrm{cit}}\right]$, which underestimates $\mathrm{k}_{\mathrm{on}}$ and may overestimate $\mathrm{k}_{\mathrm{off} .}{ }^{4-7}$ Both deviations result in a net overestimate of the equilibrium constant. All contribute to an over-estimate of $\mathrm{K}_{\mathrm{D}} \# 1$.

Alternatively, by assuming that the dissociation phase relates to the same equilibrium between the bound proteins and the dispersed nanoparticles as the association phase, a second and more accurate estimate of the dissociation kinetic constant, $\mathrm{k}_{\text {off }} \# 2$, can be obtained by fitting the decrease of SPR signal after $t_{1}$ with equation (2), as shown in Fig. S2c and also overlaid in black lines in Fig. 2a for $\mathrm{t} \geq 120 \mathrm{~s}$.
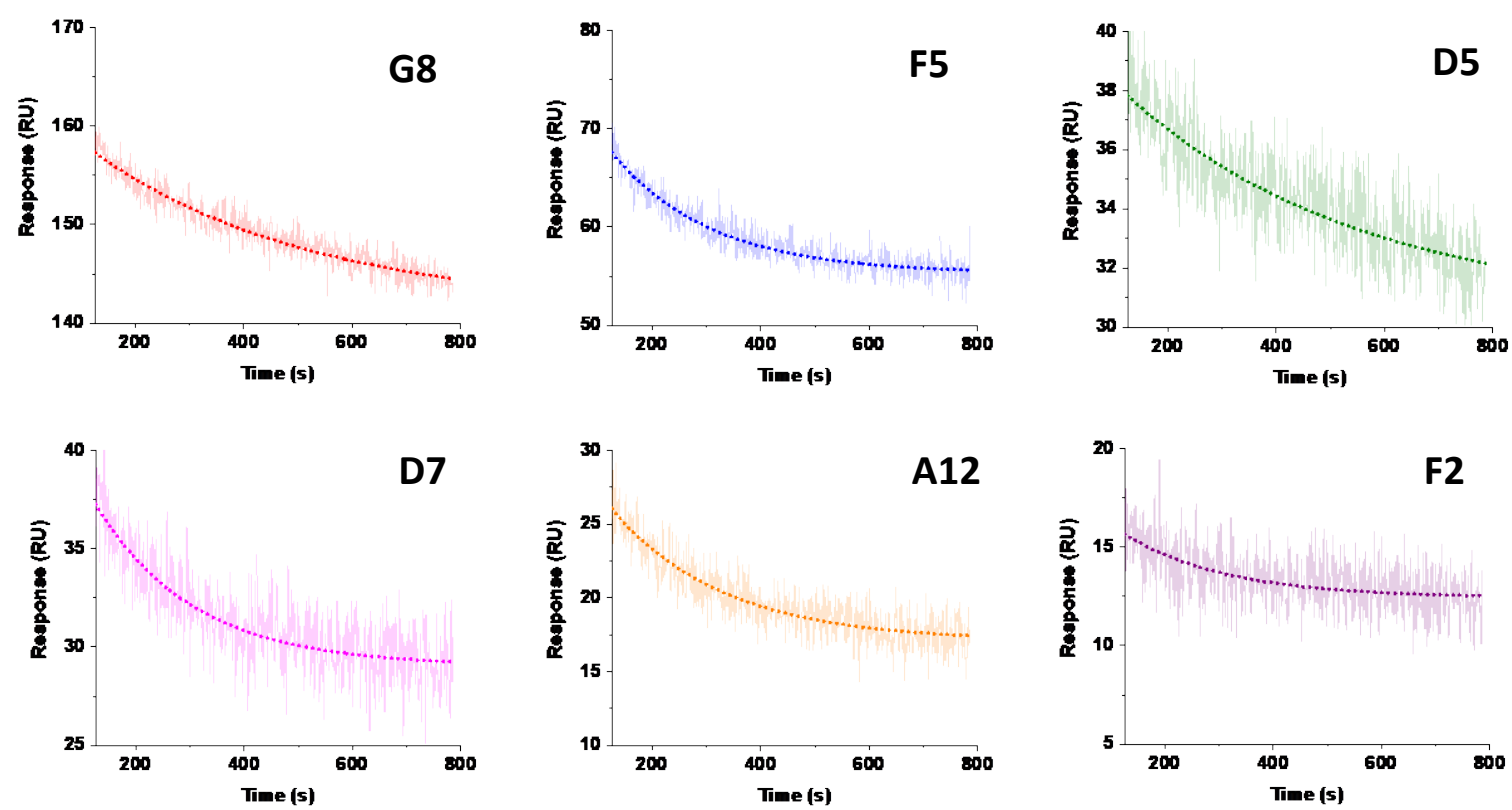

Figure S2c. Exponential decay fits on sensograms obtained upon buffer induced dissociation of loosely bound $\alpha$ Rep gold nanoparticle complex pairs at $10 \mathrm{nM}$ [Aucit] using the fully explicit Eq. (2). $\mathrm{R}_{1}$ is known experimentally, only 2 fitting parameters are used: $\mathrm{SPR}_{\infty}$ and $\mathrm{k}_{\mathrm{off}} \# 2$.

Figure S2c illustrates exponential decay fits for desorption phase of gold nanoparticles from the homogeneous ligand surface composed of any of the 5 selected $\alpha$ Rep: G8, F5, D5, D7 and A12. Note that, within the time frame of the experiments, we observe that the dissociation phase tends towards an asymptotic constant value which indicates that the rinsing step leaves a finite amount of bound proteins. This observation is accounted for by the constant term $\mathrm{R}_{\infty}$ in equation (2). Values of $\mathrm{k}_{\text {off } \# 2}$ and $\mathrm{R}_{\infty}$ (asymptotic value at infinite time) are obtained from the fits using equation (2) whereas $\mathrm{R}_{1}$ is determined directly from raw data.

To further validate the reliability of $\mathrm{k}_{\text {off }} \# 2$ values obtained through exponential decay fits, a new equation (5) was derived as follows:

Equation (2) can be re-written as:

$\frac{R_{t}-R_{\infty}}{R_{1}-R_{\infty}}=e^{-k_{o f f} *\left(t-t_{1}\right)}$

Taking logarithm on both sides, and writing $\mathrm{x}=\left(\mathrm{t}-\mathrm{t}_{1}\right) \mathrm{t}$

$\ln \left[\frac{R_{t}-R_{\infty}}{R_{1}-R_{\infty}}\right]=-k_{o f f} * x$ 
Figure S2d replots the same data and fits as Fig. S2c but in the new coordinate system. The experimental plots in Fig. S2d are indeed linear which confirms the single exponential decay with a constant $k_{\text {off }} \# 2$ that can be computed from the slope of the linear fits and are tabulated in Table1 along with empirically derived $R_{\infty}$ and pre-determined $R_{1}$ values. Of course such plots are much more sensitive as it amplifies the noise but also provides a more reliable uncertainty values.

The non-zero value of $\mathrm{R}_{\infty}$ suggests that not all $\alpha$ Rep complexed gold nanoparticles leave the surface at infinite time. A similar trend has been reported in studies conducted on several related interacting systems. $^{6,8}$

We note that we cannot fully exclude that this dissociation equilibrium might be related to a different set of species than the association phase, including modified proteins that may undergo an irreversible binding mechanism. Yet, in the absence of experimental evidence of such a case, we hypothesized that both phases were related to the same equilibrium.
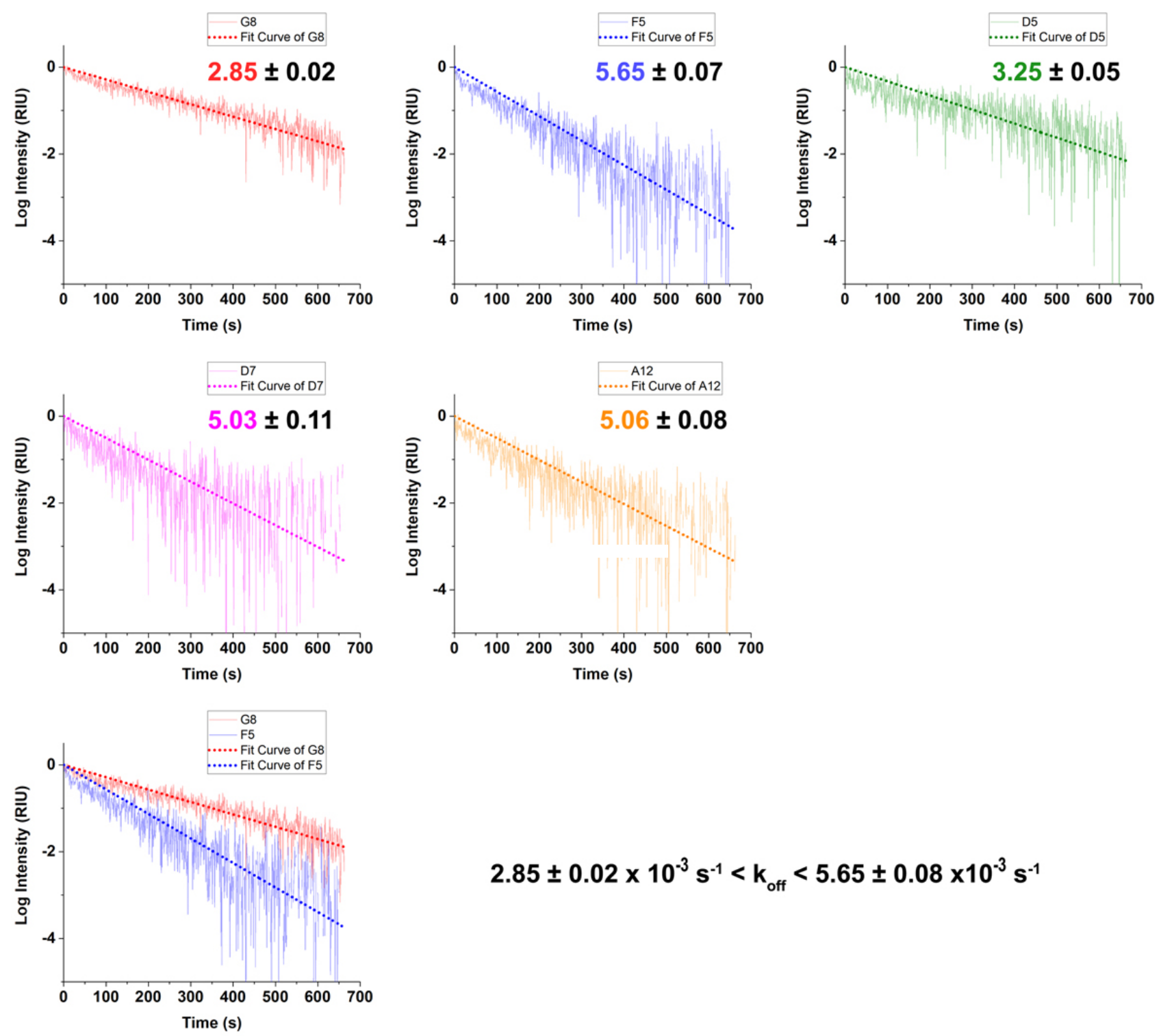

Figure S2d. Replots of dissociation phase. Linear fits to the logarithm of the normalized 10nM SPR data vs time as described by equations (4) and (5). The intercept is 0 and the slope gives the $\mathrm{k}_{\mathrm{off}}$ \#2values. The two extreme cases, G8 and F5, are replotted together in the last panel; all other data fall in between. 
The $\mathrm{k}_{\text {off }} \# 2$ are comprised between $2.85 \pm 0.02 \times 10^{-3} \mathrm{~s}^{-1}$ (G8) and $5.65 \pm 0.08 \times 10^{-3} \mathrm{~s}^{-1}$ (F5), i.e. almost systematically lower than $\mathrm{k}_{\text {off }} \# 1$ as expected due to the plateauing in $\mathrm{k}$ vs [Au $\mathrm{Au}_{\mathrm{Cit}}$ ] plots (Fig. S2b). This corrected set of equilibrium dissociation constants, $K_{D} \# 2=\left(k_{\text {off }} \# 2\right) / k_{\text {on }}$, ranges from ca. 2 to $6 \mathrm{nM}$ and essentially preserves the affinity ranking with G8 the strongest and D5 the weakest binders.

\begin{tabular}{c|c|c|c}
\hline Immobilised protein & $\mathbf{R}_{\mathbf{1}}$ & $\mathbf{R}_{\infty}$ & $\mathbf{k}_{\mathbf{o f f}} \# \mathbf{2} \mathbf{( 1 0}^{-\mathbf{3}} \mathbf{s}^{\mathbf{- 1}} \mathbf{~}$ \\
\hline G8 & 159.3 & 141.4 & $2.85 \pm 0.02$ \\
\hline F5 & 70.6 & 55.3 & $5.65 \pm 0.07$ \\
\hline D5 & 40.5 & 30.6 & $3.25 \pm 0.05$ \\
\hline D7 & 39.2 & 29.0 & $5.03 \pm 0.11$ \\
\hline A12 & 28.7 & 17.1 & $5.06 \pm 0.08$ \\
\hline
\end{tabular}

Table 2: Empirical values for $\mathrm{R}_{1}$ and fitting parameters $\mathrm{SPR}_{\infty}$ and $\mathrm{k}_{\text {off }} \# 2$ of the dissociation phase of $\alpha$ Rep gold nanoparticle complex for 6 selected $\alpha$ Rep’s (obtained using Eq 4).

Finally, the quality and sensitivity of the fits on the association phase provides reliable asymptotic equilibrium SPR values, $\mathrm{R}_{\mathrm{eq}}$, which are fitted by the Langmuir isotherm model in Figure $2 \mathrm{~b}$ and processed using the Scatchard method in Figure 2c. The linearity of the Scatchard plots validates this approach and a third dataset in Table $2 \mathrm{~d}, \mathrm{~K}_{\mathrm{D}} \# 3$, is obtained from the slopes of the linear fits and ranges from $0.71 \pm 0.06$, for $\mathrm{G} 8$, to $5.10 \pm 0.80$, for D5.

The third approach determines the equilibrium dissociation constant directly from Scatchard plot $^{9}$ using equation (6) without measuring the kinetic constants ( $\mathrm{k}_{\mathrm{on}}$ and $\mathrm{k}_{\mathrm{off}}$ ).

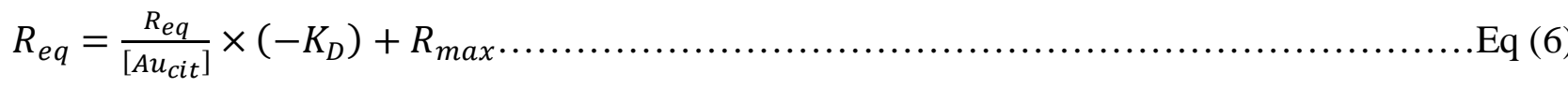

With this plot, $K_{D}$ values can be obtained from the slope of the linear fits in the $R_{\text {eq }} V_{s} R_{e q} /\left[\mathrm{Au}_{\text {cit }}\right]$ graph. The $\mathrm{K}_{\mathrm{D}} \# 3$ values obtained from Scatchard plot are summarized in the table of Fig. $2 \mathrm{~d}$ in the main text and agrees well with the $\mathrm{K}_{\mathrm{D}} \# 1$ and $\mathrm{K}_{\mathrm{D}} \# 2$ affinity values considering the limitations of each approach. 


\section{S3. TEM and agarose Gel Electrophoresis on $\alpha$ Rep-capped Au seeds}
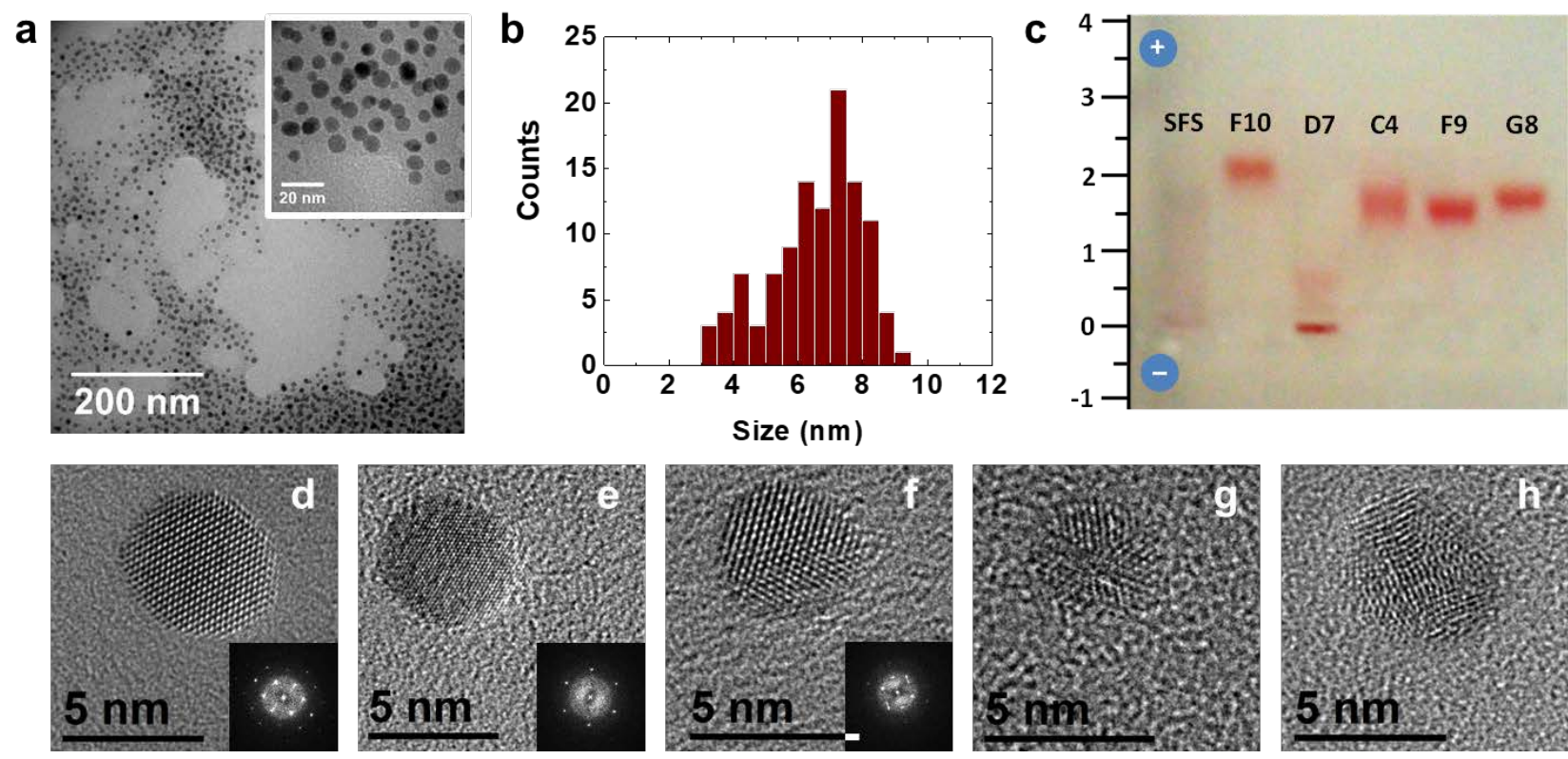

Figure S3. Structural characterisation of $\alpha$ Rep capped Au seeds. (a-b) A typical TEM micrograph of G8 capped seeds demonstrating the presence of small nanoparticles with an average size distribution of $6 \pm 2 \mathrm{~nm}$. (c) Agarose gel electrophoresis showing mobility of Au seeds produced in the absence (leftmost lane labelled "SFS") and presence of 5 different $\mathrm{Au}(111)$ selected $\alpha$ Rep proteins: F10, D7,C4,F9 and G8 (from left to right). Seeds with F10, C4, F9 and G8 are negatively charged, D7 is neutral whereas SFS (uncapped) exhibit negative surface charge but smear out in electrophoresis buffer (0.5X Tris-Borate-EDTA, $\mathrm{pH} \mathrm{8.5).} \mathrm{(d-h)} \mathrm{High} \mathrm{resolution} \mathrm{TEM} \mathrm{of} \mathrm{(d,} \mathrm{e)} \mathrm{monocrystalline} \mathrm{along}$ the [011] and [111] zone axis respectively, (c) single twinned, (d) pentatwinned and (e) polycrystalline seeds. The insets in (d), (e), (f) are electron diffraction patterns of the corresponding seeds.

The $\alpha$ Rep templated Au seeds are produced by the direct reduction of $\mathrm{Au}^{3+}$ to $\mathrm{Au}^{0}$ state with sodium formaldehyde sulfoxylate (SFS, as described in Methods Section A). Figure S3 shows the characterisation of these seeds by conventional and high resolution transmission electron microscopy (TEM) and agarose gel electrophoresis. The $\alpha$ Rep capped seeds show a wide size distribution with an average of $6 \pm 2 \mathrm{~nm}$ (Figure S3b).

To determine the stability and electrophoretic mobility of $\alpha$ Rep templated Au seeds, gel electrophoresis is performed in $0.3 \mathrm{w} / \mathrm{v} \%$ agarose gel. Seeds prepared with 5 different $\mathrm{Au}(111)$ selected $\alpha$ Rep: F10 (lane 2), D7 (lane 3), C4 (lane 4), F9 (lane 5) and G8 (lane 6) are tested against non-templated pure SFS-Au seeds (lane 1). All seeds except those prepared with D7, migrate towards the positive electrode terminal forming distinct bands. Non-templated seeds also migrated towards positive end but generated a smeared pattern instead of a clear band suggesting their lack of stability. D7 capped seeds is electrically neutral at $\mathrm{pH} 8.5(\mathrm{pI}=8.4)$ and consistently demonstrates no appreciable mobility in the gel.

The detailed crystalline structure of the seeds has been investigated by high resolution TEM. Typical representatives are shown in Figures S3(d-h). Monocrystalline, single and pentatwinned as well as polycrystalline seeds can be found without prevalence of any of these structure. It is unlikely that the final morphology and structure of the nanocrystals are determined by the seeds at this stage but rather later on as their size reaches 10-15 nm. Note that all seeds are spherical irrespective of their crystalline structure, which reinforces the simple capping role of the proteins at the seed stage rather than a facet-specific growth inhibition which is engaged at a later stage when the crystals are larger. 


\section{S4. Two-stage seededgrowth approach for morphosynthesis}

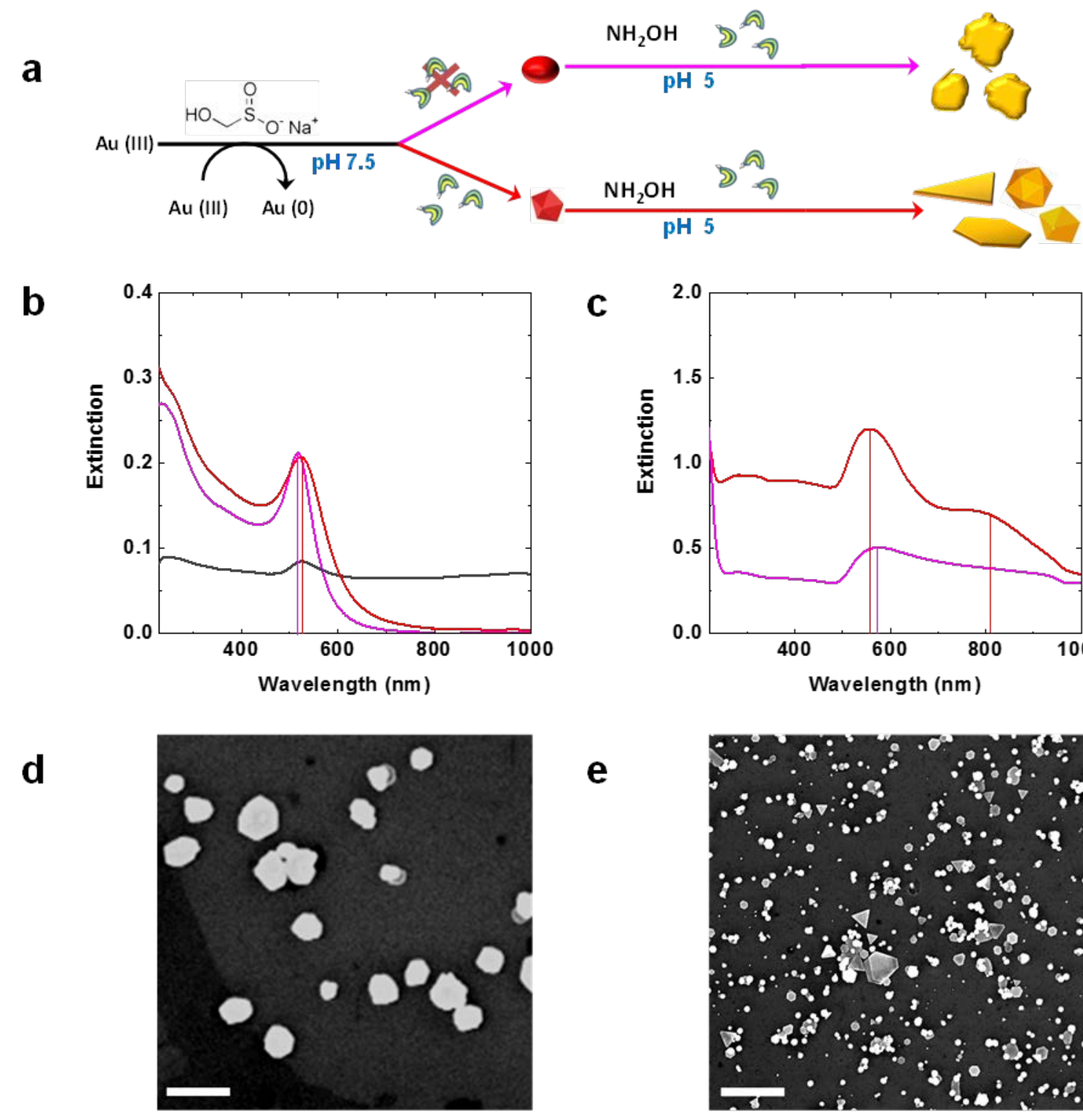

Figure S4. Comparative analysis of seeded growth method without and with $\alpha$ Rep.(a) Schematic representation of seed synthesis and growth stage of Au morphosynthesis effectuated by reducing agents SFS and Hydroxylamine respectively. UV-Vis characterisation of (b) Au seeds produced by reducing $\mathrm{Au}^{3+}$ with SFS in (i) absence of $\alpha$ Rep in pH 7.5 adjusted water (pink) and $50 \mathrm{mM}$ phosphate buffer(grey) (ii) presence of $\alpha$ Rep in $50 \mathrm{mM}$ phosphate buffer (red) (c) Au nanocrystals resulting from the hydroxylamine initiated selective reduction of $\mathrm{Au}^{3+}$ onto $\alpha$ Rep deprived seeds (pink) and $\alpha$ Rep capped seeds (red) in growth solutions supplemented with $4 \mu \mathrm{M} \alpha \mathrm{Rep}$. Morphological characterisation of Au nanocrystals obtained upon hydroxylamine mediated growth of (d) $\alpha$ Rep deprived seeds and (e) $\alpha$ Rep capped seeds. Scale bars $500 \mathrm{~nm}$.

Seeded growth approach has been widely used to synthesise monodisperse metallic nanoparticles, where a concerted action of reducing and capping agents is vital in guiding the crystal structure. ${ }^{10}$ In our approach, Au seeds are first produced by reduction of HAuCL4 with sodium formaldehyde sulfoxylate (SFS) at $\mathrm{pH}$ 7.5. The selective reduction of $\mathrm{Au}^{3+}$ on $\mathrm{Au}$ seeds is then initiated by hydroxylamine under mild acidic condition ( $\mathrm{pH}$ 5.0) to give rise to faceted nanocrystals. As schematically illustrated in Figure S4a, the exclusion of capping agent ( $\alpha$ Rep) at the seed stage can abruptly disorient the crystal growth process. For a detailed inspection, spectroscopic and structural characterisation of colloids are performed at the end of seed and growth stages. As evident in Figure 
S4b, SFS-reduced Au seeds $\left(\lambda_{\text {res }}=517 \mathrm{~nm}\right)$ maintain colloidal stability in water adjusted to $\mathrm{pH} 7.5$ but destabilise in ionic buffer (shown in grey lines). When Au binding $\alpha$ Rep proteins are added to the same reaction medium, the seeds demonstrate excellent stability $\left(\lambda_{\text {res }}=524 \mathrm{~nm}\right)$. While some spectroscopic resemblance is present at the seed stage, the spectra after hydroxylamine seeding demonstrates obvious differences, which stems from the crystallography of seeds. Nanocrystals emerging from $\alpha$ Rep capped Au seeds exhibit two distinct resonance peaks at $556 \mathrm{~nm}$ and $804 \mathrm{~nm}$ in the UV-Vis spectrum(Figure S4c), which translates into the presence of pseudo-spherical shapes (including icosahedrons and decahedrons) and platonic structures respectively (Figure S4e). Au seeds grown in the absence of added $\alpha$ Rep are devoid of these characteristics and instead show a broad peak at $576 \mathrm{~nm}$ which results from 0.2-1.0 $\mu \mathrm{m}$ irregular/pseudo-spherical nanostructures (Figure S4d) 
S5. SEM characterization of Au nanocrystals synthesized in the presence of $\mathrm{Au}(111)$-selected $\alpha$ Rep.

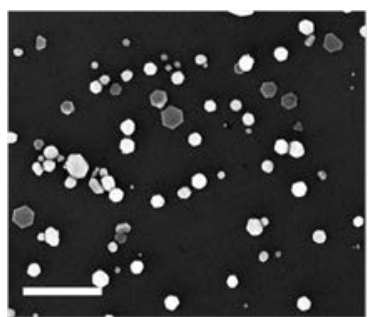

G8

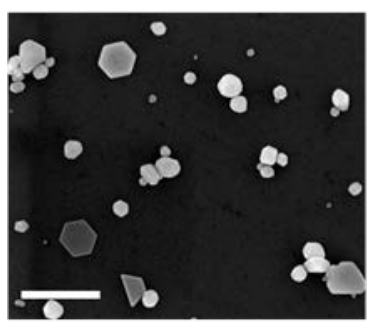

D5

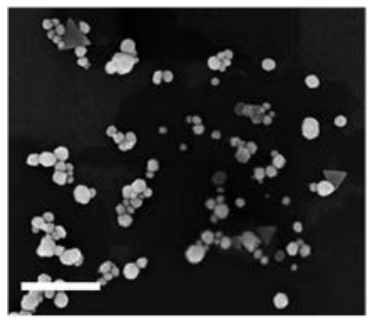

A12

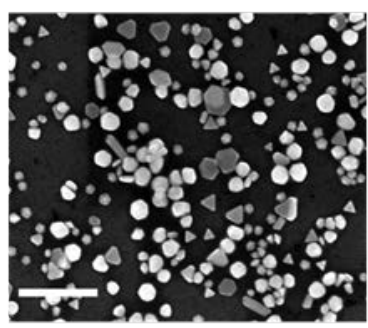

F9

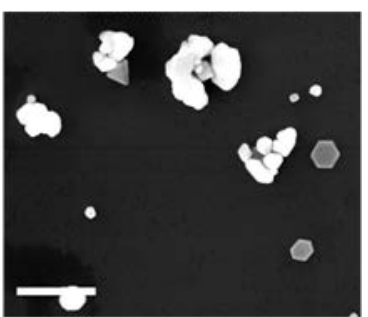

F5

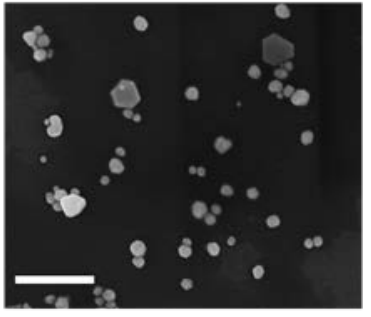

D7

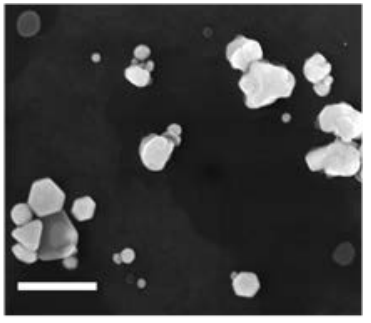

F2

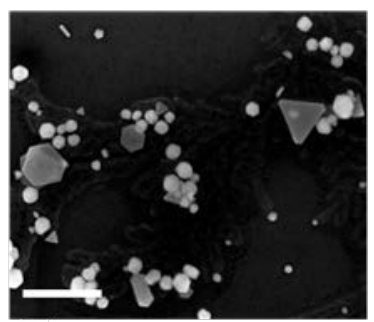

C4

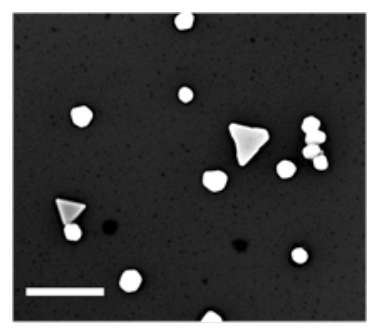

F10

Figure S5. SEM micrographs of 9 different Au nanocrystal batches synthesized in the presence of one particular $\mathrm{Au}(111)$-selected $\alpha$ Rep protein indicated by the label.(Scale bar: $500 \mathrm{~nm}$ ) 
The influential role of the $\mathrm{Au}(111)$-selected $\alpha$ Rep during the growth of the Au nanocrystals is illustrated in Figure S5. All selected proteins are able to produce platonic and pseudo-spherical nanostructures under experimental conditions. However, subtle efficiency differences in morphosynthesis can be observed and correlated to SPR affinity signals, which allows categorising these proteins into three subgroups.

\section{Group I.}

It includes G8, D5 and F9, which all have a pI lower than 7. These proteins lead to colloidally stable nanocrystals (nanoplates, icosahedra and decahedra particles) alongside a small fraction of irregular shapes. In these acidic $\alpha$ Rep proteins, no statistic enrichment of the variable position is observed, except for a slight reduction of lysine in favor of glutamic acid,. Interestingly, these proteins are the longest ones $(n=6,7,10)$ but the protein length does not account for their morphosynthetic activity as N10 (See section S7) and G8 have the same number of internal repeat without sharing the surface specificity.

\section{Group II}

Contains proteins with a few internal repeats $(n=1,2$ or 3$)$ such as $\mathbf{C 4 , ~ F 1 0 ~ a n d ~ A 1 2 , ~ D 7 . ~ T h e ~ p I ~ i s ~}$ lower than 7 for the former two and higher than 7 for the latter two. The former two give a low SPR signal while the latter two show a significant affinity for citrate-stabilized Au nanoparticles, which could be enhanced by attractive electrostatic interactions even if the specific affinity for the Au surface were moderate. This group of proteins is almost as capable as Group I in giving rise to (111)-faceted nanostructures, but the nanocrystals tend to coalesce after synthesis. This suggests the inability of these low molecular weight ligands to effectively stabilize the submicron-sized objects in buffered medium either because of their close-to-neutrality $\mathrm{pH}$ or their relatively weaker chemisorption that forces them to quit the nanocrystal surface after synthesis.

\section{Group III}

F2 and F5 are single internal repeat proteins with high pI, which produce only a small fraction of large $\mathrm{Au}(111)$ faceted nanoparticles. Among large structures, ill-shaped ones are more prominent and colloidal aggregation occurs readily. Those two binders present similar size, pI and morphosynthesis properties. The phage display procedure on (111)-terraced Au substrates does not exclude the selection of very short gold-binding proteins that were electrostatically or even non specifically attached on locations exposing facets with different orientations.

Finally, it appears that the 9 selected proteins might not have been isolated for the same type of interactions with the substrate, which would explain why the sequence analysis does not show well defined trends. Group I and C4, F10 appear to be genuine and specific Au(111) binders with the morphosynthetic performances of the latter two slightly hampered by their small size. Group III and A12, D7 are strong electrostatic Au binders with less prominent (111) crystal facet specificity. 


\section{S6. Spectral characterization of Au nanocrystals synthesized in the presence of Au(111)- selected $\alpha$ Rep.}

Au nanocrystals synthesized with one $\alpha$ Rep templates (A12, C4, D7, F2, F5, F9, F10 or G8) are characterized by UV-Visible spectroscopy (Cary-5000 UV-vis NIR spectrophotometer).

As depicted in Figure S6, well-defined plasmon resonance peaks for pseudospherical and platonic nanostructures ( $\sim 30 \mathrm{~nm})$ are observed in the spectra of Group I (G8, F9) and II (C4, D7, F10). Other nanocrystal batches produced with low internal repeat $\alpha$ Rep (A12 and Group III) exhibit lower absorbance and broader spectra in the UV-vis region which is essentially attributed to nanoparticle aggregation due to lack of colloidal stabilization by close-to-neutral protein coating, but could also be explained by a lower concentration of nanoparticles and concomitant increase in nanoparticle size due to limited nucleation in the growth medium.

Spectra for G8, F9 and C4 also present the shoulder at 750-800 nm that is attributed to higher order plasmon mode in submicron nanoplates.

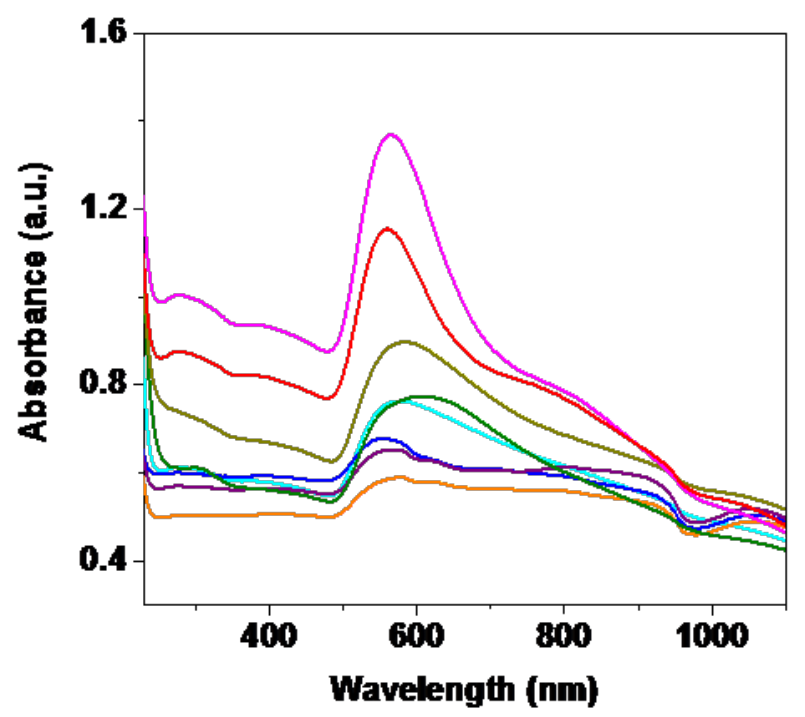

Figure S6. UV-Vis spectra of as-synthesized Au nanocrystal batches obtained using one of the Au(111)-selected $\alpha$ Rep protein: F10 (cyan), A12 (blue), F2 (purple), F5 (orange), D7 (olive), C4 (dark yellow), F9 (pink) and G8 (red). 


\section{S7. Control experiments with non-selected $\alpha$ Rep's}
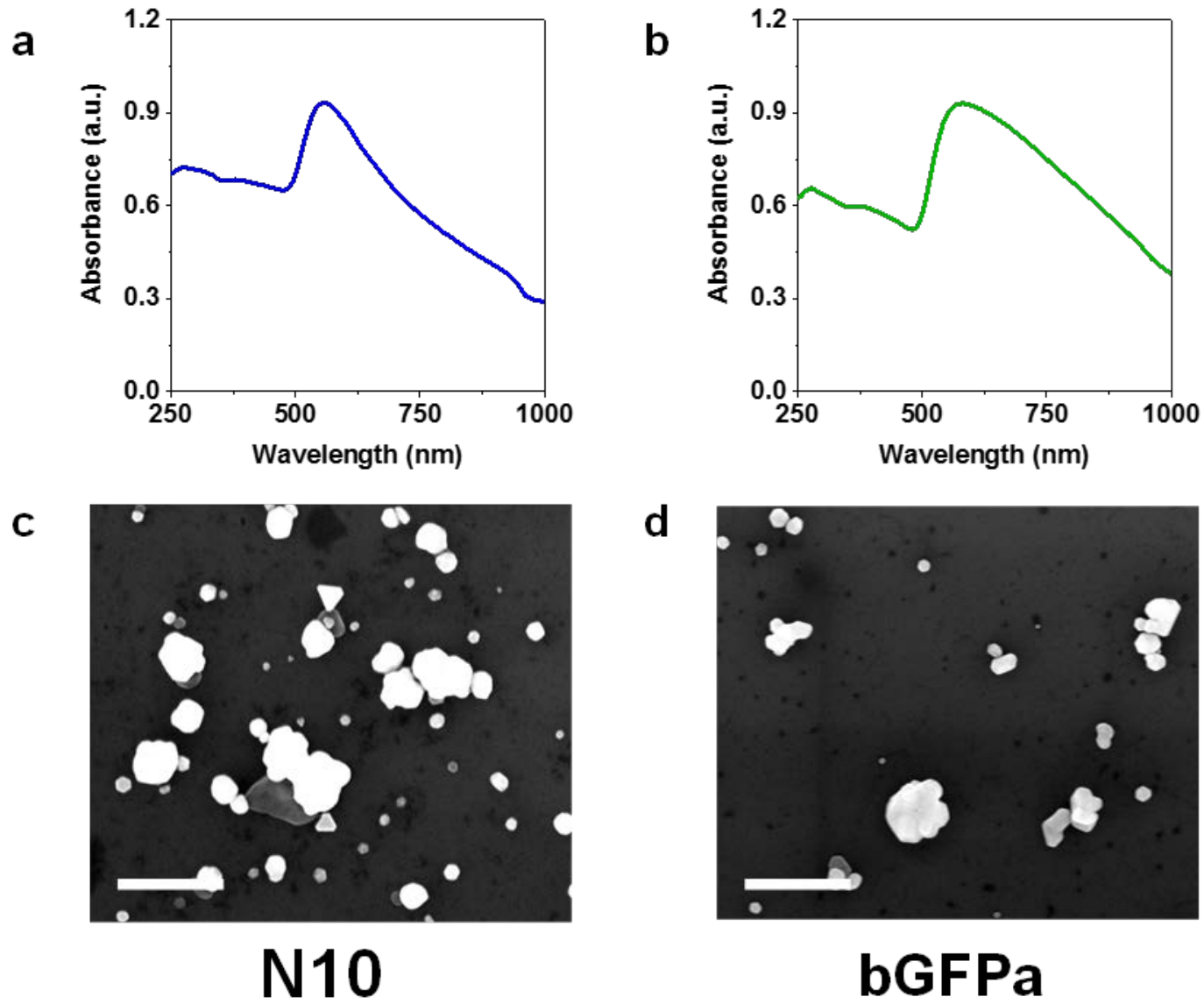

Figure S7. (a,b) UV-visible and (c,d) SEM characterization of Au nanostructures formed by the templating action of non-selected $\alpha$ Rep proteins. (a,c) N10 is a non-selected, consensus sequence $\alpha$ Rep protein with no specific affinity properties that shows some Au nanoparticle reduction activity but no morphological control (positive control). (b,d) $\alpha$ Rep bGFPa was selected against green fluorescent protein (GFP) and so underwent the phage display procedure but similarly lead to the production of shapeless Au nanoparticles(negative control). SEM Scale bar: $500 \mathrm{~nm}$.

Positive and negative controls were performed using non-selected $\alpha$ Rep N10 and anti-GFP selected bGFPa respectively, to assess the critical role of $\mathrm{Au}(111)$ facet binding selection for $\alpha$ Rep to acquire the capability to control the morphosynthesis of facetted gold nanocrystals. UV-visible spectra of control samples prepared in the presence of N10 and bGFPa proteins (Figure S9a-b) shows a peak for pseudospherical structures $\left(\lambda_{\mathrm{abs}} \sim 540 \mathrm{~nm}\right)$, but lacks the characteristic peak for platonic nanostructures. A detailed analysis with scanning electron microscopy further confirms that indeed both N10 and bGFPa gives rise to majority of complex-shaped nanoparticles (> 75\%) when included in the seeded-growth medium (Figure S9a-d). This strongly demonstrates that only facet selective $\alpha$ Rep proteins promote the growth of $\mathrm{Au}$ (111) terminated Au nanocrystals. 
S8. Au nanocrystal size tunability during $\alpha$ Rep-controlled morphosynthesis.
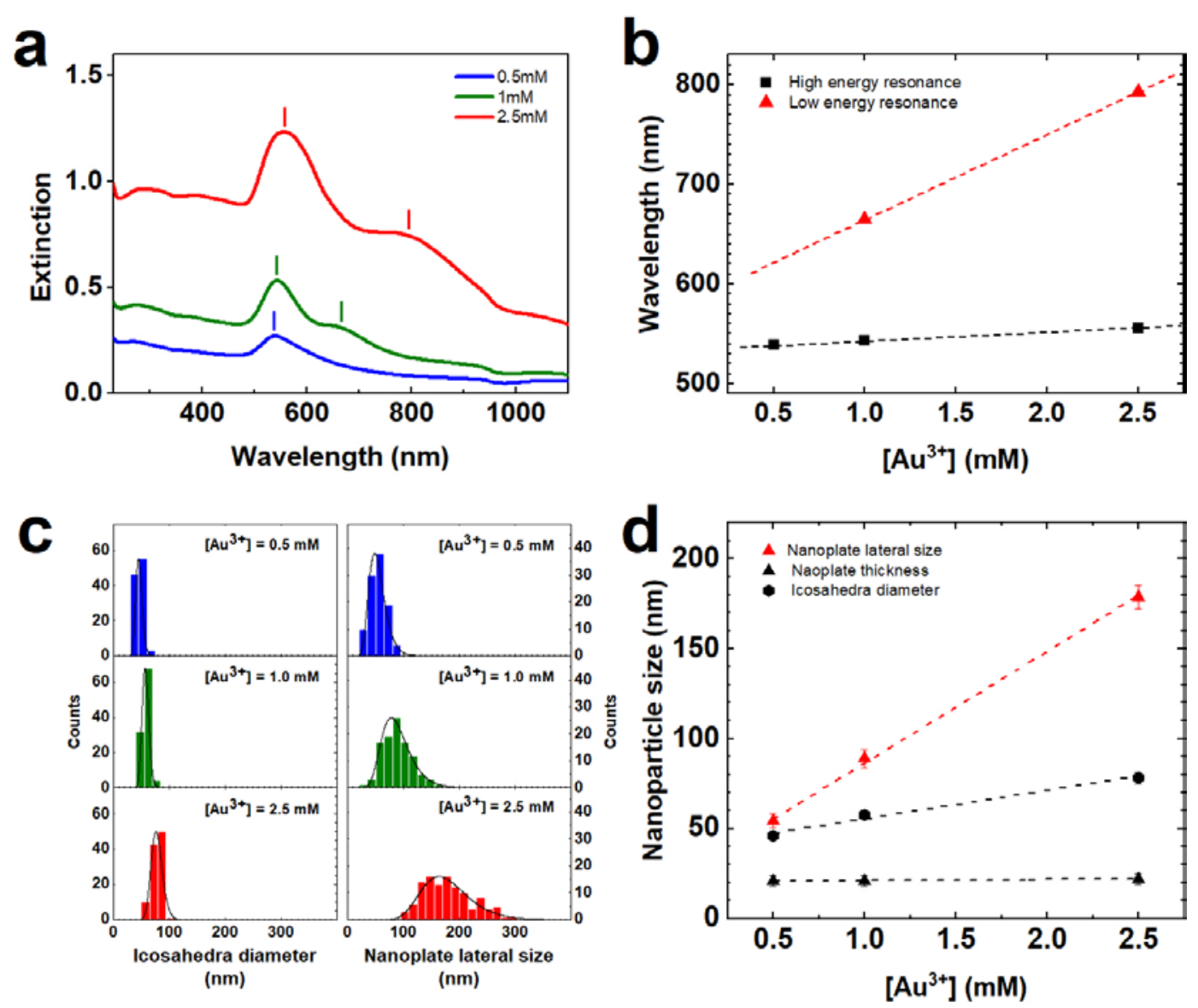

Figure S8. (a) UV-Vis spectroscopy of Au nanocrystals synthesized with 3 different $\mathrm{Au}^{3+}$ concentrations: $0.5 \mathrm{mM}$ (black), $1.0 \mathrm{mM}$ (blue) and $2.5 \mathrm{mM}$ (red). A progressive increase in absorbance intensity and red shift in resonance position is observed as the $\mathrm{Au}^{3+}$ concentration increases indicating increase in particle size. Distinct in-plane higher order modes mode of anisotropic gold nanoplates becomes evident in the spectra at and above [ $\left.\mathrm{Au}^{3+}\right]$ of $1 \mathrm{mM}$ (indicated by the second vertical marker above $600 \mathrm{~nm}$ ). (b) Evolution of the energy of the plasmon resonances with [ $\left.\mathrm{Au}^{3+}\right]$. The transverse mode is plotted in black and the approximate central energy of the higher order modes is plotted in red. (c) Particle size lognormal distributions as a function of initial $\left[\mathrm{Au}^{3+}\right](0.5,1.0$ and $2.5 \mathrm{mM})$ for icosahedra (diameter) and plate (lateral size). (d) Evolution of the mean lateral size of the plates (red triangle) and their thickness (black triangles) and of the icosahedra diameter (black circles).

$\alpha$ Rep capped $\mathrm{Au}$ seeds were injected into growth solutions containing different initial $\mathrm{Au}^{3+}$ concentrations along with hydroxylamine and free $\alpha$ Rep proteins as described in the Experimental sections of the main text and Section A of this document. The $\mathrm{pH}$ for each growth solution was set to 5.5 .

A first step is indicated by the solution colour changing to greyish blue which takes 15 min for $\left[\mathrm{Au}^{3+}\right]=0.5 \mathrm{mM}$, almost 10-12 min for $\left[\mathrm{Au}^{3+}\right]=1 \mathrm{mM}$ and 2-3 min for $\left[\mathrm{Au}^{3+}\right]=2.5 \mathrm{mM}$. This initial, diffusion limited step corresponds to the partial reduction of the bulk $\mathrm{Au}(\mathrm{III})$ into $\mathrm{Au}(\mathrm{I})$ by the hydroxylamine.

In a second step, the autocatalytic disproportionation occurs where $\mathrm{Au}(\mathrm{I})$ reaches the solid $\operatorname{Au}(0)$ surface where it is reduced and contributes to the nanocrystal growth. This $\mathrm{Au}(\mathrm{I})$ adsorption and autocatalysis is the limiting step, therefore the "rate of crystallization" does not vary with the initial $\left[\mathrm{Au}^{3+}\right]$. Indeed, we observe that the completion time increases as the initial $\mathrm{Au}(\mathrm{III})$ concentration is 
increased. It is 1 hour for $\left[\mathrm{Au}^{3+}\right]=0.5 \mathrm{mM}, 1.5-2.0$ hours for $\left[\mathrm{Au}^{3+}\right]=1 \mathrm{mM}$ and 2-3 hours for $\left[\mathrm{Au}^{3+}\right]=2.5 \mathrm{mM}$. Our data suggest a sublinear dependency of the completion time with the initial $\left[\mathrm{Au}^{3+}\right]$, which rules out the possibility to have a reaction rate increasing with the initial $\left[\mathrm{Au}^{3+}\right]$.

The second step leads to purple-coloured solution that are characterized by UV-visible spectrophotometry. Figure S8a shows the extinction spectra of three seeded growths of G8-capped nanocrystals for $\mathrm{Au}^{3+}$ concentrations of $0.5 \mathrm{mM}, 1 \mathrm{mM}$ and $2.5 \mathrm{mM}$ using the same Au seed volume. At low initial $\mathrm{Au}^{3+}$ concentration, a single asymmetrical peak is observed, consistent with spheroidal and nanoplates of similar sizes as shown in Fig. 5a. Once the initial $\mathrm{Au}^{3+}$ concentration exceeds $1 \mathrm{mM}$, two peaks become clearly distinct and are indicated with vertical markers in Figure S8a. The peak centered at around 525-540 nm originates from icosahedrons, decahedrons and the small fraction of pseudo-spherical particles but also from the transverse mode of the nanoplates. This peak barely red-shifts with the increasing $\mathrm{Au}^{3+}$ concentration (Fig. S8b, black data) since the evolution of the diameter of spheroidal particles and of the nanoplate thickness is slow. The shoulder peak on the low energy side of the spectra originates from the in-plane higher order modes of the $\mathrm{Au}$ nanoplates. As expected, this shoulder shifts more rapidly with increasing $\mathrm{Au}^{3+}$ concentration (Fig. S8b, red data) as the in-plane modes are very sensitive to the nanoplate edge length that varies from ca. $50 \mathrm{~nm}$ to $200 \mathrm{~nm}$ for the considered concentration variation.

This is accompanied by the SEM observation that the final nanoplate edge length becomes significantly larger than the average decahedra/icosahedra diameter. By labelling the data shown in Figures 5b-d, we can determine separately the icosahedra diameter and plate lateral size distributions as a function of initial $\left[\mathrm{Au}^{3+}\right]$ as shown in the Figure S8c. Clearly the lateral growth of the plates is much faster than the icosahedra diameter expansion and summarized in Figure S8d. If one considers also the almost constant plate thickness obtained from AFM measurements (See, for example, Figs. $3 \mathrm{i}$ and $3 \mathrm{j}$ ) for this $\left[\mathrm{Au}^{3+}\right]$ range, we have a perfect match with the plasmon bands shift as a function of initial $\left[\mathrm{Au}^{3+}\right]$ shown in Fig. S8b. The low energy resonance is due to higher order modes along the plate edges and so varies much faster than the high energy band, which is due to the averaged contribution of the isotropic resonance of the icosahedra (and decahedra) and the transverse mode of the plates. Figure S8d thus provides the simple linear scaling law between the mean size of crystals and initial $\left[\mathrm{Au}^{3+}\right]$.

The action of the proteins is to bind to the (111) surfaces where the reaction rate is significantly reduced leading to the observed shapes, in particular the platelets. The less effective binding to (100) and (110) facets results in a faster growth rate of the platelet sides even in the presence of the proteins. Yet, the $\mathrm{K}_{\mathrm{D}}$ are finite, the bound proteins have a non-zero probability to detach (partially or entire) creating an opportunity for the small and labile ions, $\mathrm{Au}(\mathrm{I})$, to reach the metallic surface. A protein can later on occupy the empty site. Therefore, a very slow diffusion of Au(I) underneath the protein layer remains possible leading to a much slower yet non-zero thickening of the platelets by reduction of $\mathrm{Au}(\mathrm{I})$ onto the basal planes. Similarly, a slow growth of the diameter of the icosahedra and decahedra occurs which may be more pronounced than the plate thickening because of the presence of ridges separating two adjacent (111) facets where the protein binding may be sub-optimal. 
S9. Effect of $\mathrm{pH}$ on the seeded growth process

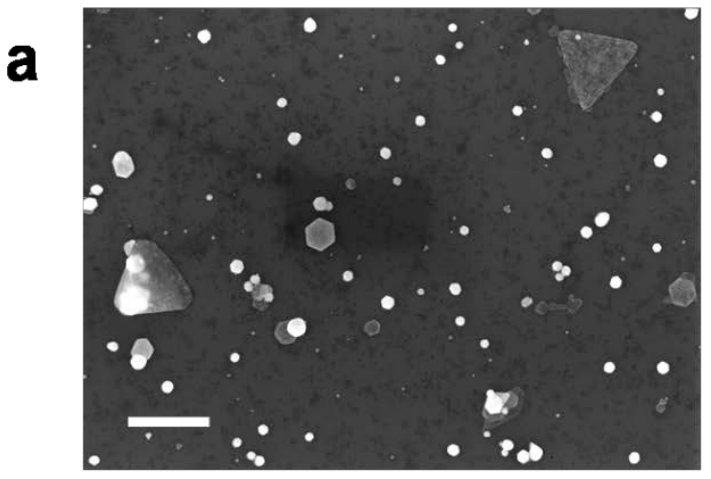

$\mathrm{pH} 3.0$

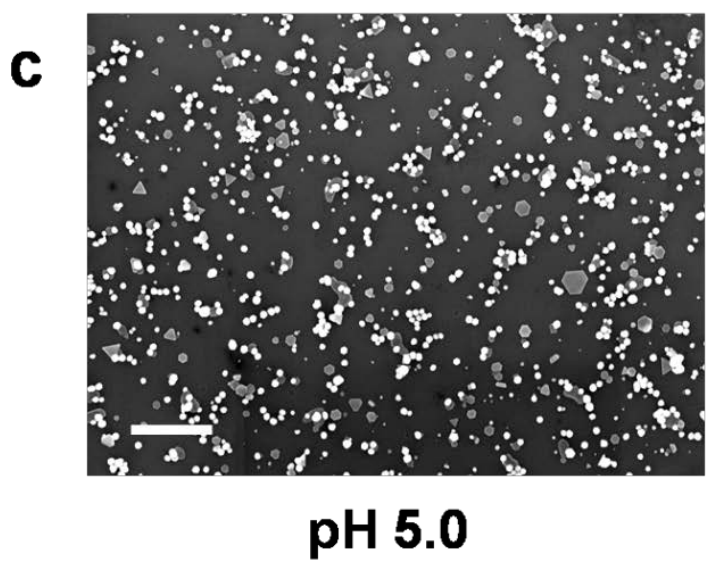

b

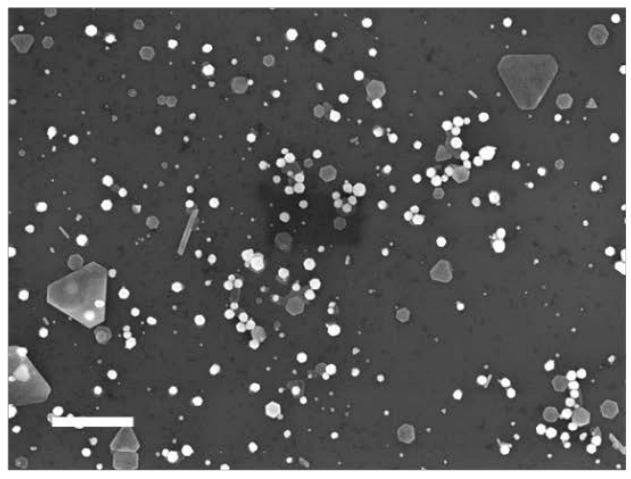

pH 3.8

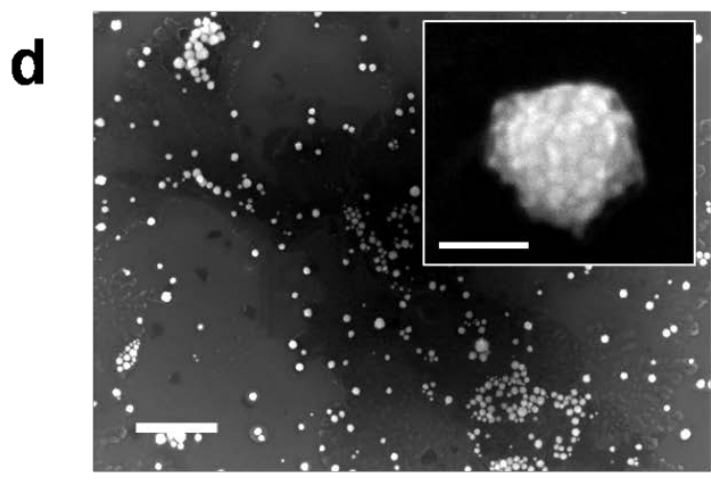

pH 7.5

Figure S9. SEM micrographs showing effect of solution $\mathrm{pH}$ on the growth process of G8 capped Au nanocrystals. (a-c) Growth occurs on the surface of seeds at $\mathrm{pH}<6$ resulting in the formation of nanoplates, icosahedrons and decahedrons (d) No growth occurs on seed surface rather hydroxylamine itself directly reduces $\mathrm{Au}^{3+}$ to $\mathrm{Au}^{0}$ at $\mathrm{pH}>6$ to produce fractal shaped nanoparticles. Scale bars: (a-d) $1 \mu \mathrm{m}$; d inset $100 \mathrm{~nm}$.

A typical seeded growth method proceeds through the disproportionation reaction, ${ }^{11}$ catalysed by the $\mathrm{Au}$ seeds $\left(\mathrm{Au}_{\text {seeds }} / \mathrm{Au}_{\text {ion }}=+1.68 \mathrm{~V}\right)^{12}$ in the presence of a weak reducing agent. Previous studies have indicated that all popular reducing agents ${ }^{13-15}$ feature a $\mathrm{pH}$ - dependent reduction potential and can spontaneously generate new nuclei at basic $\mathrm{pH}$ in the absence of seeds.

Therefore, we chose reaction parameters under which secondary nucleation can be suppressed or at least minimized during the growth step. In the present case, hydroxylamine has been used to promote the seeded growth. Hydroxylamine coexists as $\mathrm{NH}_{2} \mathrm{OH}$ and $\mathrm{NH}_{3} \mathrm{OH}^{+}$in the growth solution ( $\mathrm{pKa}$ 6.03). ${ }^{15}$ At $\mathrm{pH}>6$, the fraction of the deprotonated form, which has a higher reduction power, increases together with cathodic shift in gold redox potential resulting in the spontaneous reduction of $\mathrm{HAuCl}_{4}$ leading to self-nucleation of irregular dendritic nanostructures. ${ }^{15}$ Similar ill-shaped nanostructures are observed in our case at alkaline $\mathrm{pH}$, irrespective of the presence of gold seeds during the growth step (Figure S9). Hence, a $\mathrm{pH}<5$ has been adopted for hydroxylamine seeding method to allow the surface-catalysed reduction of $\mathrm{HAuCl}_{4}$ to take place and suppress any parasitic nanoparticle nucleation and growth. Figure S9 indicates formation of platonic and pseudospherical nanocrystals at $\mathrm{pH}$ values between 3 and 5 . Besides variations in growth rates of plates and pseudospherical populations no additional effect on the morphology of crystalline subpopulations of Au nanocrystals was observed. 
S10. Effect of reaction temperature on morphosynthesis

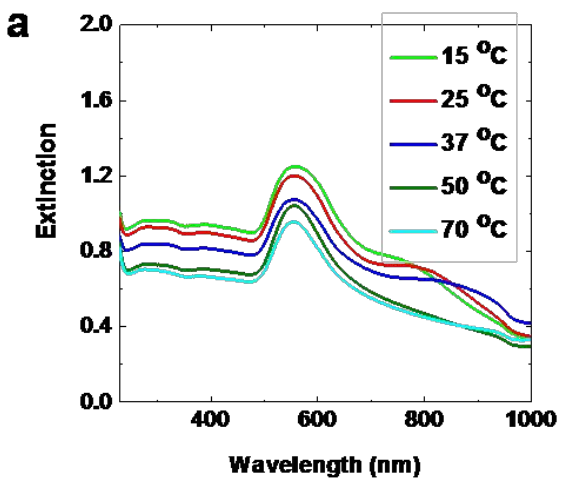

b

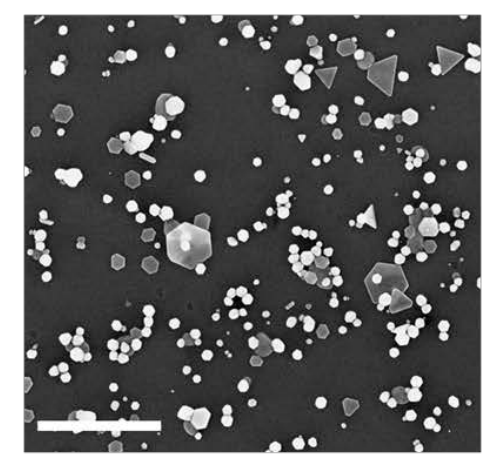

c

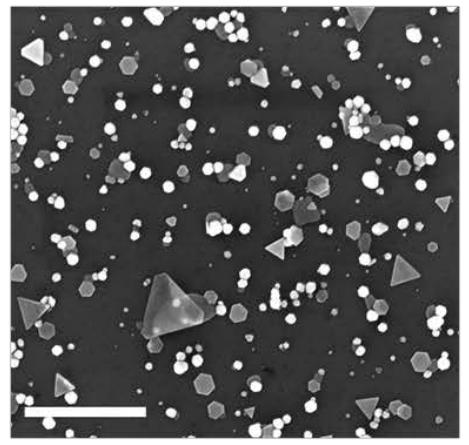

d

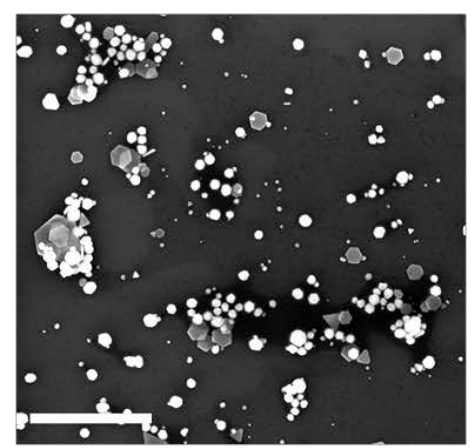

$\mathbf{e}$

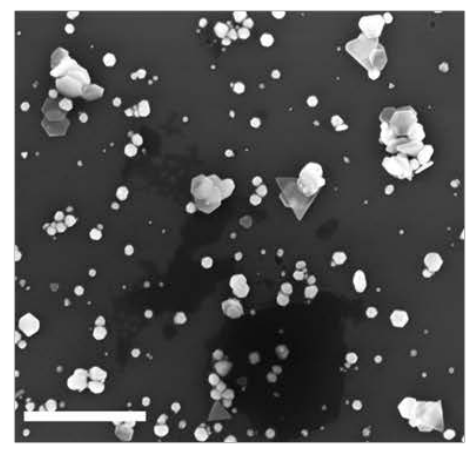

$\mathbf{f}$

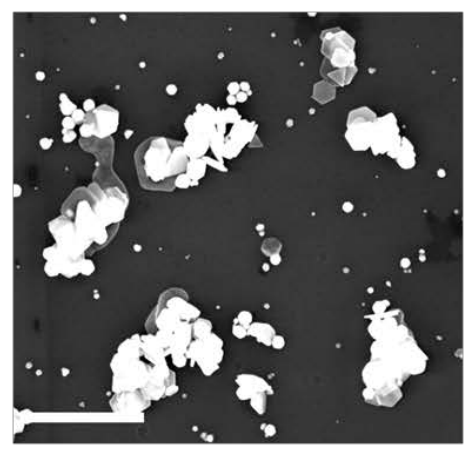

g

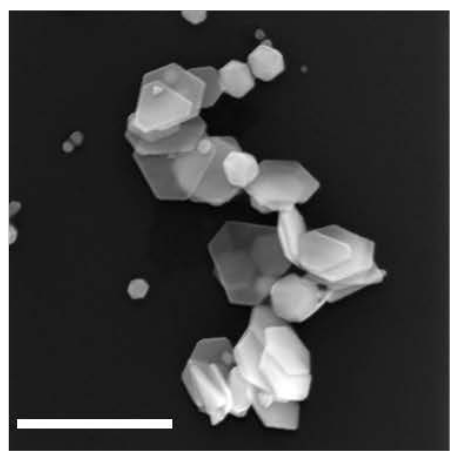

h

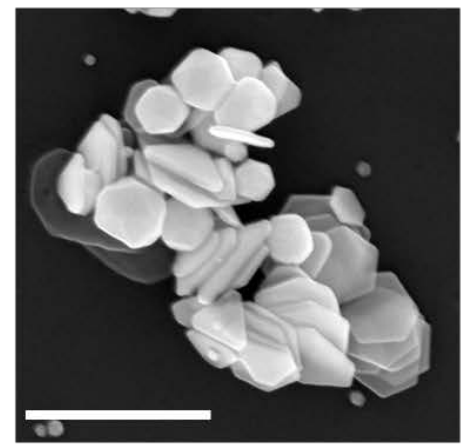

Figure S10. Temperature dependent morphosynthesis of Au nanocrystals at fixed concentrations of $\mathrm{Au}^{3+}$ and G8.(a) UV-Vis spectroscopy showing progressive disappearance of in-plane dipole peak of nanocrystal sample at reaction temperatures of $37^{\circ} \mathrm{C}$ and above. SEM micrographs of G8 capped nanocrystals at synthesised at temperatures of (b) 15 ${ }^{\circ} \mathrm{C}$ (c) $25{ }^{\circ} \mathrm{C}$ (d) $37{ }^{\circ} \mathrm{C}$ (e) $50{ }^{\circ} \mathrm{C}$ and (f) $70{ }^{\circ} \mathrm{C}$. (g-h) Representative images showing high order basal stacking of nanoplates at $70^{\circ} \mathrm{C}$. (Scale bars: $500 \mathrm{~nm}$ ) 
The growth of gold nanocrystals at $15^{\circ} \mathrm{C}, 25^{\circ} \mathrm{C}, 37^{\circ} \mathrm{C}, 50^{\circ} \mathrm{C}$ and $70^{\circ} \mathrm{C}$, all other parameters being kept identical,are studied to determine the effect of the temperature on the synthesis rate and nanoparticle structure. As shown in Figure S10, and on the contrary to previously reported literature, ${ }^{16-19}$ the overall structural composition and yield of the nanocrystal samples remain unaffected even at higher temperatures $\left(50-70^{\circ} \mathrm{C}\right)$. In particular, no increase in spherical or shapeless particles is observed. This suggests that the $\alpha$ Rep morphosynthetic activity is preserved at high temperatures which allows the formation of $\mathrm{Au}(111)$ terminated nanostructures. Interestingly, a slight and gradual increase in nanocrystal size occurs with increase in temperature.

We should note that higher temperatures lead to progressive aggregation of the Au nanocrystals, which eventually leads to disappearance of the characteristic nanoplate 804-nm shoulder in the extinction spectra. The marginal decline in absorbance at $540 \mathrm{~nm}$ suggests that pseudospherical structures are less affected by temperature rise. SEM observations show indeed that the nanoplates tend to irreversibly stack together once the synthesis temperature reaches and exceed to $37^{\circ} \mathrm{C}$. One possible explanation for this temperature-triggered agglomeration is a partial unfolding although unbound $\alpha$ Rep protein have been shown to sustain temperatures as high as $90^{\circ} \mathrm{C}$ without denaturation. Another possible reason is the establishment of entropically favored protein-protein interactions though side chains. ${ }^{20}$ The limited diffusion and surface adsorption of the $\alpha$ Rep onto the $\mathrm{Au}$ surface when the surface-confined disproportionation reaction rate increases at higher temperatures could also be a factor. Although this would indeed lead to poorly stabilized facets prone to particle-particle flocculation, it is unlikely since the facet growth inhibition is still observed thus certifying that the proteins do interact strongly with the growing facets. 


\section{S11. Surface composition of G8-capped nanocrystals}

Energy dispersive spectroscopy (EDS) is conducted to study the composition of $\alpha$ Rep templated Au nanoparticles (using AMRAY 1820D STEM equipped with EDAX Genesis EDS system). The samples are drop casted onto ultrathin $(10 \mathrm{~nm}) \mathrm{SiO}_{2}$ membranes to enable the carbon and nitrogen analysis

The EDS spectrum shown in Figure S11 is obtained when the electron beam is positioned on a single nanoplate and it reveals the predominant presence of $\mathrm{Au}$ and $\mathrm{Si}$ signals which comes from the nanoparticle surface and the support $\mathrm{SiO}_{2}$ membrane grid respectively. Additionally, the EDS scan also verify peaks at $0.39 \mathrm{keV}$ and $0.28 \mathrm{keV}$ representing nitrogen $(\mathrm{N})$ and carbon(C) respectively. Nitrogen is considered a strong marker of the protein, which confirms the presence of $\alpha$ Rep proteins on the surface of the gold nanoparticles. The experimental element molar ratio of $\mathrm{N}: \mathrm{C} \approx 5.0$, which was quite close to the theoretically predicted values. The excess carbon could be contributed by hydrocarbon contaminants present in the microscope chamber. Elemental presence of oxygen and copper can be attributed to the $\mathrm{SiO}_{2}$ membrane and sample holder or to surface contamination. The sodium, chlorine and calcium signal appears from the buffer systems that has been used during protein extraction, purification and rehydration stages.

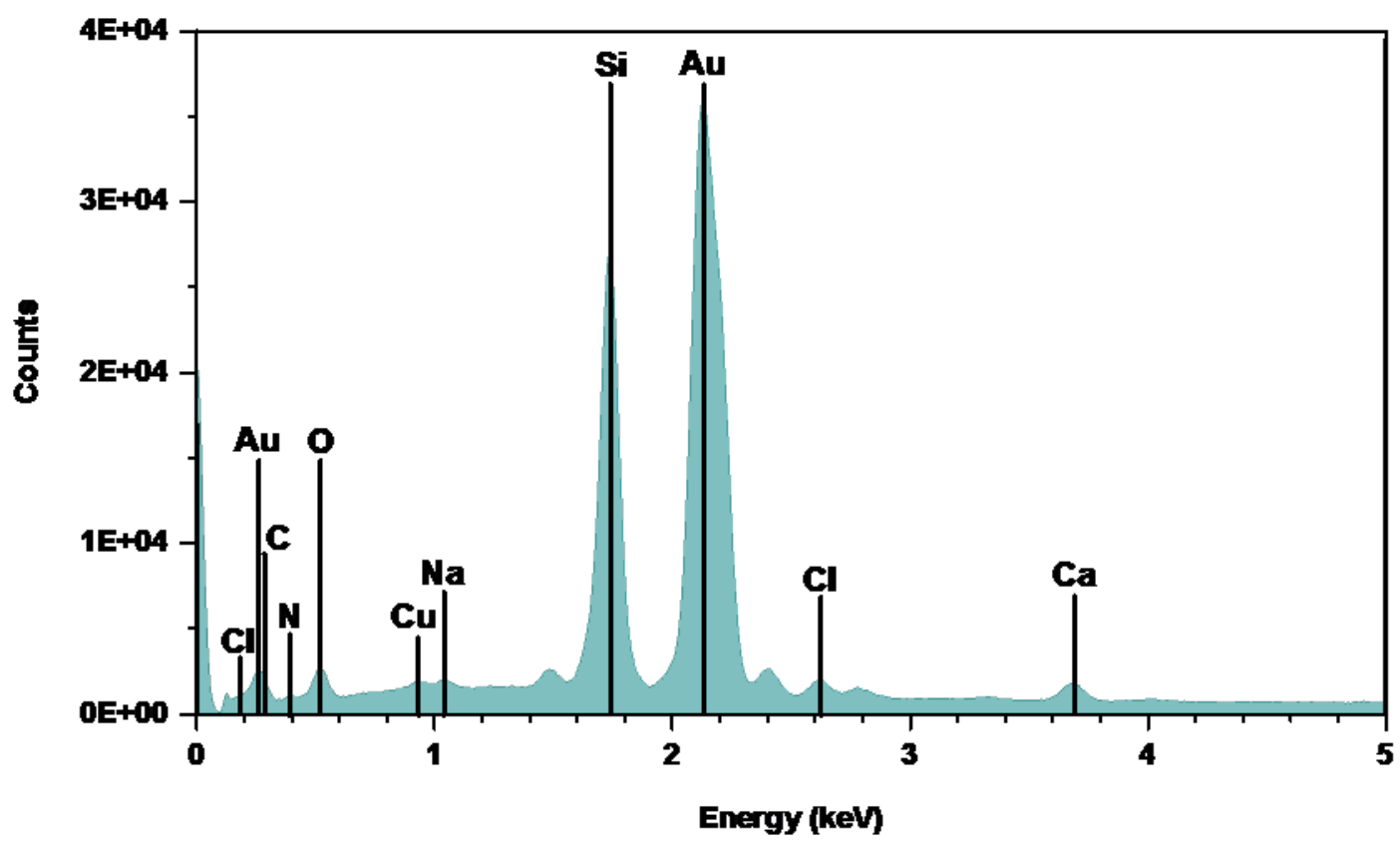

Figure S11. EDS profile shows a strong Au signal along with weak nitrogen (N) and carbon (C) peaks, originating from the $\alpha$ Rep molecules bound to the surface of the gold nanoparticles. The silicon(Si) and oxygen (O) signals appear from the $\mathrm{SiO} 2$ support grid, and copper $(\mathrm{Cu})$ from the surface contamination. Peaks due to sodium (Na), calcium (Ca), chlorine $(\mathrm{Cl})$ can be attributed to buffer system used for the proteins. 
S12. Core-Satellite assembly on streptavidinylated nanostructures
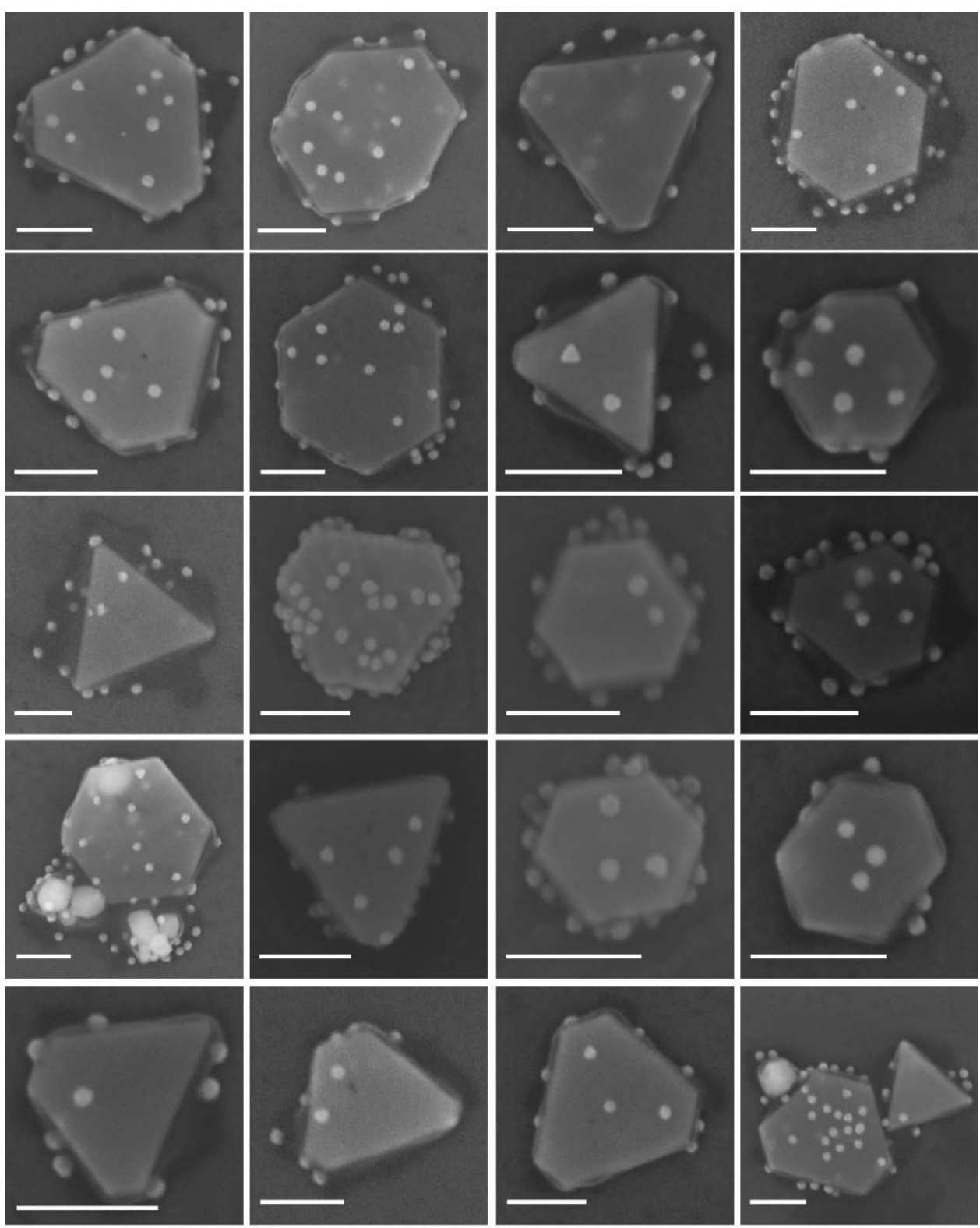

Figure S12. Representative SEM micrographs showing core-satellite assemblies produced by co-incubation of biotinylated Au nanospheres with streptavidinylated G8-capped Au nanocrystals. (Scale bar: $100 \mathrm{~nm}$ ) 


\section{S13. On-surface DAB encapsulation on HRP-functionalized streptavidinylated nanostructures}

$\alpha$ Rep capped gold nanoparticles can be upgraded to multifunctional catalytic platforms by the attachment of biotinylated enzymes onto the secondary streptavidin layer. Biotinylated-horse radish peroxidase (Biotin-HRP) enzyme is complexed with streptavidin-functionalized Au nanocrystals and surface-confined catalysis of aromatic benzidines is performed. Figure S13a shows multiple examples $\mathrm{Au}$ nanocrystals immobilised on an $\mathrm{SiO}_{2} / \mathrm{Si}$ substrate prior to induction of the HRPcatalyzed oxidative polymerisation of $1 \mathrm{mM} 3,3^{\prime}$-diaminobenzidine (DAB) ${ }^{21}$ in presence of $\mathrm{H}_{2} \mathrm{O}_{2}$ which results in the in-situ precipitation of a polyDAB shell. The water insoluble polymeric DAB layer $^{22}$ of uniform thickness $(23 \pm 3$ ) can be clearly observed around Au nanocrystals (See also panel (a) of Figure S13b).

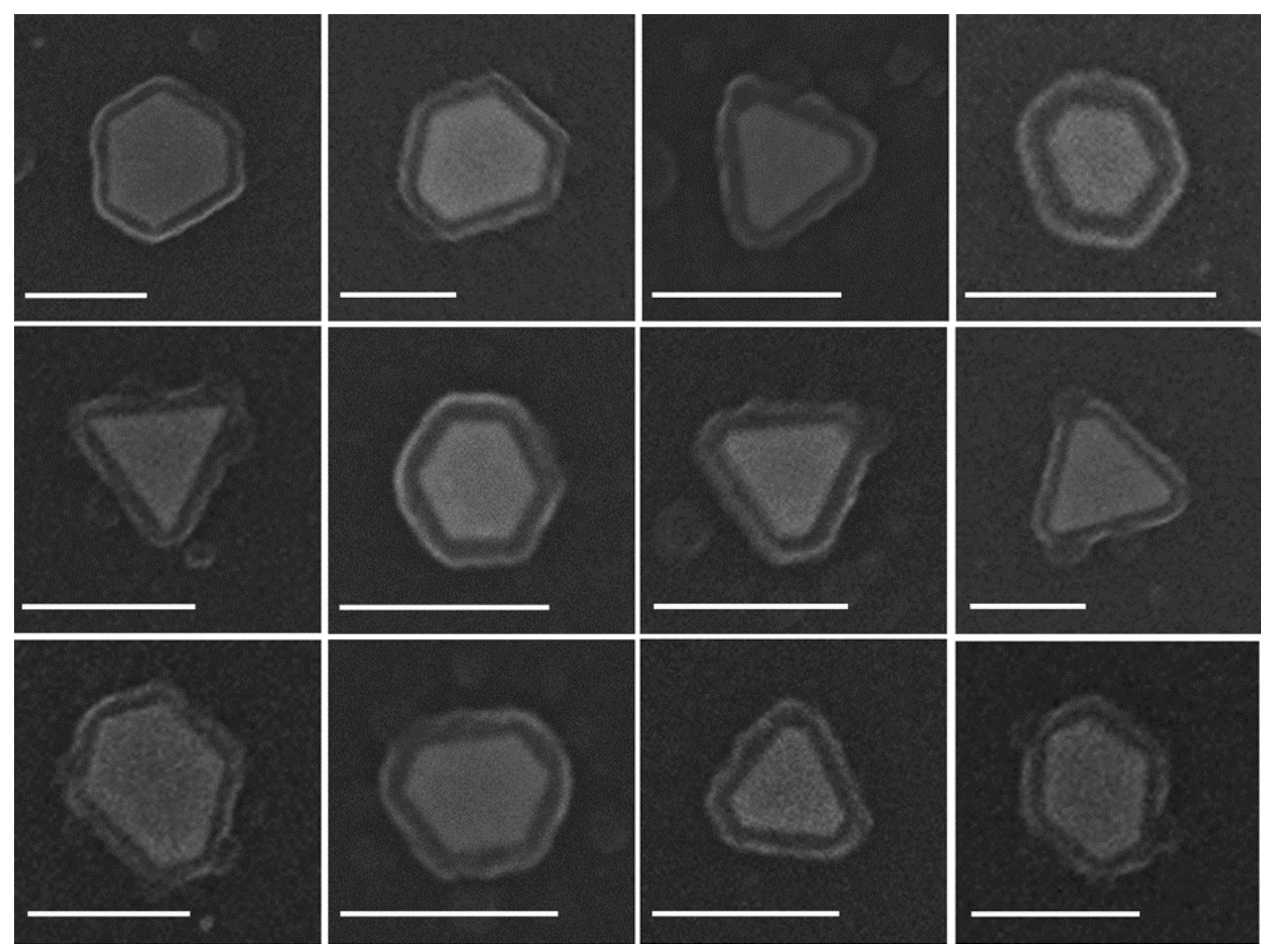

Figure S13a. Representative SEM micrographs showing polymeric DAB shell formed around HRP-Au nanocrystals through catalytic oxidation of $1 \mathrm{mM} 3,3$ ' diaminobenzidine after a reaction time of 3h. (Scale bars: $200 \mathrm{~nm}$ )

The oxidation of DAB molecules on the surface of HRP-Au nanocrystals is also monitored in solution by UV-visible spectroscopy. In Figure S13b(b), the continuous red shifting of the plasmon resonance peak reveals the gradual development of the polymeric DAB shell around the $\mathrm{Au}$ nanoparticles. This shift is limited when the DAB precursor concentration is low $(1 \mathrm{mM})$. But for a DAB concentration $20 \mu \mathrm{M}$ DAB, a larger build-up of the polymerized DAB layer leads to a $25 \mathrm{~nm}$ 
red shift in agreement with the ca. $25 \mathrm{~nm}$ thickness of the high index medium observed by SEM on the nanocrystals. Interestingly, as the shell grows and the coated Au nanocrystals become more hydrophobic, they tend to slowly coalesce together into water-insoluble aggregates which can be monitored by the continuous decline in plasmon peak intensity as displayed in Figure S13b(c). The effective HRP catalysis reflects the stability of surface-bound enzymes and could be harnessed for multple on-surface sensing applications.
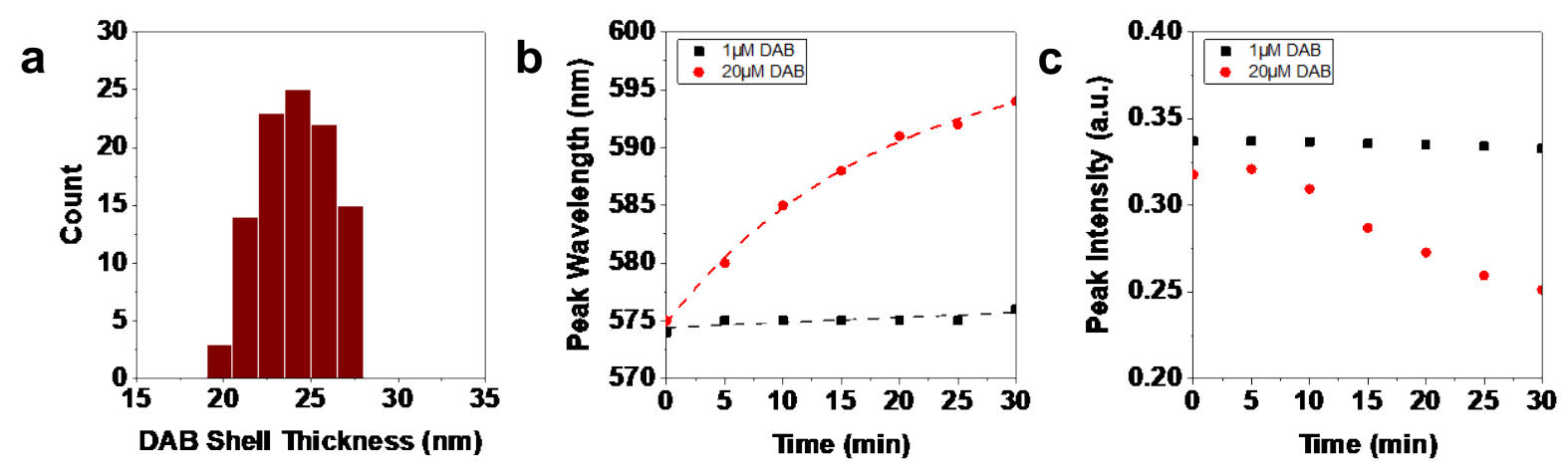

Figure S13b. Characterisation of on-surface DAB catalysis by HRP conjugated $\alpha$ Rep-Au nanocrystals. (a) Polymeric $\mathrm{DAB}$ shell thickness encapsulating Au nanocrystals immobilized on a $\mathrm{SiO}_{2} / \mathrm{Si}$ substrate. (b) Spectral shift of the plasmon resonance of Au nanocrystals during solution phase $\mathrm{DAB}$ polymerisation reaction for two bulk concentrations of the DAB monomer (1 and $20 \mu \mathrm{M}$ in black and red respectively). (c) Time evolution of the plasmon resonance peak intensity as the HRP-induced, on-surface DAB polymerization proceeds. The observed intensity decline is due to the coalescence of water-insoluble Au nanocrystals as they become more hydrophobic due to the DAB encapsulation. 


\section{S14. References}

1 Guellouz, A. et al. Selection of Specific Protein Binders for Pre-Defined Targets from an Optimized Library of Artificial Helicoidal Repeat Proteins (alphaRep). PLoS One 8, e71512, (2013).

2 Binz, H. K., Amstutz, P. \& Pluckthun, A. Engineering novel binding proteins from nonimmunoglobulin domains. Nat. Biotechnol. 23, 1257-1268, (2005).

3 Boersma, Y. L. \& Pluckthun, A. DARPins and other repeat protein scaffolds: advances in engineering and applications. Curr. Opin. Biotechnol. 22, 849-857, (2011).

4 Oshannessy, D. J. \& Winzor, D. J. Interpretation of deviations from pseudo-first-order kinetic behavior in the characterization of ligand binding by biosensor technology. Analytical Biochemistry 236, 275-283, (1996).

5 Nedelkov, D. \& Nelson, R. W. Practical considerations in BIA/MS: optimizing the biosensor-mass spectrometry interface. Journal of Molecular Recognition 13, 140-+, (2000).

6 Duan, X. et al. Quantification of the affinities and kinetics of protein interactions using silicon nanowire biosensors. Nature Nanotechnology 7, 401, (2012).

7 Rostova, E., Ben Adiba, C., Dietler, G. \& Sekatskii, S. K. Kinetics of Antibody Binding to Membranes of Living Bacteria Measured by a Photonic Crystal-Based Biosensor. Biosensors-Basel 6, (2016).

8 Oshannessy, D. J., Brighamburke, M., Soneson, K. K., Hensley, P. \& Brooks, I. Determination of Rate and Equilibrium Binding Constants for Macromolecular Interactions Using Surface Plasmon Resonance: Use of Nonlinear Least Squares Analysis Methods. Analytical Biochemistry 212, 457468, (1993).

9 Gorlatova, N. et al. Protein Characterization of a Candidate Mechanism SNP for Crohn's Disease: The Macrophage Stimulating Protein R689C Substitution. PLoS One 6, e27269, (2011).

10 Grzelczak, M., Perez-Juste, J., Mulvaney, P. \& Liz-Marzan, L. M. Shape control in gold nanoparticle synthesis. Chemical Society Reviews 37, 1783-1791, (2008).

11 Scarabelli, L., Sánchez-Iglesias, A., Pérez-Juste, J. \& Liz-Marzán, L. M. A “Tips and Tricks” Practical Guide to the Synthesis of Gold Nanorods. The Journal of Physical Chemistry Letters 6, 4270-4279, (2015).

12 Jana, N. R., Gearheart, L. \& Murphy, C. J. Evidence for Seed-Mediated Nucleation in the Chemical Reduction of Gold Salts to Gold Nanoparticles. Chemistry of Materials 13, 2313-2322, (2001).

Sirajuddin et al. The formation of gold nanoparticles using hydroquinone as a reducing agent through a localized $\mathrm{pH}$ change upon addition of $\mathrm{NaOH}$ to a solution of HAuCl4. Colloids and Surfaces A: Physicochemical and Engineering Aspects 370, 35-41, (2010).

Zhou, J., Zeng, J., Grant, J., Wu, H. \& Xia, Y. On-Chip Screening of Experimental Conditions for the Synthesis of Noble-Metal Nanostructures with Different Morphologies. Small 7, 3308-3316, (2011).

15 Wang, Z. et al. pH-Dependent Evolution of Five-Star Gold Nanostructures: An Experimental and Computational Study. ACS Nano 7, 2258-2265, (2013).

16 Xie, J., Lee, J. Y. \& Wang, D. I. C. Synthesis of Single-Crystalline Gold Nanoplates in Aqueous Solutions through Biomineralization by Serum Albumin Protein. The Journal of Physical Chemistry C 111, 10226-10232, (2007).

17 Liu, B., Xie, J., Lee, J. Y., Ting, Y. P. \& Chen, J. P. Optimization of High-Yield Biological Synthesis of Single-Crystalline Gold Nanoplates. The Journal of Physical Chemistry B 109, 1525615263, (2005).

Kumari, M. et al. Physico-Chemical Condition Optimization during Biosynthesis lead to development of Improved and Catalytically Efficient Gold Nano Particles. Scientific Reports 6, 27575, (2016).

19 Fang, G., Yang, Y., Yao, J., Shao, Z. \& Chen, X. Formation of different gold nanostructures by silk nanofibrils. Materials Science and Engineering: C 64, 376-382, (2016).

20 Bolisetty, S. et al. Amyloid-mediated synthesis of giant, fluorescent, gold single crystals and their hybrid sandwiched composites driven by liquid crystalline interactions. Journal of Colloid and Interface Science 361, 90-96, (2011).

21 Chen, S., Svedendahl, M., Van Duyne, R. P. \& Käll, M. Plasmon-Enhanced Colorimetric ELISA with Single Molecule Sensitivity. Nano Letters 11, 1826-1830, (2011). 
22 Klibanov, A. M., Tu, T.-M. \& Scott, K. P. Peroxidase-Catalyzed Removal of Phenols from CoalConversion Waste Waters. Science 221, 259, (1983). 